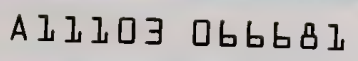

NBS SPECIAL PUBLICATION 514

U.S. DEPARTMENT OF COMMERCE / National Bureau of Standards

\title{
Product Durability and Life
}

\section{MFPG \\ 27th Meeting}

C

00

57

ic

10.514

1978 



\section{Product Durability and Life}

Proceedings of the 27th Meeting of the

Mechanical Failures Prevention Group,

held at the National Bureau of Standards,

Gaithersburg, Maryland, November 1-3, 1977

Edited by

T. Robert Shives and William A. Willard

National Measurement Laboratory

National Bureau of Standards

Washington, DC 20234

The 27th meeting of the MFPG and these proceedings were sponsored by the Institute for Materials Research and the Center for Consumer Product Technology of the National Bureau of Standards, Washington, DC 20234; the Office of Naval Research, Department of the Navy, Arlington, VA 22217; the Naval Air Development Center, Department of the Navy, Warminster, PA 18974; the National Aeronautics and Space Administration, Goddard Space Flight Center, Greenbelt, MD 20771; and the Department of Energy-Fossil Energy, Washington, DC 20545.

This work was co-sponsored by the Institute for Materials Research prior to the NBS reorganization effective April 9, 1978. The Institute for Materials Research is now included in the National Measurement Laboratory of NBS.

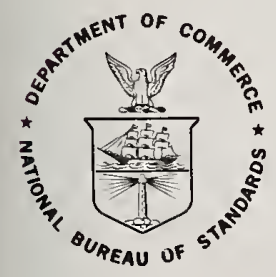

U.S. DEPARTMENT OF COMMERCE, Juanita M. Kreps, Secretary

Dr. Sidney Harman, Under Secretary

Jordan J. Baruch, Assistant Secretary for Science and Technology

NATIONAL BUREAU OF STANDARDS, Ernest Ambler, Director

Issued May 1978 . 


\section{Library of Congress Cataloging in Publication Data}

Mechanical Failures Prevention Group.

MFPG, product durability and life.

(National Bureau of Standards Special publication ; 514)

"Sponsored by the Institute for Materials Research ... [et asl.]." Supt. of Docs. no.: $\mathrm{Cl} 3.10: 514$

1. Durable goods, Consumer-Reliability-Congresses. 2. Durable goods, Consumer-Testing-Congresses. I. Shives, T. R. II. Willard, William A. III. Title. IV. Title: Product durability and life. V. Series: United States. National Bureau of Standards. Special publications; 514.

QCl00.U57 no. 514 [TS173] 602'.1s [658.5'6] 78-606044

\section{National Bureau of Standards Special Publication 514}

Nat. Bur. Stand. (U.S.), Spec. Publ. 514, 188 pages (May 1978)

CODEN: XNBSAV

\section{U.S. GOVERNMENT PRINTING OFFICE WASHINGTON: 1978}

For sale by the Superintendent of Documents, U.S. Government Printing Office, Washington, D.C. 20402 Stock No. 003-003-01935-6 Price \$3.75

(Add 25 percent additional for other than U.S. mailing). 
The 27th meeting of the Mechanical Failures Prevention Group was held November 1-3, 1977, at the National Bureau of Standards in Gaithersburg, Maryland. The program was organized by the MFPG committee on Mechanisms of Failure under the Chairmanship of Marshal Peterson of the Office of Technology Assessment, United States Congress. In addition to the members of the Mechanisms of Failure Committee, Kenneth C. Ludema of the University of Michigan, and A. William Ruff and Andrew J. Fowell of the National Bureau of Standards, made significant contributions in developing the program. All those involved with planning the program, and especially the speakers, are to be commended for producing an excellent meeting.

Most of the papers in these proceedings are presented as submitted by the author on camera ready copy with some minor editorial changes.

Special thanks are due Sara R. Torrence of the NBS Office of Information Activities for the meeting arranqements.

Appreciation is extended to the following members of the NBS Metallurgy Division: T. Robert Shives and William A. Willard for their editing, organization and preparation of the proceedings, Paul M. Fleming for handling financial matters, Todd Eudy and Leonard C. Smith for photographic work, Marian L. Slusser for typing, and to other members of the Division whose help contributed to the success of the meeting.

HARRY C. BURNETT

Executive Secretary, MFPG

Metallurgy Division

National Bureau of Standards 

$\underline{\text { Page }}$

FOREWORD

SESSION I : PRODUCT DURABILITY ISSUES

1. Opportunities and Implications of Extending Product

Life. Robert T. Lund and William Michael Denney*

2. Economic Considerations and Product Life. Paul Lerman

3. Technical Durability of Products. Elio Passaglia

(abstract only, see Appendix A)

4. Labeling Products for Durability. Mark J. Raabe

SESSION II : PRODUCT TESTING

1. Methodology of Product Life Testing. Julius Cohen

2. Small Appliance Life Testing. Kenneth W. Yee

3. Product Life Testing and Durability. N. R. Pugh

4. Hydraulic Pump Contaminant Life Evaluation. L. E. Bensch

5. Control of Design Quality. Andrew W. Dorney

6. Factors Affecting Product Lifetime: Preliminary Results

of a Research Study. W. David Conn, * Carol Inge, Biswapriya Sanyal, and Elaine Warren

SESSION III: DURABILITY TECHNOLOGY IN INDUSTRY

1. Brake Wear. S. K. Rhee

2. Accelerated Testing of Compressors. Frank E. Kalivoda

3. Automobile Durability. C. J. Brady and H. W. Larsen*

4. Wear Analysis in Office Machines. P. A. Engel 
SESSION IV: PRODUCT PERFORMANCE - - WHY CARE?

1. Materials Conservation through Increased Durability.

M. B. Peterson (abstract only, see Appendix A)

2. Extended Life and Waste Reduction. F. Smith (no manuscript or abstract submitted)

3. Household Retention of Consumer Appliances: USDA

Actuarial Estimates. Marilyn Doss Ruffin* and

Katherine S. Tippett

4. Application of Historical Repair Data in Life Cycle

Costing Analysis. S. Wayne Stiefel* and

William B. Beine

5. The Concepts of Product Life and Consumer Product Safety. Joann H. Langston (abstract only, see Appendix A)

6. Environmental and Economic Impacts of Product Durability and Life. P. L. Fontaine

SESSION V: PANEL DISCUSSION: CAN AND SHOULD PRODUCT LIFE BE EXTENDED?

Introductory Remarks of Panelists:

1. William E. Davis

2. W. A. Glaeser

3. N. R. Pugh

APPENDIX A

Abstracts of Papers for which no Manuscripts were Submitted:

1. Technical Durability of Products. Elio Passaglia

2. Materials Conservation through Increased Durability.

M. B. Peterson

3. The Concepts of Product Life and Consumer Product Safety. Joann H. Langston 
APPENDIX B

List of Registrants for the 27th MFPG Meeting

MFPG Publications

* Indicates speaker when a paper had more than one author. 
These proceedings consist of a group of nineteen submitted papers from the 27 th meeting of the Mechanical Failures Prevention Group which was held at the National Bureau of Standards in Gaithersburg, Maryland, on November 1-3, 1977. The central theme of the proceedings pertains to the durability of consumer products. Special emphasis is on durability technology, product testing, product performance, the economics of extending product $1 \mathrm{ife}$, and labeling products for durability.

Key words: Design quality; durability; durability technology; materials conservation; product 1 ife; product performance; product testing; wear analysis

\section{UNITS AND SYMBOLS}

Customary United States units and symbols appear in many of the papers in these proceedings. The participants in the 27 th meeting of the Mechanical Failures Prevention Group have used the established units and symbols commonly employed in their professional fields. However, as an aid to the reader in increasing familiarity with and usage of the metric system of units (SI), the following references are given:

NBS Special Publication, SP330, 1977 Edition, "The International System of Units."

ISO International Standard 1000 (1973 Edition), "SI Units and Recommendations for Use of Their Multiples."

E380-76 ASTM/IEEE Standard Metric Practice (Institute of Electrical and Electronics Engineers, Inc. Standard 268-1976).

Disclaimer:

Certain trade names and company products are identified in order to adequately specify the experimental procedure. In no case does such identification imply recommendation or endorsement by the National Bureau of Standards, nor does it imply that the products are necessarily the best available for the purpose. 


\section{SESSION I}

\section{PRODUCT DURABILITY ISSUES}

CHAIRMAN: K. C. LUDEMA

UNIVERSITY OF MICHIGAN 



\author{
Robert T. Lund \\ Center for Policy Alternatives \\ Massachusetts Institute of Technology \\ Cambridge, Massachusetts 02139 \\ Center for Policy Alternatives \\ Massachusetts Institute of Technology \\ Cambridge, Massachusetts 02139
}

Abstract: This paper begins by discussing the various benefits associated with extended product life, and possible negative impacts are noted, as well. It is pointed out that the factors influencing product life are not only technological in nature, but also include product usage behavior by consumers. The discussion then turns to a fourfold classification scheme for policy alternatives for extending product life. This scheme is built on the distinction between consumer versus product-related influences on product life, and a distinction between short-term and long-term policy impacts. The final section of the paper identifies options available to policymakers attempting to prolong product life. The concept of remanufacturing, as a strategy deserving more careful attention, is particularly stressed.

Key words: Product life; remanufacturing; consumer usage; product durability; product design; resource conservation.

How often have we heard the lament: "Why can't they make a product that lasts?" To the average consumer, the desire for longer lasting products probably seems beyond debate. This is corroborated by the recent Sentry Insurance study, Consumerism at the Crossroads, which found that 78 percent of the public believes that products do not last as long now as in the past [1]. Whether this is objectively true is open to question $[2,3]$ but the shape of consumer sentiments is clearly in the negative. Beyond the desire to satisfy public sentiment, however, there are persuasive arguments in favor of making products live longer.

There is, first of all, the prospect for direct savings to consumers that could accrue from less often having to replace products in which they have a major investment. Moreover, to the extent that increased product life also means greater reliability and fewer repairs, we might 
expect consumers to become more satisfied with the performance of their purchases.

In addition to benefits for the individual consumer, extending product life also promises to benefit society as a whole. There is an increasingly recognized need for a shift in societal values toward resource conservation as dictated by encroaching scarcities (or the economic measure, rising costs). Thus, a primary societal incentive for extending product life involves the opportunity to save material and energy resources that go into the manufacture of consumer goods. It can also be expected that longer product life will help alleviate the waste disposal burden that has become one of the nastier by-products of this age of technological prosperity.

As with most issues, however, the question of product life is not all one-sided. There are potential problems and limitations in what can be achieved. It is possible, for example, that increased life for certain products can be purchased only through significantly increased costs of production. This would be the case when more costly materials are used, or when more expensive fabrication or assembly techniques are required. If longer lasting products are also more expensive, the direct savings to consumers may not be possible. Because most of us have some intuitive "discount rate" built into our evaluation of future savings arising from present costs, the extension of life of a product, such as an appliance that already has an average life of fifteen years, may have a rather low value at the time of purchase.

A second and related problem involves reliance on scarce or precious materials to achieve greater product durability. Not only might the cost of certain products be increased through increased use of stainless steels and brass, for example, but it would also be counterproductive to promote product life when it might only serve to place heavier demands on copper, chromium, nickel and zinc--more valuable and increasingly scarce materials.

A third problem raised by the prospect of longer product life is its potential effect on product innovation. If products last longer, the turnover rate for the total product stock will fall; this in turn may inhibit the rate at which new product designs and related innovations can be introduced into the existing stock. In an era when we find ourselves promoting and encouraging consumers to switch to more energy efficient cars and appliances, more pollution-free automobiles, safer products, and so forth, it can be argued in some instances that we should not attempt to perpetuate existing product designs.

A final argument stems from the potential economic dislocations that might result from extending the life of products. If longer product life leads to a reduction in consumer demand, this would imply a slowdown in economic growth for the affected industry. Unemployment and profit losses could result. Generally, however, such negative impacts 
can be regarded as temporary, since the long-term effects of consumer savings in one product category should be a redistribution of expenditures to other kinds of goods and services. During the transition, however, the consequence for production workers, suppliers and retail dealers can be painful.

Longer product life, then, as with many aspects of product design, manufacture and use, is a situation involving important trade-offs. The reason why product life has become an important topic today is that the values that go into the trade-off equilibria have been shifting--some very rapidly. We now need to see if there are ways of achieving new balances that provide longer life at an acceptable cost.

\section{Factors Determining Product Life}

When most people talk about increasing product life, they usually focus on technological solutions to product durability. (The program for this conference reflects this prevailing concern.) Naturally, how long a product lasts is heavily dependent upon its design, the materials used in its construction, and the processes by which it is manufactured and tested for quality. In addition, however, product life is also dependent upon consumer attitudes and usage behavior.[4] Products all wear out--eventually. But they will wear out more quickly when they are used more heavily or when they are abused. The care and maintenance given a product will influence its durability. And finally, of course, the very decision that a product is no longer "worth keeping" is ultimately a subjective and only partly economic judgement by the consumer, rather than one based on purely technological considerations.

Opportunities for extending product life are not merely questions of design and manufacturing technology. A great deal depends on consumer attitudes and perceptions as these influence product usage behavior.

Not only are there these two major sources of influence on product 1ife, but an additional level of complexity arises out of the interplay between product design and consumer psychology. Perhaps the most widely recognized example of that interplay involves stylistic changes in product design. This is the familiar phenomenon of new products being bought to keep up with new styles and appearances, in disregard of functional qualities. Critics of industry frequently argue that superficial style changes, without significant change in underlying design, are exploited as a marketing device to the detriment of the consumer. The counter-argument is that consumers want "style," and business is only meeting the legitimate needs of consumers to pursue their aesthetic tastes whether these needs are rational or not in some more objective sense. Furthermore, new models often contain a mix of functional improvements and styling changes. [5] 
The achievement of longer product life is a desirable objective, provided that the means of accomplishing the objective do not generate unacceptable side effects. Society, we believe, is willing to opt for products that live longer if the consequences of this course of action are reasonably benign. There are, then, two principal issues confronting policy formulation in this area: (1) to identify specific product categories for which longer life is a desirable goal; and (2) to identify appropriate strategies for accomplishing the objective of extended life with minimal adverse effects.

While definitive answers to these issues are not yet readily available, a useful starting point would be to specify the criteria that are most relevant for assessing the policy alternatives that may be considered. In identifying product targets, at least the following four criteria should be taken into account: (1) value-added during manufacture; (2) materials and net energy involved in production; (3) effects of the product on the environment; and (4) actual potential for increased life. First, the prime candidates for extended life policy should be products with a comparatively high level of value-added, since these offer the greatest opportunity for conservation of labor, energy, and materials invested in products. In this sense, extending product life complements recycling as a conservation strategy. Secondly, while the value-added criterion covers both material and energy overhead costs, these also deserve separate consideration. At present, the full social costs of many materials are not internalized in production costs; the same may be said for energy resources to perhaps an even greater degree. Therefore, the relative scarcity of and potential substitutes for these resources should be a direct policy concern independent of their cost contribution to production overhead.

The same may be said for those products which, when discarded, produce undesirable social consequences - litter, pollution, waste handling costs. These social costs have not even been adequately accounted for, and certainly have not been made internal to the products.

The fourth major consideration in identifying target products is the pragmatic one of whether there is actually a significant life-extension opportunity. It is senseless to devote time and effort to promoting product life in cases where only marginal improvements are possible.

Turning to the question of what policy strategies will generate the greatest benefits with the fewest adverse effects, we encounter somewhat greater problems for systematic treatment. Earlier, we cited a number of the most critical negative impacts that could result from illconceived efforts at extending product life. Any policy program should certainly strive for prior assessments of both the intended and unintended consequences of alternative strategies. Before this can be done, however, it is necessary to have some basis for determining what the possible policy strategies themselves may be. 
As a first step toward delineating the policy alternatives for extending product life, we propose a fourfold classification scheme. We are led to this scheme, first, by the previous observation that product life depends both upon factors of consumer psychology as well as properties of the product itself. More generally, consumers make up the demand side of the marketplace. In the complete array of product life policies, the consumer-related policies may very well be as important as the technologically-oriented policies of the supply side.

From a policy standpoint, moreover, it is important to recognize the difference between short- and long-term processes of change. Shortterm policy strategies in the case of durable products would pertain primarily to the existing stock of products, while long-term strategies would apply to products not yet offered for sale to consumers. The total problem/policy environment can thus be usefully depicted according to the following fourfold matrix:

MARKET BEHAVIOR SUPPLIER BEHAVIOR

SHORT-TERM IMPACTS

LONG-TERM IMPACTS

\begin{tabular}{|l|l|}
\hline $\begin{array}{c}\text { Consumer usage } \\
\text { behavior }\end{array}$ & $\begin{array}{l}\text { Existing product } \\
\text { maintenance \& } \\
\text { disposal technology }\end{array}$ \\
\hline $\begin{array}{l}\text { Consumer purchase } \\
\text { behavior }\end{array}$ & $\begin{array}{l}\text { New product } \\
\text { performance-design } \\
\text { and manufacture }\end{array}$ \\
\hline
\end{tabular}

Within each of the four cells of this scheme, we have specified what appear to be the primary controlling factors on product life. These, in effect, comprise the leverage points available to policy intervention. If one wishes to promote longer product life, the resources of policy intervention (e.g., tax incentives or penalties, product material and performance standards, consumer information and persuasive appeals) should be directed to affect one or more of these controlling factors.

In the short-term, market quadrant, efforts to promote longer product life must focus on the way consumers use the products they currently own and/or on the service and disposal mechanisms that are currently available. Examples of strategies that could be employed to influence consumer usage behavior are: (1) education to help consumers appreciate the value of improved product care and information to indicate the most efficacious ways of increasing the useful life of products already owned; and (2) tax incentives for expenditures on repairs and basic maintenance that enhances product longevity -- analogous to the tax deductions allowable now for medical expenses.

On the supply side, short-term policy options could include: (1) incentives to suppliers to encourage them to keep up parts inventories, 
both to assure the availability of replacement parts and to help hold down the cost of such parts for product repair; (2) encouragement and perhaps direct public support for used product markets, both for direct re-use (second-hand) by consumers and for purposes of total or part remanufacturing; and (3) lower servicing costs.

In the long-term, strategies to promote longer product life must focus more on making changes in the composition of the total product stock. Initiatives directed at market behavior should concentrate on inducing the purchase of models with the potential for a longer technicallyuseful life. While consumers may be concerned about product durability, they often lack the information to evaluate their purchase alternatives in this light. This implies some form of consumer education or information that assists consumers in their product selections. Having purchased more durable products, consumers must be encouraged to keep them to the end of their useful lives or to get them into second-hand markets or collection points for remanufacturing.

In the long-term, where we are considering new products replacing existing products in use, suppliers have a major role in increasing product life through product design. Not only can the functional durability of the product be enhanced, but its cosmetic durability (resistance to degradation of appearance) should also be considered. Repairability -- low cost replacement of either functional or cosmetic parts -- is an alternative to designs for very long-term durability. This approach obviously depends on the supplier's willingness to maintain stocks of replacement parts over the life of the product. Finally the product can be designed for ease of disassembly and remanufacture. This latter alternative has been given very little attention by either the public or private sector, and needs further consideration.

\section{Remanufacturing -- A Neglected Alternative}

Even when a complex durable product such as an automobile, an appliance or a machine has come to the end of its useful life, there is much in that product that retains its full functional value if the components could be put to use again. The brushes in electric motors may wear out but the armatures and their windings are good; bearings may fail, but the castings in which they are set are still sound. Each of these functionally useable parts have a value (as represented by the materials, labor, energy, and overhead costs associated with its manufacture) that is many times the residual material value as scrap. Remanufacturing is an approach that finds intermediate methods of preserving the functional value of the original product -- essentially giving older products new lives.

We would like to suggest that remanufacturing is an especially promising strategy for achieving a fully extended product life. We are not speaking here of unit-by-unit rebuilding of products, which would be too small in scale to have significant economic impact. Rather, we 
refer to the highly organized business of total disassembly of products, pooling of interchangeable parts, and production-line reassembly with some replacement of worn parts. It is a strategy aimed at capturing the residual functional value (or value-added) in a used product that might otherwise be destined for disposal, by reprocessing all usable parts to arrive at a like-new product or functional value nearly equal to the original.

Remanufacturing promises an unusually strong array of advantages compared to alternative methods of extending product life. Unlike strategies aimed simply at increasing the life of the original product (e.g., increased durability), remanufacturing helps deal with the fact that all products do eventually wear out. While repairs can keep a product in operation for an extended period, there arrives a time when repair costs become prohibitive and the unit is discarded. When this happens, the residual value of the product (or of its salvageable parts) is entirely lost. Recycling, to recover the materials content of products is, if collection costs are included, a far less attractive alternative. Through remanufacturing, by contrast, one has the opportunity to preserve a much larger share of the product's functional value over an extended period.

Remanufacturing involves a number of process steps that are relatively labor intensive. The bulk of the work is in parts refinishing, testing and assembly, where people are needed. Remanufacturing, therefore, implies employment opportunity, especially at unskilled and semi-skilled levels. It can provide a stimulus to new jobs not only in the remanufacturing operations, but also in the development of collection and distribution networks needed to sustain such an industry.

This stimulus to employment need not be merely a trade-off for jobs lost through a reduction in work in original equipment manufacturing plants. Remanufacturing will provide lower cost, like-new products in the market. These will undoubtedly compete with some portion of the new product market, but there is a high probability that the lower prices on the remanufactured models will expand the market among lower income consumers and to higher income consumers wishing to add to their household stock (a second refrigerator, for instance).

Remanufacturing is also an attractive way of providing lower-cost replacement assemblies to repair products still in use. This is about the only contribution remanufacturing makes today. There is an active remanufacturing industry for major automobile parts, such as alternators, starter motors and water pumps. These lower-cost replacement parts directly contribute to prolonging the lives of automobiles which might otherwise be abandoned.

While remanufacturing offers attractive opportunities for extending product life, a number of issues need to be better understood before this approach can be successfully implemented. Among the major problems to be resolved is the need to establish efficient channels for both 
collecting worn-out products and, at the other end of the line, for distributing and retailing the reprocessed products. Not only must these commercial operations be established, but the whole proposition must gain consumer acceptance. Consumers must cooperate in getting their used goods into the remanufacturing system (some incentive may be needed), and then some segment of the consuming public must be ready to buy remanufactured products. Price savings should provide a strong inducement, but there may still be some degree of attitudinal resistance to be overcome.

Another set of issues pertains to the fit between product designs and the remanufacturing process. It would clearly be helpful if emphasis were given to new product designs that allow for easy disassembly of component parts and reassembly once cleaning and refurbishing have been done. Similarly, it would facilitate the remanufacturing process if there were greater standardization of product components across brand and model categories. While such standardization should not be sought at the expense of product innovation, there surely can be greater compatibility of component designs particularly in products with a relatively stable technology.

A final set of issues centers on the process technology of remanufacturing per se. Since this is not yet a large industry, little experience is available as to the most practical and efficient methods of operation. There are questions about the optimal scale for such operations, the degree of centralization possible (given constraints imposed by collection and distribution channels), and the most promising approaches for starting up such an operation. For that matter, it is not yet clear what product categories are the prime targets for remanufacturing, although the criteria described earlier can help guide such choices.

What we are suggesting here is that remanufacturing holds great promise as both a strategy for extending product life, and as a potentially lucrative business venture in its own right. However, much needs to be learned before substantial investments are warranted. A closer look will undoubtedly reveal technical, economic and social problems that must be dealt with. This is an important area for research, and we are preparing to explore it further.

\section{Conclusion}

We began this paper by noting that the opportunities for extending product life carry both positive and negative potentials. It is not a one-sided propostion, and great care must be taken in determining the most effective life-extending strategies with the fewest undesirable consequences. Well-reasoned policies to promote longer product life must begin by assessing the alternative strategies that are actually available. 
As a step in this direction, we have stressed the point that product life is affected not only by inherent characteristics and durability of the product itself, but also by the way consumers use the product. Technological solutions can be ineffectual if consumers refuse to cooperate. More than this, it must be recognized that products and people interact, and that efforts to prolong product life must take the human factor into account.

As with any complex problem, the challenge of extending product life has many different facets. There are differences between short-term and long-term policies -- i.e., whether you are trying to extend the life of products already on the market versus trying to reshape the nature of the total stock of products over time. There are also crucial differences in whether one wishes to concentrate on making the original product live longer or on trying to establish some intermediate mechanism, such as remanufacturing, that fulfills essentially the same function of preserving the functional value of products or product parts.

The point is not that any one approach is better than others, but rather that such judgements must begin by discerning what actually are the alternatives before us. The optimal solution is very likely to involve a mix of strategic alternatives--technological change, market and consumer behavior change, and perhaps even the emergence of whole new industries.

\section{References}

1. Consumerism at the Crossroads, Sentry Insurance, report prepared by Louis Harris and Associates, Inc. and Marketing Science Institute, 1977 , page 23.

2. Lund, R. T., "Incentives for Longer Product Life: A Case Study," paper presented to O.E.C.D., Paris, Apri1 1976.

3. Ruffin, Marilyn Doss and Katherine S. Tippett, "Service-Life Expentancy of Household Appliances: New Estimates From the USDA," Home Economics Research Journal, Vol. 3, March 2975, pp. 159-170.

4. Smith, Frank A., Product Design Modifications for Resource Recovery, Source Reduction, or Solid Waste Management Purposes, Section entitled "Economic Durability of Products," Mimeo, May 1973 (largely reproduced as Appendix B of Second Report to Congress, Resource Recovery and Source Reduction, U. S. Environmental Protection Agency, 1974).

5. White, Lawrence J., The Automobile Industry Since 1945, Chapter 12, "Product Behavior: Durability, Styling Models and Model Proliferation," pp. 189-210, Howard University Press, Cambridge, 1971, 348 pp. 


\title{
Paul Lerman
}

Fairleigh Dickinson University

Rutherford, New Jersey 07070

\begin{abstract}
The economic and financial considerations associated with al $\mathbf{1}$ product decisions has become increasingly important in recent years due, in large part, to relatively high capital costs and the resulting desire on the part of corporate decision makers to invest their capital funds in those projects yielding acceptable returns.

Most cases involving an improvement in product durability will require a commitment of managerial, engineering, and production resources, all of which will ultimately be measured in financial terms. Thus, the final decision regarding product durability would seem to be based on economic and financial considerations, assuming technological feasability.

This paper discusses the economic and financial considerations that must be recognized in determining the viability of an improvement in product durability. Included in this discussion are current accounting and tax policies that affect the decision.
\end{abstract}

Key words: Discounted cash flow; financial analysis; product durability; product life; tax effects.

\section{INTRODUCTION}

It has become increasingly clear in recent years that all corporate decisions have, and continue to, come under increasing scrutiny by the financial decision makers. The ultimate decision is based at least as much on financial considerations as on technological considerations since, in most cases, they are inseparable. Thus, in order to make a rational decision as to the desirability of increased product durability or prolonged product life, it is necessary to consider the financial institutions 
that affect the decision.

\section{GENERAL CONSIDERATIONS}

The decision to improve product durability would be simple to arrive at if it were possible to accomplish the improvement at no additional cost to either producer or consumer. However it would be unrealistic to expect that product cost would not increase with such an improvement in product durability. From the standpoint of the producer it could be expected that his production cost, including research and development and other capital investment, would increase. This might result in a change in sales revenue which could be negative (due to reduced volume caused by increased price) or positive (due to wide acceptance of the improved product at the higher price).

Thus, in consideration of changes in revenue and costs, the producer's decision rests on whether future sales will provide a sufficient incremental benefit to justify increased investment. The consumer would also be concerned with the tradeoff of higher initial cost against the future incremental benefits purchased by the increased initial expenditure. Both producer and consumer would presumably utilize the so called "discounted cash flow" analysis to determine the worthiness of the additional expenditure. The basic equation used for the analysis is:

$$
\mathrm{NPV}=\mathrm{C}_{0}+\frac{\mathrm{C}_{1}}{(1+i)}+\frac{\mathrm{c}_{2}}{(1+i)^{2}}+\ldots+\frac{\mathrm{C}_{\mathrm{n}}}{(1+i)^{n}}
$$

where:

$$
\begin{aligned}
& \mathrm{NPV}=\text { net present value }(\$) \\
& C_{j}=\text { cash flow }(\$) \quad j=1,2, \ldots, n \\
& i=\text { discount rate. }
\end{aligned}
$$

If we assume, for example, that $\mathrm{C}_{0}$ is negative representing the incremental initial outlay, and each $\mathrm{C}_{j}$ is positive, representing the incremental benefit due to improved product durability, the calculation of NPV would provide an indication of the desirability of the additional investment.

An investigation of the denominator of each term in the net present value equation provides some insight into 
the nature of the analysis. It can be seen from the NPV equation that as the benefit to be received is further in the future, the contribution to NPV per dollar of benefit decreases due to the increasing nature of the denominator. Alternately stated, one dollar of additional expenditure at the outset requires more than one dollar of benefit at a future time period in order to make the original investment worthwhile. Just how much larger depends upon the timing of the benefit and the discount rate. The effect of time as well as the effect of the discount rate may be seen in Table 1 .

The table reveals that as the time of the receipt of the benefit is pushed into the future, the discounted value of the benefit decreases. Additionally, the table shows that as the discount rate is increased, holding the benefit receipt period constant, the discounted value of the benefit decreases. For industrial decisions, the discount rate usually represents the minimum acceptable rate of return on corporate investments. It is usually determined by considering such factors as the cost of capital, project risk, expectations regarding inflation, etc. In many corporations this rate is varied, depending on the risk nature of the specific investment under consideration. It is significant to note that, currently, it is quite commonplace for the discount rate to be in excess of twenty percent, with it not being uncommon for some corporations to use a discount rate of thirty percent for at least some of its investments.

These rates have very serious ramifications from the viewpoint of at least one aspect of product durability, that is, extended product life. For, if the increase in product life has resulted in a one year extension of that life, say from nine years to ten years, it can be seen from Table 1 that each one dollar benefit in year ten, assuming a twenty percent discount rate, has a net present value of \$0.1615. Alternately stated, this one year extension of product life can be justified only if each additional dollar of benefit cost no more than $\$ 0.1615$ at inception. Of course, if the discount rate is increased to thirty percent, each additional dollar of benefit received in year ten can be justified by an additional expenditure of no more than $\$ 0.0725$ at inception. 
TABLE 1

PRESENT VALUE OF ONE DOLLAR

$$
\frac{1}{(1+i)^{n}}
$$

YEAR OF

RECEIPT

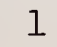

2

3

4

10

15
5

(1)

2

3

4

5

10
$5 \%$

0.95238

0.90703

0.86384

0.82270

0.78353

0.61391

0.48102

DISCOUNT RATE

$10 \% \quad 20 \%$

0.90909

0.83333

0.69444

0.57870

0.75131

0.68301

0.62092

0.38554

0.23939

0.48225

0.40188

0.76923

0.59172

0.45517

0.35013

0.26933

IDENTIFICATION OF COSTS AND BENEFITS

In order to apply the discounted cash flow method, it is necessary to quantify the costs and benefits (net cash flows) associated with a decision to alter product durability. From the viewpoint of the producer, an improvement in product durability can be expected to require additional outlays in research and development, machinery, etc. As discussed earlier, given no external disturbance such as increased government intervention, a rational producer would undertake such an investment only if the future sales are expected to result in a sufficiently high cash flow stream. The actual cash flows are significantly affected by taxation policies, a subject discussed in some detail below.

Likewise, the consumer would be required to expend an incremental amount of money at the time of the purchase on the improved product. His expectation of the future benefits to be received for this additional outlay would include such things as reduced maintenance and/or increased product life. Of course there are other less tangible benefits that enter into consumer decisions. In any event it should be noted that consumers (other than industrial) discount future benefits quite heavily (ref. 1) and thus the initial price usually plays more of a role in his decision than for the industrial consumer.

ACCOUNTING AND TAX EFFECTS

A simple definition of the term "net cash flow" may be stated as the incremental amount of money that an 
investor finds in (or out) of his pocket for having made the investment under consideration. For industrial producers and industrial consumers, the actual determination of net cash flow depends very heavily on the accounting and tax treatment of the original expenditure and the future benefits.

The two major categories of increased initial outlay have previously been identified as research and development and, equipment (fixed assets). Current tax law (1977) permits research and development to be deducted from income in the year paid or incurred, or over a period of 60 months or more. Any additional or new equipment must be capitalized and depreciated over the expected useful life of the equipment. There are several methods permitted to be used in the calculation of annual depreciation charges. Table 2 provides an example of the charges as calculated by the three most commonly utilized methods. All are accepted by the Internal Revenue Service for income tax purposes. The table shows that all three methods result in the same total depreciation over the life of the investment. The differences between the three methods can be found in the timing of the depreciation charges. The accelerated methods, double rate declining balance and sum of the years digits, provide larger expenses in early years and smaller expenses in later years when compared to straight line depreciation. Depreciation charges themselves are non-cash charges however, since depreciation is an allowable expense in the computation of income taxes, it can be seen that the accelerated methods while resulting in larger charges in early years have the effect of reducing income taxes in those years while increasing them in later years. Even though the total amount of taxes paid over the life of the investment will be the same regardless of which method is used for the computation of depreciation, the discounted cash flow equation reveals that it is desirable to defer tax payments to later years since deferal of taxes results in larger cash flows in early years when the present value factors are the greatest.

One additional feature of the current tax law important to machinery investment decisions is the investment tax credit. The investment credit was originally intended as a device for stimulating increased business investment 
in machinery and equipment. The Tax Reduction Act of 1975 raised the credit from 7\% in effect since 1962 to 10\%. A tax credit differs from a deduction in that it is applied dollar for dollar against the actual tax bill, whereas a deduction, such as depreciation, results in a tax saving of $\$ 0.48$ for each dollar of deduction. (The current tax law places all corporations earning over $\$ 50,000$ in a $48 \%$ tax bracket.) The investment tax credit, for equipment having a life in excess of seven years is $10 \%$ with reductions for equipment having useful life of between three and seven years. There is no credit for equipment having a useful life of less than three years. Therefore, for the example of Table 2, the purchase would result in an actual tax saving of $\$ 1600.00$ thereby effectively reducing the initial outlay for the equipment to $\$ 14,400$. The tax credit has no effect on regular depreciation.

Thus it can be seen that if a corporation chooses an accelerated depreciation method, coupled with the investment tax credit, the major portion of the tax benefits are taken in early years.

\section{TABLE 2 \\ COMPARISON OF DEPRECIATION METHODS}

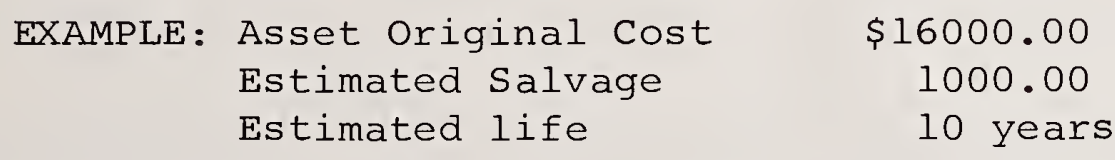

$\begin{array}{rccc}\text { YEAR } & \text { STRAIGHT } & \text { DOUBLE RATE } & \text { SUM OF THE } \\ & \text { LINE } & \text { DECLINING BALANCE } & \text { YEARS DIGITS } \\ 1 & \$ 1500.00 & \$ 3200.00 & \$ 2727.27 \\ 2 & 1500.00 & 2560.00 & 2454.55 \\ 3 & 1500.00 & 2048.00 & 2181.82 \\ 4 & 1500.00 & 1638.40 & 1909.09 \\ 5 & 1500.00 & 1310.72 & 1636.36 \\ 6 & 1500.00 & 1048.58 & 1363.64 \\ 7 & 1500.00 & 838.86 & 1090.91 \\ 8 & 1500.00 & 785.15 & 818.18 \\ 9 & 1500.00 & 785.15 & 545.45 \\ 10 & 1500.00 & 785.15 & 272.73 \\ & \$ 15000.00 & \$ 15000.00 & \$ 15000.00\end{array}$

NOTE: For double rate declining balance, the deprec- 
iation rate is twice the reciprocal of the asset's expected life, with no explicit recognition of end of life salvage. The practice is to switch to straight-line depreciation in the year that the declining balance charge falls below the average depreciable amount.

\section{EFFECT ON DURABILITY DECISIONS}

The previous discussions all seem to point in the same direction. Financial management seems to be oriented toward early return of the benefits associated with any given investment. The tax laws appear to be written to provide this early return through the investment tax credit and accelerated depreciation provisions. These observations should provide some insight into which durability improvements can be made viable. If the only effect of improved durability is to increase product life for a product having a relatively long product life, say ten years, it could be justified only by a small additional outlay requirement. However, if the improvement provides reduced maintenance costs throughout the life of the product, it may be possible to justify a relatively larger initial outlay

\section{REFERENCES}

(1) Flanagan, W.F. and R.T. Lund. "Factors Controlling Longer Product Life: The Case for Consumer Durables" Proceedings of a Workshop on Wear Control to Achieve Product Durability. Analytical Rework/Service Life Project Office, Naval Air Development Center, Warminster, $\mathrm{Pa}$. 
Mark J. Raabe

House Committee on Interstate and Foreign Commerce

2125 Rayburn House Office Building

Washington, D. C. 20515

Abstract: Review of Congressional Action with respect to past consideration and current bills dealing with labeling products for durability, as well as for other characteristics. Discussion of present governmental action in the overall product labeling area, including comments on primary problems being encountered. A focus specifically on durability labeling along with comments on prospects for future congressional action.

I am pleased to be here this afternoon to discuss labeling of products for durability. I plan to first review Congressional action in this area with respect to both past consideration and current bills before the House and the Senate.

Next, I shall discuss what government agencies are doing -- and potentially can do -- in this overall area, in the absence of further congressional action. This will include comment on some of the problems that are currently being encountered.

And finally, I shall focus on durability, and the prospects for congressional action in that area -- as I see it from my vantage point.

Congressional action -- So far in the 95th Congress, which began in January of this year, there have been two basic bills introduced on subject matter relating to durability.

(1) Congressman Ben Rosenthal of New York is the prime sponsor of the first bill I shall discuss. This bill would require that durable consumer products be labeled as to durability and performance life. If enacted, it would be known as the "Performance Iife Disclosure Act." Through successive introductions of this bill, there are now 33 cosponsors of the legislation.

In format, this is a relatively uncomplicated, straight-forward and simple bill. That is not to suggest, however, that carrying out the legislative mandate of the bill would be easy or not fraught with difficult and complex problem areas.

Under this bill, the National Bureau of Standards (NBS) would be called upon to establish regulations requiring manufacturers of durable 
consumer products, including appliances and electronic items, to disclose on a conspicuous label or tag affixed to each item sold at retail to consumers, the product life of each manufactured durable product as used under normal operating conditions.

Under this bill, the NBS would have final authority over the selection of products and components of those products for which performancelife designations would be made, as well as over the procedures for determining and establishing performance life of those products. The bill is silent on the manner in which the NBS is to carry out its responsibilities. As I indicated earlier, this is a rather abbreviated bill -- consisting of only two pages in length -- which leaves many problems of implementation unanswered.

The Federal Trade Commission (FTC) would be authorized, under this bill, to enforce the Act with the same jurisdiction, power and duties as are contained in the FTC Act. (Comment on FTC jurisdiction.)

(2) The second and more comprehensive bill introduced in the current session is H.R. 24. This bill would establish uniform test protocols for consumer products and mandate labeling them. The bill was introduced by Congressman John Murphy of New York and, if passed, would be known as the "Consumer Product Testing Act of 1977."

H.R. 24 closely parallels a bill known as the "Consumer Product Testing Act of 1975," co-sponsored in the last session by Senators Magnuson and Moss in the Senate and Congressmen Moss, Dingell and Van Deerlin in the House. While the two bills I have mentioned have been introduced in the House, no legislation bearing upon durability has been introduced in the Senate during this session. However, while hearings have not been held in the House, they have been held in the Senate during the past session. I will say more about this later. First, I will comment briefly on the provisions of H.R. 24 .

The bill would require the FTC, in conjunction with the NBS, to promulgate uniform product test protocols which would provide a basis for judging and comparing "product characteristics". Product characteristics include, but are not limited to (1) effectuation of purpose, (2) durability, (3) average annual cost of repair, (4) maintenance requirements, (5) frequency and nature of repair, and (6) environmental impact in the manufacture, use and disposal of the product.

Section 4 of the bill directs the commission to initiate proceedings for the development of test protocols when it determines that the protocols would materially assist consumers in purchasing decisions. Section 5 details the procedure for the development of test protocols. The Commission, in conjunction with the NBS, would have the responsibility of initially identifying product characteristics capable of objective measurement. Thereafter, interested persons would be invited to develop test protocols. A proposed protocol would be published in the 
Federal Register as a proposed rule. Protocols would be promulgated pursuant to the informal rulemaking provisions of section 553 of the APA. (Cf. procedures of sec. 553 with those of Magnuson-Moss Act.)

Section 6 of the bill would authorize the FTC to promulgate regulations governing the manner in which manufacturers, distributors, and retailers may advertise that their products have been tested in accordance with a test protocol. Results of such testing would be required to be disseminated to consumers at the point of sale prior to sale. Section 8 provides that the commission may conduct compliance testing to insure the veracity of test results. Sections 9,10 and 11 , respectively, provide for injunctive relief to injured parties, set forth prohibited acts and provide for civil and criminal penalties.

During the Senate hearings on S. 643 (counterpart of H.R. 24) in the last session of Congress, strong opposition to the bill was heard from both government and industry groups. It might be of interest to you just to note briefly the positions of the principal parties who testified. I should caution, however, that viewpoints can and do change with the passage of time. This would be particularly possible where a change in administrations has taken place such as we have undergone since the 94th congress.

The Federal Trade Commission, through then Chairman Engman, expressed unanimous support for the basic concepts of the bill. The Commission felt the bill would help correct problems both of deficiency and noncomparability of product information. In addition, the Commission took the position that labeling as to quality and performance would lead to increased competition and promote product improvement. Generally, FTC disagreement with the bill focused on language in section 5 (a) which seemed to suggest that the offeror process would be the primary tool to obtain test protocols. The commission sought more flexibility in this regard and recommended that the bill also make clear that the Commission has the discretion to make the testing of consumer products and dissemination of the results thereof, voluntary or mandatory, depending upon which approach would best serve the public interest.

The Department of Transportation opposed the bill largely on the basis that it could produce conflicting standards with those of NHTSA, FAA and the coast Guard, thereby causing confusion and rendering the latter ineffective.

The Department of Commerce strongly supported the concept of more consumer product information but urged development of voluntary programs.

The National Bureau of Standards echoed its parent organization in opposing mandatory requirements and endorsed voluntary programs. NBS gave assurance, however, that it could meet the responsibilities assigned to it under the legislation, provided appropriate funding would be forthcoming. 
The Department of Justice strongly opposed S. 643. The Department's views could be summarized by the following: consumers already have access to considerable product information; the FTC has authority to stop false advertising where it exists; the government should not become involved to a greater degree in product testing; the proposed testing would increase substantially the cost of consumer products; and consumer injunctive suits are highly undesirable.

Consumers Union supported the bill but had reservations about certain provisions. Basically, CU found the bill unclear as to what consumer information would be required. It recommended the bill be amended to allow experimentation with various alternatives relating to the consumer information program. The most desirable consumer information varies under different circumstances, i.e., from point of sale mandatory labeling in some instances to "take one" sheets at the counter in others. CU noted there is a potential problem of too much information which could cause consumer confusion and this too requires experimentation to resolve. CU raised other questions including conflict of interest, translation of raw test data into performance grades, and the determination of who best can develop a test protocol.

The American Society for Testing and Materials (ASTM) generally supported the concept but felt S. 643 could not meet the stated objective as written. Specifically, ASTM felt the statutory time limits unworkable (180 days clearly inadequate); the statutory emphasis should be on competence in developing test protocols and not on technical competence per se; and, there should be clear provision for due process in developing protocols so that a consensus on protocols is reached with a minimum of government bludgeoning. ASTM also warned that the development of standards is a costly business. ASTM's developmental work with CPSC as offeror on the matchbook standard cost $\$ 213,000$ and ASTM estimated another $\$ 250,000$ costs were incurred by CPSC and private industry before the project was completed.

Industry trade associations, representing appliance manufacturers, were strongly opposed to the bill. These included the National Electrical Manufacturers Association, Electronic Industries Association, Gas Appliance Manufacturers Association and the American Gas Association. The objections of these groups centered on charges that the bill was unnecessary, would be unworkable through the offeror process, would cause consumer confusion by producing too much information, would result in severe damage to the free market economy by unwarranted intrusion of government into standard setting, would adversely affect conpetition and reduce innovations in product design, and would significantly increase product costs far beyond any resulting consumer benefits.

Generally, consumer groups were not represented at the hearings, although the National Consumers League appeared and endorsed the bill. NCL pointed to some difficulties in the offeror process experienced by 
CPSC, i.e. lack of consumer participation and insufficient funds, and felt these had been corrected in the current bill.

From the foregoing, it is clear that while there appears to be a consensus that disclosure of product information is good, there is a wide variety of views as to how this can best be accomplished.

At this point, I would like to shift gears and move on to the second point to examine the FTC's ongoing activities with respect to measuring product performance. The commission currently has several pending proceedings which propose to require labeling of products with respect to certain product qualtities or characteristics. I think it is pertinent to review these proceedings because they can provide insight into factors which must be weighed in connection with any consideration of labeling for durability.

Energy Policy and Conservation Act (EPCA) -- The testing and disclosure requirements of the Energy Policy and Conservation Act, P. L. 94163, are generally similar in many respects to those contained in H.R. 24. The major differences are that Ji'CA (I) vests responsibility for protocol development in the Federal Energy Administration (FEA), and

(2) sets forth limited and specific characteristics, energy efficiency and cost of operation, that should be tested and disclosed to consumers. The FTC bears no responsibility for developing uniform test protocols. Rather, the Commission is charged with the development of prototype appliance labels to insure that the annual operating cost of the products in question as well as the range of costs for comparable products are effectively communicated to consumers.

The EPCA specified target dates for proposed and final rules concerning each of three groupings of thirteen categories of appliances -- the rules to be adopted under section 553 procedures.

Group I

refrigerators \& refrigerator-freezers

freezers

dishwashers

clothes dryers

hot water heaters

room airconditioners

Group II

televisions

home heating equipment

ranges and ovens

Group III

humidifiers \& dehumidifiers

central airconditioning

furnaces

clothes washers proposed rule - $6 / 30 / 76$
final rule $-9 / 30 / 76$

proposed rule - 9/30/76

final rule $-12 / 30 / 76$

proposed rule - 6/30/77

final rule - 9/30/77 
There has been considerable slippage in the target dates. At the present time, no final rules have been issued; with respect to Group I, the responsible agencies are well over a year behind schedule.

The principal delay has been caused by difficulties encountered in developing acceptable test protocols. The FEA has now proposed testing procedures for all thirteen categories and final procedures have been adopted for nine of those categories with still others nearing completion. Final procedures are anticipated soon with respect to ranges and ovens. On the other hand, it is expected that it will be some time before final test protocols are developed for central airconditioning and furnaces. Similarly, home heating equipment has presented the biggest problem because of the wide variety of products and resulting variables involved and the lack of an industry standard. In some instances, such as room aix conditioners, the FEA's work was greatly simplified by the existence of a largely acceptable industry standard.

In the meantime, the FTC has contracted the services of an expert to conduct consumer research in an effort to detemine the most effective labeling technique to disclose pertinent energy related information. This research has now been completed and the results are expected to be available to the FTC staff in the near future. It is possible that proposed labeling procedures will be issued by the FTC by the end of this year for written and oral comment. If this schedule is met, it is conceivable that the labeling rule could be final by September, 1978, which, even if it does occur then, will be two years behind the statutory schedule. In addition, the statute permits a 90-day lead time for labeling compliance, with an opportunity for an additional 90-day extension, if necessary.

In developing proposed labeling, the FTC is working closely with the FEA and the expert who is analyzing consumer reaction. This is an extremely critical phase of the rulemaking because labeling that finally is adopted must be informative and also receive consumer acceptance. Without the latter, critical information will not be imparted to potential buyers. Questions such as whether the information should be displayed in narrative form (which can be cumbersome and complex) or by some kind of scale (which may be more meaningful but provide less data) must be considered. Moreover, some products, by their very nature, create a more complicated situation. For example, dishwasher performance is affected by the amount (and perhaps kind) of detergent used; the type of water (hard or soft), and the frequency of use (daily, full load, etc.). And, of course, utility rates will have an overriding effect on all of these factors.

Vacuum Cleaners -- While the program to develop a cleanability standard for vacuum cleaners has been under development for some time, it has been held in abeyance for approximately the last year. During this period, the Commission has lacked the contract funds needed to support 
development of an adequate test protocol. The FTC had hoped to contract with the NBS to evaluate a test protocol that is being developed by the industry, however, the cost of such an evaluation has been estimated in the neighborhood of $\$ 100,000$. (NBS has already done some work in this area under a voluntary program.) While these funds may be available in FY 78, a manpower shortage at the FTC may continue to frustrate the project. So at this point, the immediate fate of this proceeding is uncertain. If the proceeding can move forward, it appears it will take NBS at least a year to refine the protocol. At this point, the FTC would then proceed under the Magnuson-Moss rulemaking procedures, which have been protracted at best. From this, you can see that standards for vacuum cleaners are still some time off.

Detergents -- The FTC formally commenced its investigation into the need for disclosures with respect to a cleanability standard for detergents approximately two years ago. An immediate advantage was gained in this proceeding from the fact that there is an existing, widely accepted industry protocol. But even here, a problem exists because the industry standard is not adapted to the FTC's proceeding. First, there must be a standard detergent for comparison purposes, and the industry standard has not provided this. In the absence of a standard detergent, there would be a meaningless comparison of Brand A with Brand B or Brand C with Brand D. Second, the industry test protocol is based on an outdated detergent containing $12 \%$ phosphate which, while it apparently cleans better than lower phosphates, it appears to be less desirable environmentally. Presently, most detergents contain 6\% phosphates, while some contain no phosphates at all. Thus, the FTC proposes to develop two test protocols -- one for 6\% phosphate detergents and one for $0 \%$ phosphate detergents. Each product would be measured against its own class of products.

Other complications have been encountered with the detergent standard. There are many potential variables in use, for example, results will vary when (1) cold or luke warm water is used, or when (2) hard or soft water, or (3) more or less detergent is used.

Further, problems arise if labeling is designed to encompass all of the foregoing possibilities. It might not only be potentially confusing to consumers, but it would be highly expensive. It is estimated that each such test (hard water vs. cold water, etc.) costs approximately $\$ 20,000$. Such an added expense has the potential of creating an anticompetitive effect. If a number of tests are required, it could place a heavy financial burden on the small manufacturer and potentially bar him from the market. For this reason, it appears that the FTC will consider one overall standard for implementation.

At this time, it is possible that a proposed detergent standard could be published within six months. Such a standard conceivably could affect advertising as well as labeling. It should be noted that this 
proceeding is already meeting stiff opposition from the predominant soap and detergent manufacturers. There is some speculation that the Commission may eventaully promulgate a guide instead of a rule.

Thermal Insulation -- The FTC is expected to act momentarily in authorizing a proceeding which would propose requiring the disclosure of " $R$ " values in home insulation both in labeling and advertising. There is an existing industry standard which appears to be acceptable. Moreover, NBS, under its voluntary program, appears to have already devised suitable testing for measuring performance.

The FTC's proceeding will be conducted under a newly streamlined Magnuson-Moss procedure. It is anticipated that the new procedure will take approximately a year, thereby shortening the existing time span by years.

It is my understanding that both the NBS voluntary program and the FTC's effort will move forward in a coordinated fashion. Thus, even though NBS may provide exclusively for flammability and the FTC may exclusively cover advertising, care will be taken to insure that the ultimate standards do not conflict.

Durability -- From the foregoing, it is clear that the development of test protocols to measure product quality and performance is a complex, time-consuming and expensive undertaking. This has been aptly demonstrated by the FTC's efforts with cleanability ratings for detergents and vacuum cleaners and by the FTC/FEA attempt to produce energy efficiency ratings for major appliances.

Ratings reflecting cleaning ability and energy efficiency will be based on rather direct scientific determinations and would therefore be more susceptible to accurate measurement than ratings based on more camplex or subjective evaluations. For example, it would be more difficult to measure such product characteristics as "frequency and nature of repair," (contained in H.R. 24) since other factors are involved, e.g., performance is completely dependent upon unknown factors of maintenance, use and abuse of the products by consumers.

To a layman, it would seem that measuring durability would pose problems of unusual difficulty, more complicated than cleanability, for example. The need to somehow simulate years of wear on materials, or on a mechanical or electrical device, is a step beyond the mere measurement of performance.

In any event, there appears to be at least two levels at which an assessment of durability could be helpful: (1) a calculated average use of a product, and (2) an actual expected life-span of a product. Obviously, while the latter would be more difficult to measure, it would also be more informative to purchasers. But the degree of difficulty is not in my province to judge. The feasibility and ease of 
developing tests to measure durability is a matter that you must deal with.

Prospective Congressional Action - As I stated earlier, no bills relating to this subject have been introduced in the senate during the current session. I would draw no conclusion either from the absence of legislative activity in the senate or from the fact that two bills sponsored by a number of Members have been introduced in the House. It is not unusual for bills to be introduced over the course of several years before they finally reach the Floor of either body of congress.

While it appears that neither the House nor the Senate will consider durability labeling in the current congress, durability raises a strong public policy question which will become increasingly urgent as an awareness of our depleting natural resources and energy supplies continues to grow. (It is my understanding that materials production in the U.S. consumes about 25\% of total energy used.)

However, even though initial indications suggest the desirability of developing a test protocol on durability, other factors will also be given consideration. While greater product durability and materials conservation are highly desirable objectives, they may require tradeoffs of increased costs and the risk of reductions in technical innovations. (With respect to cost, it has been estimated that development of a test protocol from scratch would cost about \$l million.) Moreover, material savings are apparently not directly or necessarily proportional to a longer life. (In a study done for OTA, it was found that if mechanical lifetimes of refrigerators and automobiles were extended $50 \%$, sales and materials consumption would be reduced only 15\% and 9\%, respectively.)

There is also the competitive issue to consider. Opponents of any labeling effort related to product characteristics state that government involvement has an anticompetitive effect because a new or lowvolume manufacturer may not be able to meet the added expense of testing and labeling. The counter to that argument is that governmental involvement would favor the new or small entrant into the field (and therefore have a good competitive effect) because the small company could concentrate on high quality of a few products which could be labeled as such, and would not have to compete on the basis of advertising which the big companies can afford.

Whenever a test protocol is feasible, however, the need for consumers to have an opportunity to make intelligent and discriminating purchasing decisions in the marketplace should be carefully balanced against any potentially negative factors.

In conclusion, I would say that public policy strongly argues in favor of developing a capability of measuring durability with respect to a 
wide range of products. If legislation is eventually enacted, it is conceivable that it would fall somewhere between the two bills that currently have been introduced in the House. Obviously, this is impossible to predict at this time. It would be my personal judgment, however, that there will not be definitive congressional action in this area until such time as the pending related projects are completed and can be fully evaluated. 


\section{SESSION II}

\section{PRODUCT TESTING}

CHAIRMAN: A. J. FOWELL

NATIONAL BUREAU OF STANDARDS 



\author{
Julius Cohen \\ Center for Consumer Product Technology \\ National Eureau of Standards \\ washington, D.C. 20234
}

\begin{abstract}
A methodology was formulated for estimating, through laboratory testing, useful life and associated performance of consumer products. Excerpts from two key parts--concepts of reliability engineering and procedure to guide the formulation of tests--are given here. Criteria for assessing tests are presented.
\end{abstract}

Key Words: Consumer products; testing methodology; reliability engineering; useful life.

\title{
INTRODUCTION
}

Test methodology is a generalized, coherent body of operational concepts, terminology, rules, methods, and procedures. It is used to guide the formulation of particular tests. The purposes of this methodology are 1) to standardize testing; 2) to make testing more objective and accurate; 3) to make test designing logical and easier (bacause one does not have to rethink the steps each time).

A methodology was formulated for estimating, through laboratory testing, the useful life and associated performance (e.g., failure classification and mechanism; reliability) of consumer products. It is not feasible to present the full scope here; instead, extracts from two key parts--concepts and procedure--will be given. Also, the assessment of tests will be considered.

\section{BASIC CONCEPTS}

The six basic concepts of reliability engineering are: performance, failure, maintenance, repair, reliability, and useful life. These will be defined and performance will be seen to be the primal concept. 
First, however, a few prefatory definitions: Use conditions are the manner and method by which a product is employed, including the load (that which is acted upon or processed by a product for accomplishing its main utilitarian purpose). Environmental factors are those elements in the surroundings of the product which can be expected to influence

performance. Examples are temperature, humidity, dust, and vibration.

Performance is defined as the selected and designated accomplishments of a product under specified and implemented use conditions and environmental factors.

A consideration of the concept is warranted by its eminence. It is tacit in the definition, above, (which labels the concept) that performance is not an intrinsic property of a product. Rather, it is the resultant of precepts; its implementation; and product. The test designer issues the precepts--it is he who specifies the use conditions and environmental factors; selects the accomplishments from among many possible attributes; and sets the criteria for satisfactory and unsatisfactory performance (failure). But his precepts must be implemented by people and by apparatus, and that which is established and that which was called for may not be the same. Then, the results may be spurious. The rule is: Do not accept failures at face value-investigate and confirm or invalidate.

The notion that performance is the reaction of a product to an applied stress--stress being the conjoined use conditions and environmental factors--is useful for making analyses. Normal stress means the way the product is most usually used in the field (or home), including the accompanying environmental factors. Understress and overstress mean, respectively, less severe and more severe than normal. In systems, containing components, all three kinds of stress may be operating simultaneously. Additionally, l) elements of stress may be synergistic; e.g., temperature and vibration; and 2) performance may be nonlinear with stress; i.e., a small increase in stress may have a large, even inordinate, effect on performance. This completes, for the time being, the consideration of the performance concept; the other concepts will now be mentioned.

Failure is defined as the inability of a product or component to perform a function in accordance with test specifications.

Usually, minimum levels of performance will be specified for systems. Failure and satisfactory performance are quantal: 
something either performs satisfactorily or it does not-there is no in-between.

Maintenance is defined as a prescribed action executed on a product capable of performing satisfactorily, to prolong its period of capability.

Repair is defined as an action carried out on a failed product to restore its ability to perform satisfactorily.

Reliability is defined as the probability that a product will be able to perform satisfactorily within an arbitrary duration. (It is assumed that the product will be capable at the onset.)

Useful life is defined as the duration of satisfactory reliability measured from when the product is first employed.

The above definition is consistent with English usage, but more importantly it meets the needs of cost-conscious consumers. That others may dispose of products beforehand for whatever whim or reason does not detract from a product's capability.

Usefulness of a product is intimately bound up with functionality in the sense of both intended performance and service expected as due. Specifically, if a product generally performs satisfactorily, does not break down in use, and will perform satisfactorily when demanded, the product is useful. These criteria can be summarized with the single term, reliability, as satisfactory performance is inherent in reliability. Factors influencing reliability expectations are 1 ) the nature and structure of the product; 2) the age and condition of the product; 3) maintenance; 4) purchase price; and 5) repair cost. Unlike satisfactory performance criteria which remain constant throughout the product's life, satisfactory reliability criteria generally change as the product ages and expectations change.

Now that the six basic concepts have been given, notice how the performance concept pervades all others. Important as they are, the others are still satellite concepts which owe their existence to the need for satisfactory performance in the present and in the future. And however sophisticated the statistical handling of the test data be, whatever is derived--e.g., reliabilities; mean times--will be for naught if the performance test itself is not sound. 


\section{PROCEDURE}

The goal of the laboratory life testing is to generate normal failure modes; i.e., those which prevail in the field, and to ascribe average times to failure. If the product in the laboratory receives an approximately normal stress, normal failure modes should result and in approximately the same amount of use time as that in the field. If the product is overstressed too much, failures will occur rapidly, but they may be abnormal. On the other hand, if the product is understressed too much, failures may not occur at all and there will be no data; in any event, the times-to-failure will be prolonged. Little wonder the test designer wants to know what constitutes normal stress; market research and observation of human subjects are possible means of assistance. And does there exist any other field where failures are the measure of success?

Now, a generalized procedure, in outline form, will be offered for guiding test formulation:

\section{State Test Objectives}

Example: To estimate useful life and associated performance of a widget.

\section{List Data to be Sought}

Example: a) probable useful life, together with confidence level and limits;

b) number and type of maintenance actions during useful life;

c) number and causes of failures, repair actions (components, materials, time-to-repair) during useful life.

\section{Search and Familiarization}

a) Sampling Characterization

1) homogeneous or heterogeneous? (If heterogeneous, different tests for different units may be required.)

2) repairable or nonrepairable? 
3) product evolution slow or rapid? (If slow, historical data will be of value. If rapid, historical data may be of no value: the product may be obsolete by the time tests are completed.)

b) Historical data, particularly as regards failure modes, mean times to or between failures and stresses. (For slowly evolving products, historical data, if available, will not only greatly facilitate test design, they may also permit accelerated or overstress testing to be made.) In-warranty data, service records, laboratory results are all useful information.

c) Existent Tests--if available, review for applicability.

d) Published Literature--service manuals, trade journals, market research reports, etc.

e) Discussions--with design and test engineers, home economists, etc., to aid in making judgments.

f) Inspection--design; construction; materials; operation. Identify major working parts and likely wear-out contenders. (This is to aid test design, but guard against becoming biased therefrom.)

\section{Test Design and Development}

a) Human Factors Input

1) Determine use conditions; load; use-environment, all as a population distribution. (These nay not be independent variables);

2) Frequency and duration of use;

3) How was information obtained (e.g., questionnaires, observatons)?;

4) Number in sampling;

5) Is sampling random? How chosen?

6) Is sampling representative of user population?

7) What will be the confidence level and limit of these data? 
Which use (including load) and use-environment conditions are known to or believed to affect performance significantly? Consider use and environment singly and in combination. Examples of possible environmental factors: ambient temperature; humidity; dust; mechnical shock; vibration; temperature and humidity, temperature and vibration.

c) Selection of Stress Pattern

1) If historical data are available, consider accelerated testing and how this test might be integrated with the previous; if no historical data are available, avoid atypical overstress and attempt to use normal stress testing where possible.

2) Restrict testing to prime stresses only (side experiments may be desirable to help in determination).

3) Prescribe use, load, and environmental factors; specify allowable ranges; include customarilyexpected overstresses; prescribe operating time schedule.

d) "Stress" Analysis

1) List major components of product, especially those known to or believed to fail typically in use.

2) Indicate whether these components will be over-, under-, or normally-stressed by stress pattern.

3) Consider desirability of altering stress pattern, above $[4 . c) 3$ )].

e) Performance and Failure Specifications

1) State main utilitarian function (primary performance attribute); specify (usually minimum) level of acceptable performance.

2) Specify salient secondary performance criteria. Examples to consider are degradation of the load by the product; excessive noise; excessive vibration: leaking of liquids or gases. 
f) Specification of Useful Life Criteria

1) Specify minimum acceptable reliability or reliabilities (consider aging of product);

2) Specify maximum acceptable repair cost;

3) For allowable repairs, specify reliabilities which will justify costs.

It is advisable to obtain human factor data to assist in determination of the preceding three criteria.

For repairable products, useful life terminates with failure to meet criterion 1,2 , or 3 above. For nonrepairable products, useful life terminates with failure.

For products where average retention life is less than probable useful life, it may be desirable to terminate testing or a portion thereof at a time equivalent to the former.

g) Sampling

1) Estimate number of units required for a desired confidence level and limits; or

2) Estimate confidence level and linits for the number of samples obtainable. Are they satisfactory?

3) Obtain random sampling, if possible.

h) Repair Readiness

1) Are replacement parts readily available? If not, stock selected parts.

2) Are qualified repairmen on site? If not, secure or have personnel trained.

i) Controlled Field Tests

1) How many units (or households) are desirable or are accessible?

2) How are units (households) to be selected? Consider, for example, geographic location; income level; and size of family. 
3) How are field data to be obtained? Some possibilities are manufacturer's in-warranty records and other service records. Can arrangements be made with consumers to provide free or discounted repairs beyond warranty period? Can monitoring instrumentation be installed on products?

j) Feasibility

1) Consider funding, qualified personnel, equipment, facilities, time duration of project, etc.

2) Estimate what may be feasible under the above constraints.

3) Modify statement of objectives or data to be sought, if indicated by 2 , above.

\section{Test Execution}

ALL PERFORMANCE CRITERIA AND USEFUL LIFE CRITERIA MUST BE SPECIFIED IN ADVANCE OF TESTING! (This is a safeguard for objectivity.)

a) Simulate prescribed use conditions and environmental factors;

b) Monitor performance frequently;

c) Note, inspect, and identify all failures (be on guard for spurious failures).

d) Make qualified repair if appropriate (see 4.f); return unit to test.

e) Maintenance

1) Carry out (only) all maintenance actions prescribed by manufacturer. (Exception: if maintainability is so poor as to preclude a maintenance action by consumer, this may be omitted at discretion of test designer, but the omission should be noted.)

2) Correction of incipient failures are to be included as maintenance actions. 
f) Keep complete records of data; data forms prepared in advance are useful.

g) Testing of a unit terminates in accordance with useful life criteria.

\section{Test Analysis and Interpretation}

a) Data handling: avoid omissions; avoid rationalized "laundering"; avoid unjustified extrapolations. Early failures (infant mortalities) are customarily not counted in reliability and life testing.

b) Is test acceptable?

1) validity?

2) reproducibility?

3) correlativity? (Do failure modes and distributions of laboratory and field tests agree?)

c) Reappraise assumptions in light of field data.

d) Repeat "stress" analysis in light of field data.

e) Revise for future tests, as required.

\section{TEST ASSESSMENT}

Performance testing seeks to assess the qualities of a product. That it does so satisfactorily should not be assumed; it is conditional on the quality of the testing meeting standards. Thus, the quality of testing itself needs to be assessed and the criteria are 1) validity, 2) reproducibility, and 3) correlativity. All three criteria need to be met.

Validity is the truthfulness of the data; it relates to whether what is claimed to be measured is in fact measured. Causes of invalidness include faulty instrumentation; human errors in measurement, judgment, and reasoning; errors or negligence in sampling selection; failure to recognize or distinquish primary and extraneous factors.

Reproducibility measurements establish the consistency of a test. It is not sufficient that tests be reproducible 
within an individual laboratory; to have utility, there must also be interlaboratory reproducibility. Failure to obtain reasonable reproducibility may cast serious doubt on the test's validity. Reproducibility depends in general on l) sampling constancy or invariance; 2) measurement apparatus, techniques, and skills; 3) following of instructions and carrying out of test procedures.

To abet attainment of reproducibility--particularily interlaboratory--different samplings should be chosen judiciously to ensure they are virtually equivalent. For intralaboratory testing to establish precision, the time between successive tests should be kept short so that constancy of the product may be reasonably assumed. Also, test procedures and descriptions should be written clearly and precisely, to minimize the possibility of misunderstanding or subjectiveness by test engineers or technicians.

The usefulness of performance testing in the laboratory is contingent on the relevancy of the results to those which actually occur in the field, and the quality of the relationship is the correlativity.

Correlativity is the quality or state of exhibiting correlation between results of performance testing in the laboratory and corresponding results obtained from field or home use.

Obtaining or demonstrating correlation, however, is difficult and may be full of pitfalls: 1) it is difficult to determine or predict what actual normal use conditions and environmental factors in the field are; 2) use and environment generally cover a much broader spectrum in the field than is feasible to simulate in the laboratory; 3 ) it is often difficult to simulate changing environmental factors accurately over a prolonged period of time; 4) product evolvement, manufacturing or material changes, and variations in conformance of manufactured parts to design specifications make a statistically significant and random sampling difficult; 5) the requirement of reproducibility in laboratory testing may impose conditions which are not representative of actual field use.

Laboratory data are obtained from controlled testing; field data may be from (partially) controlled testing or uncontrolled activities, such as surveys.

Consider first uncontrolled field data. Information is obtained from the consumer on the frequency and nature of 
repairs, retention life, and possibly the reason for disposal. There are several pitfalls: 1) maintenance actions, which are important factors in life, performance, and reliability, may not have been carried out as specified; 2) products may have been misused or abused; 3) the consumer may not have perceived failures accurately or in conformity with the test designer's definition; 4) repair actions may not have been made proficiently; e.g., primary failure may not have been recognized and corrected; replacement parts may have been of substandard quality; workmanship may have been poor. If repairs are not proper, failures will occur prematurely; 5) the retention life is not necessarily the same as the useful life, and indeed products are often disposed of before the end of their useful life; e.g., because of obsolescence or for aesthetic reasons. Thus, uncontrolled field data pose a serious problem in validity. Do the data represent what are supposed to be measured or represented, free of extraneous, unaccountable or unrecognized factors which cause deleterious results? Because very little performance data on consumer products throughout life exists at the present time, the problem is perhaps academic, but it does point up the pitfalls inherent in any approach which attempts to correlate laboratory results with uncontrolled field results. It may be possible to indicate validity through use of statistical tools, but the problems would be considerable.

It is desirable, perhaps even necessary, to resort to controlled field tests instead. Here, a sufficiently large number of new units, randomly chosen together with those for laboratory testing, are placed in the field and periodic inspections are made by qualified technical personnel with appropriate test equipment and parts, to help ensure that prescribed maintenance is done, to confirm the accuracy of the consumer's perception of failure to the test specifications, and to carry out repairs proficiently, when necessary. Only the stress pattern (use conditions and environmental factors) is not controlled. On the other hand, in the laboratory, the stress pattern is controlled, and this is presumed to constitute the only difference between laboratory and controlled field tests.

Controlled laboratory and controlled field tests together constitute an experiment in which there are presumably only two variables: laboratory stress pattern and field stress pattern. The chances of demonstrating correlation are considered good and the analysis of results is much simplified. 


\author{
Kenneth iV. Yee \\ National Bureau of Standards \\ iashington, D.C. 20234
}

Abstract: Work has been underway at the National Bureau of Standards, Center for Consuner Product Technology, to determine the feasibility of and inethodology for developing standard test methods to estimate the useful life of consumer products. Initial efforts have been on sinall appliances. The hand-held blow hair dryer was selected for the demonstration product. The status of current work on the hair dryer will be described. A similar effort on a major appliance has been undertaken and will be described.

Key words: Consuner product testing; life test method; useful life.

During the past year, work has been underway at the National Bureau of Standards (NBS), Center for Consumer Product Technology, to determine the feasibility of developing standard laboratory test methods to estimate the useful life of consumer products. Previous work has been done to establish the methodology for consumer product testing. Current work is intended to determine the feasibility of, and identify the barriers associated with, developing a laboratory life test method and will not necessarily result in a completed test method for a specific product.

Why develop a life test method? Proposed legislation would require disclosure of life or durability information for consumer products and the Department of Commerce now has a voluntary Consurner Product Information Labeling Progran (CPILP) underway on a trial basis. This program is intended to make information available at the point of purchase, which will assist in the purchase decision and which is not readily discernible. Certainly information on product life would be valuable in making an informed purchase decision.

Industry now does extensive testing related to product life. The test methods used, however, are not suitable for providing uniform life information on all the models of a product class available in the marketplace. Industry testing is generally intended to evaluate designs or determine if design goals have been realized by production units. Testing is frequently terminated when design-goal operating time has been achieved and units are not run to destruction. Design 
goals are different for each manufacturer depending on the individual performance, reliability and cost objectives. The industry tests are usually developed for a specific manufacturer's product designs and models and may not be universally applicable. The tests are considered proprietary and would not generally be released for use by others. A major limitation is that the test inethods do not provide independently reproducible quantitative measurements. The results are frequently of a pass-fail nature and may require subjective judgment as to what constitutes a failure or end of life. Many tests provide only comparative information: that $A$ lasts longer than $B$ where $A$ may be the old design or previous production and $\mathrm{B}$ a new design or production lot.

The methodology followed in developing a test method for small appliances includes evaluating the design and perforinance of representative products in the marketplace; determining the use conditions and failure modes of the product; devising a laboratory test incorporating the most important use and environmental conditions; correlating the laboratory test results with actual failures or life in the field; modifying the laboratory test as necessary to provide better correlation with field results. Unfortunately not all of these steps are easy to complete adequately. Evaluating representative products is limited only by the time and money available to shop for samples and examine them. One will never obtain samples of all the models made, but enough to ascertain the typical design techniques and performance can readily be obtained. our limited experience has shown that good quantitive, statistically valid information on the use, abuse and environmental conditions and failure modes for a product are not available. How long, how of ten, where, under what loads, what voltage, what ternperature, etc. the product is used are not really known. In most cases it is not known how long products last or why people dispose of them or if and how they have failed.

A laboratory test method can never incorporate all the use and environmental conditions that affect a product's life. The best one can do is to incorporate the factors that most significantly affect product life. Without good information on how long the product lasts and what fails, correlation of the laboratory test results and field results is difficult. The method used is a controlled field test where a limited number of instrumented products have been placed in the field. After all the preceding steps the test method may have to be modified to change the test conditions or incorporate additional factors which have been found to be significant.

The goal of the initial laboratory effort at NBS is to develop a test method that will estimate the useful operating life in hours. An ultimate goal is to estimate the useful life in years. A simple motorized product, the hand-held blow hair dryer, was selected for the 
test. It has low but significant cost in the $\$ 10$ to $\$ 25$ range, with significant sales and market saturation, about one million units per year and $15 \%$ saturation. A failure is easy to define, generally there is no air output or no heat output and there is negligable loading effect by the user. It is generally not repaired beyond the warranty period.

Even for this limited product class there are many variables. There are significant design differences in air flow pattern (radial and axial) and motor type (universal and dc permanent magnet) as shown in Figure 1. The use pattern is not well known, but various surveys report time per use of from 5 to 25 minutes and uses per week of from 1 to 7. This variation makes the transition from life in terms of operating time to years difficult. An estimate is about 25 to 50 hours per year. Additionally, there are manufacturing variations in the same model, some due to quality control and some due to design changes or alternate sources for components.

Many factors were considered in designing the initial laboratory test. The sample size is limited to 15 to 30 units due to power consumption and room heat exhaust capability. The power consumption of blow hair dryers is now in the 800 to 1500 watt range. Twenty produce as much heat as a typical residential electric furnace. The cost of the test samples and the noise generated by the units are additional considerations limiting the sample size.

It has been found that motor loading and exhaust air temperature are not affected by the presence of a head 2.5 centimeters from the outlet. The heat-up and cool-down times for a representative motor bearing were measured and are shown in Figure 2. The temperature essentially stabilizes within 10 minutes after turn-on but takes much longer to cool down after turn-off. A 10-minute on and 10-minute of $f$ test cycle was selected as a compromise between the actual use cycle and accumulating the maximurn operating time in a given clock time period. Subsequent tests indicate that operating time variations in the region of 5 minutes to 30 minutes have little effect on life in operating hours.

In the tests, the units are fixed in one orientation and powered from a regulated 120 volt ac supply which is switched on and off by notor driven cam-operated switches, see Figure 3. The dryer power switch is not tested since it is subject to a UL endurance requirement of 6000 cycles. The heater is operated at maximum power level. The dryers are not subjected to any vibration, dropping, hair or hair spray which all may affect life. The units in a test sample are all of the same date code or manufacturing lot to eliminate design or alternate component differences. The test ambient temperature is similar to a warm bathroom, but the effects of high humidity have not yet been investigated. 
Six test lots including several models of about 15 units each have been run in the laboratory. Operating lives from 100 to over 1500 hours have been observed. A test takes 10 to 150 days to complete with the units operating 24 hours a day at 50\% duty cycle. Ratios from 1.5:1 to 2.5:1 between the longest life and shortest life sainples in a test lot have been observed. The weibull chart, Figure 4, shows the results of a typical test. The mean life of this lot was 179 hours and the standard deviation 42 hours. All failures for this test lot were motor brush wear out. Except for a few manufacturing defects (early failures) all failures observed have been related to motor wear out. In some models both brush and bearing failures have been observed. Motor slow down results in a failure as the dryers are protected by a thermostat which turns the heater off when the exit air temperature rises due to reduced air flow. Preliminary results indicate that this test method can measure significant differences in operating life. There is a question as to the significance of operating hours in excess of a few hundred hours in view of the estimated 25 to 50 hours annual use.

A laboratory experiment is planned for the near future to determine the effect of a periodic shock to the dryer on the measured operating life. Each dryer will drop about 2 centimeters twice each on-off cycle. This experiment is intended to determine if the effect is significant and is not intended to be representative of shocks that occur in normal use.

Two efforts are underway to provide some correlation between the laboratory test results and actual field results. About 50 discarded hair dryers have been collected and examined. Unfortunately most have been very old designs or of the styler (side air discharge) design rather than blower design. Failures attributed to the motor, heater element, fan, switch, thermal protector and cord were observed. Most failures were possible effects of manufacturing defect or were randorn failures. Surprisingly, 8 of the units are the same model and all failed due to motor slow down caused by bearing wear or contamination. Their operating hours as estimated by the users ranged from 10 to 350 hours. None of the discarded units is a model that has been run in the laboratory. The discarded units show that a wide variety of early and random failures occur and failure due to motor wear can occur in some models.

A controlled field test is underway to provide information on units of the same model and manufacturing lot as one lot run in the laboratory. Thirty units were instrumented with a box, shown in Figure 5 , that records operating time and the number of times the unit is turned on. The box was designed and built at NBS to make the measurements at the end of the power cord without any modification or other attachment to the product under test. These dryers are in use in households with more than one user of the dryer. The dryer recording boxes were read 
after eight weeks of use. The use averaged 1/2-hour per week and about 3 minutes per turn on. An unanticipated occurrence is that nany users turn the dryer off and back on during one hair drying session. The total ininutes per drying session cannot be found without knowledge of the user's habits. Better use infornation will be obtained after a longer period in the field. To date there has been one early failure which nay have been caused by a design or production defect. Notor wear out in the field is not anticipated. The samples in the laboratory test have exceeded 1500 operating hours. Between the time of an initial test of this nodel, the results of which were shown in the Weibull plot, and the acquisition of the lot used in the field test, the manufacturer changed motor suppliers. The visual differences are ninor but the operating life of the new motor is greater by an order of inagnitude.

In the next year the test method will be modified to include the additional complication of variable loading by the user. The electric hand drill or the electric hand inixer is under consideration as a demonstration product. The applicability of overstress accelerated testing will be investigated.

A similar effort has been undertaken for a major appliance, the electric clothes dryer. This appliance was selected as the simplest major appliance. Compared with the hair dryer the clothes dryer is indeed major. The clothes dryer costs about 10 times the cost of a hair dryer, will be repaired, and has an estimated service life of almost 14 years. 1 The testing involves many more factors: power requirement, heat and moisture exhaust, test space, clothes load, rewetting, lint, and time.

Supplying regulated power and exhausting the heat and moisture for the dryers requires a major capital investment. Five electric dryers produce as much heat as a typical electric house furnace. End of life is not a simple judginent. Most failures are repairable and an acceptable repair cost is an economic decision which may be a function of the age of the dryer and the cost of replacement. For some individuals, sufficient reliability will be a consideration.

Testing time is long even if compressed time accelerated testing is used. To accumulate the operating cycles equivalent to 14 years of use at an estimated 3 loads per week takes 8 months of 24 hour per day testing if one cycle is run each hour. Additional time is required due to equipment failures, intermediate testing, holidays, etc.

The goal of the current effort on clothes dryers is to demonstrate the methodology and determine the barriers to developing a laboratory life

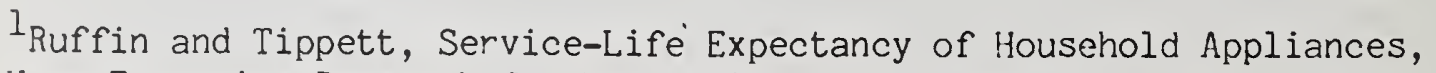
Home Economics Research J., March 1975, Vol. 3, No. 3 
test for a major appliance. As short term objectives we hope to determine if energy efficiency changes over the life of the dryer; deterinine if repair incidence and the nature of probable repairs over the life of the product can be measured in the lab; and deternine if it is feasible to estimate life in terins of cycles or operating hours and ultinately years.

Sixteen dryers have been run in the laboratory for a six-month period (see Figure 6). Eight dryers of two popular brands and models are under test. In the present installation, excess lint which passes through the machine filter is captured by a nylon stocking and the room ventilating system is capable of handling the exhaust. Each dryer is automatically restarted and the test load automatically rewetted. The normal test load consists of 2.5 kilograns of bath towels wet to a moisture content of $80 \%$ of the dry weight. A load takes about 40 minutes to dry and is restarted once each hour. Periodically a load of twice the weight of towels is run to simulate normal overloads. An additional load with metal buttons is used as an abrasive test load. One model has accumulated 4 years of loads and the other 6 years of loads. One early failure of a timer and one randon failure of a heater element have been observed. No change in energy efficiency has been measured. Wear out failures are anticipated in the next calendar year of testing.

In conclusion, we have demonstrated that a laboratory life test can identify significant differences between various models of hair dryers. It is not yet known how the laboratory measured operating life and the operating life in the field are related. The significance of laboratory life in excess of a few hundred hours is not known for the hair dryer. Perhaps this indicates that wear out is not likely to occur and that early or random failures, which may be related more to quality control than design, will dominate in use. The results of laboratory testing on clothes dryers is too incomplete to draw any conclusions. 


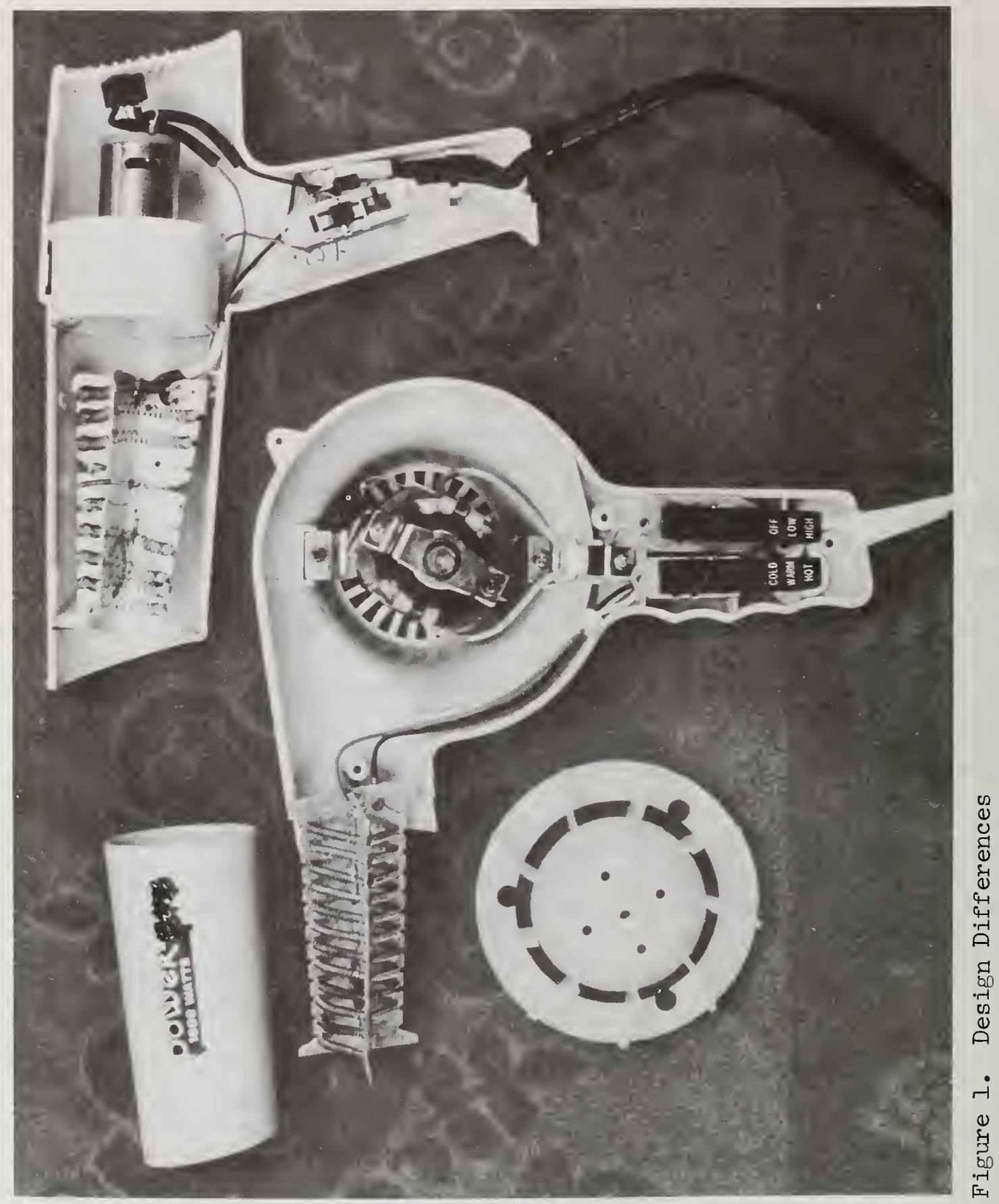




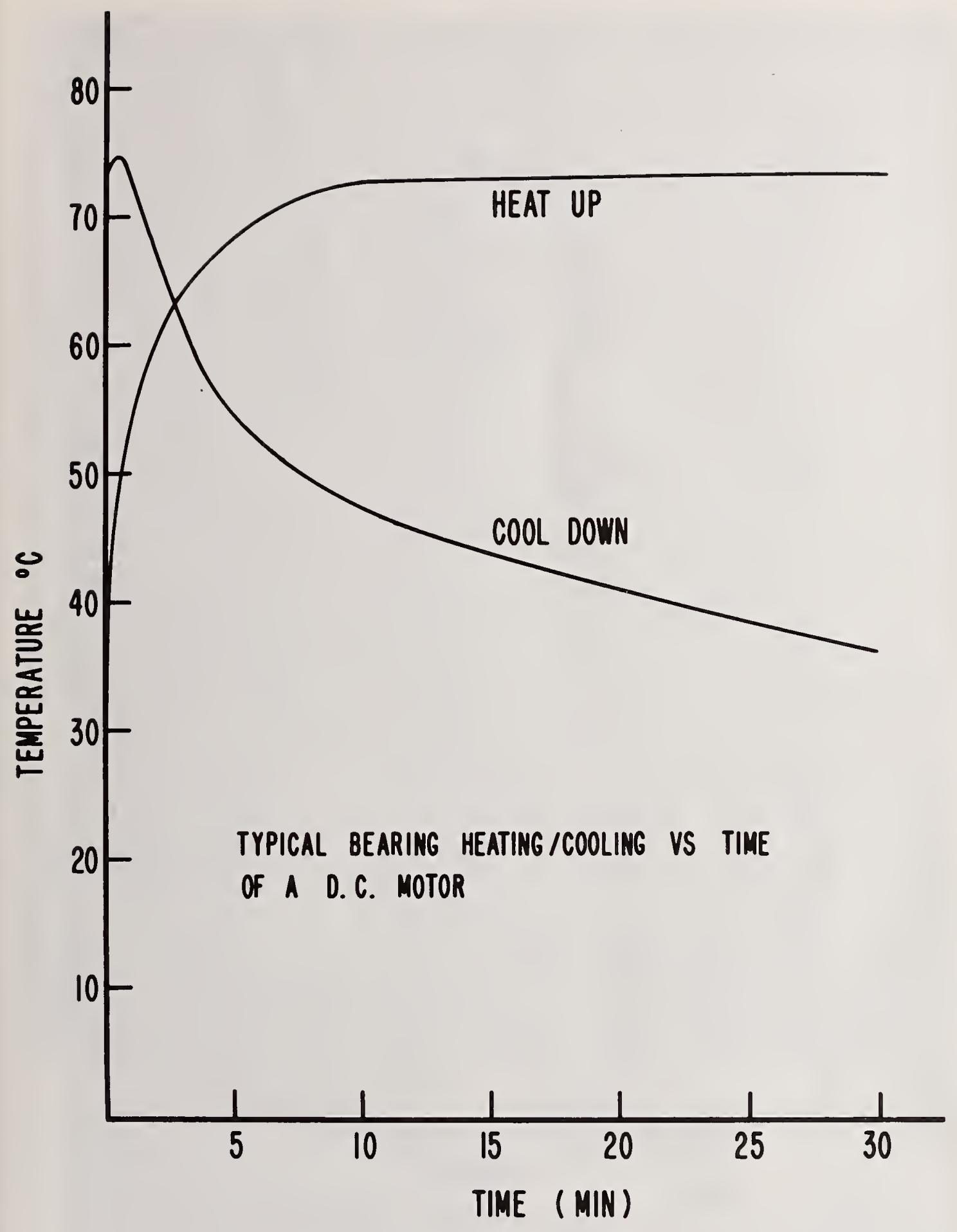

Figure 2. Bearing Heating/Cooling Time 


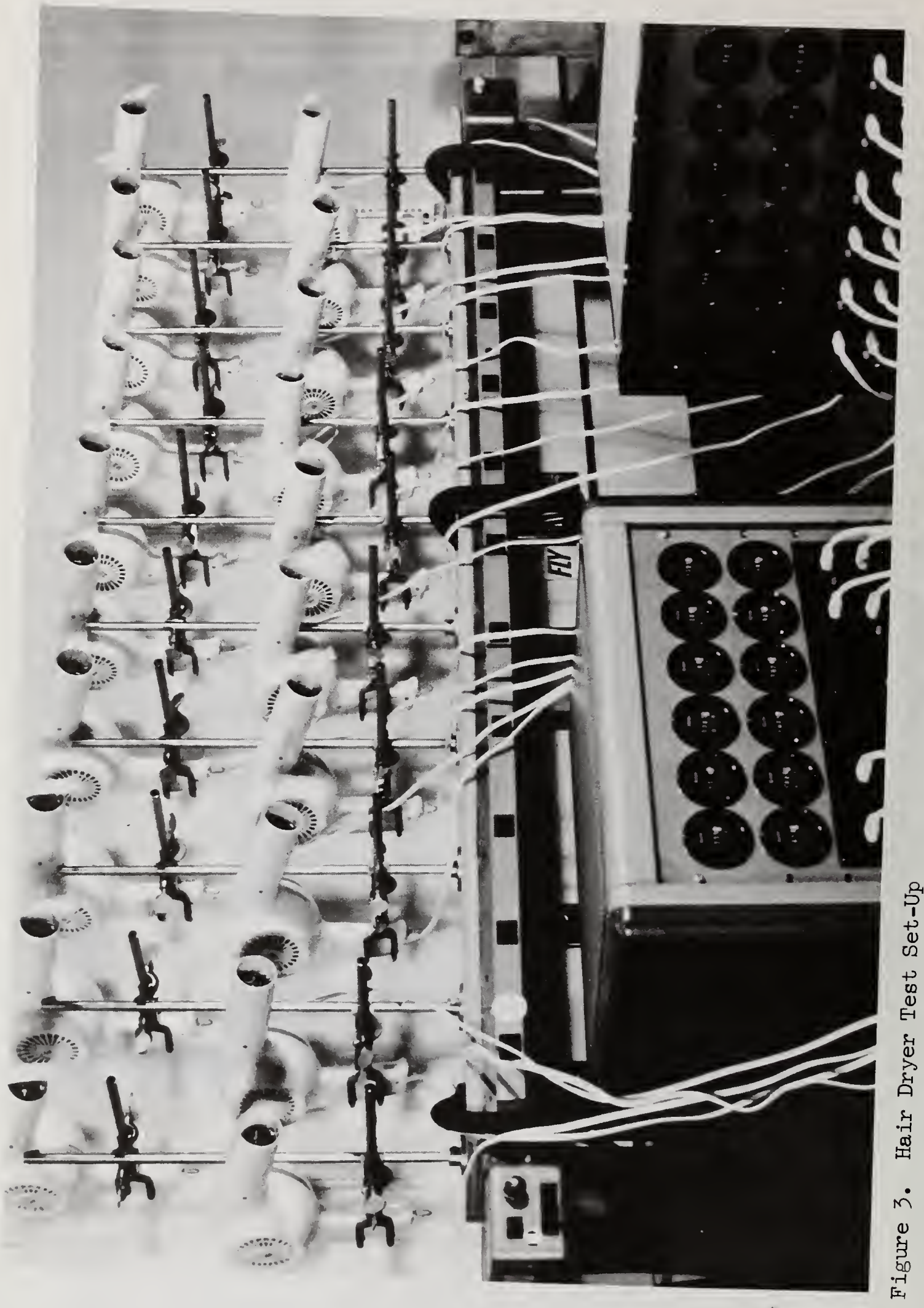




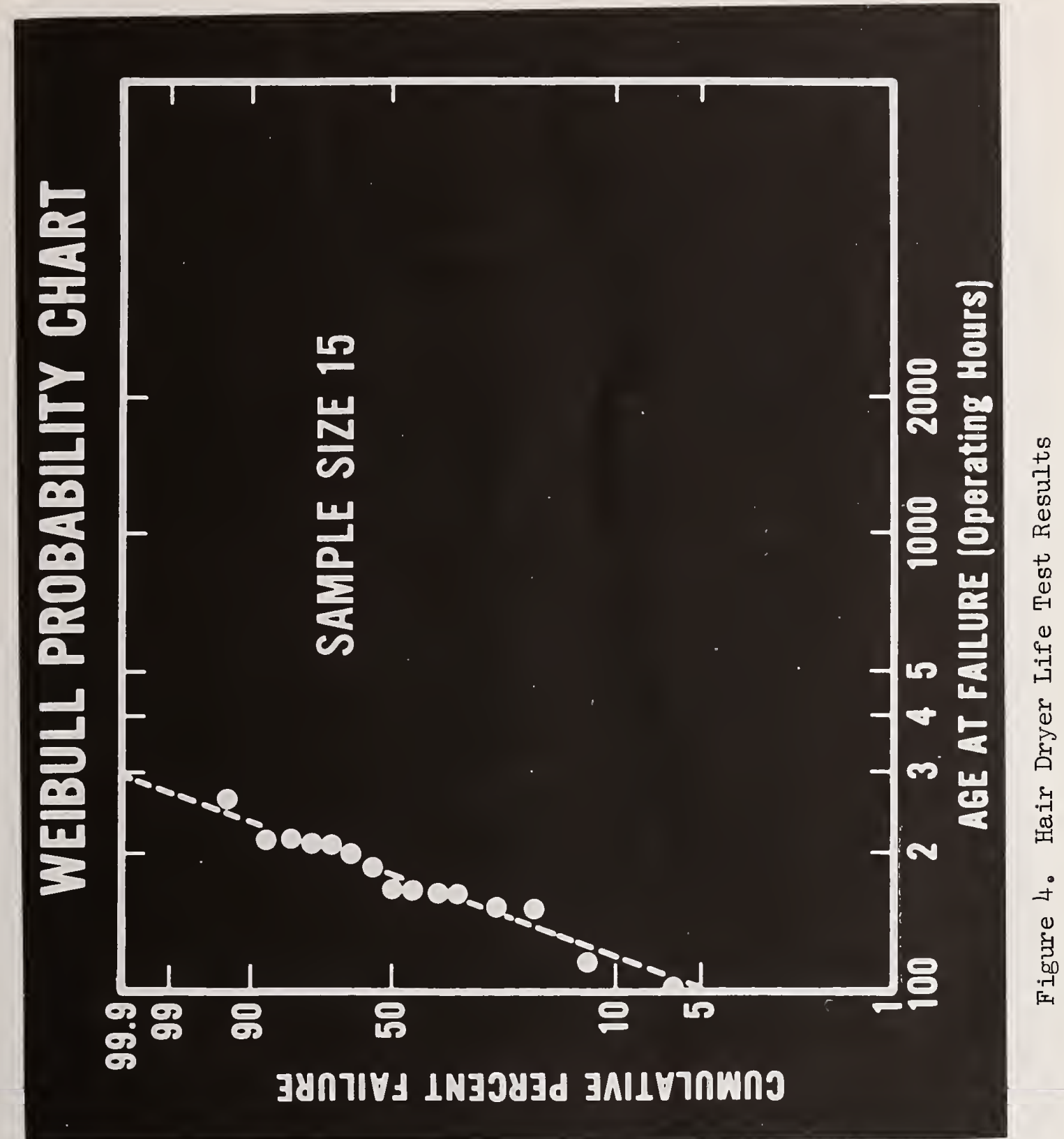



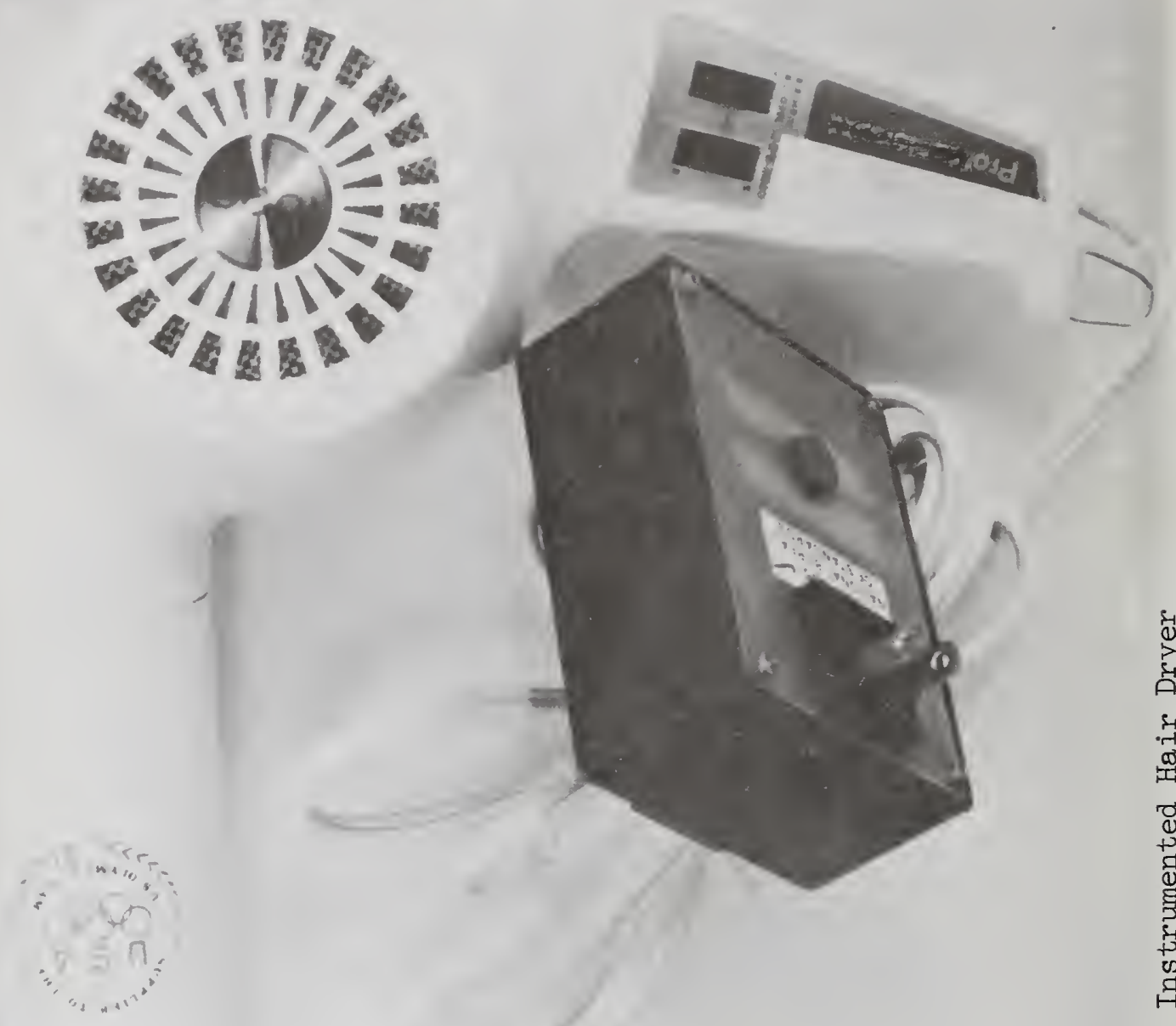

 


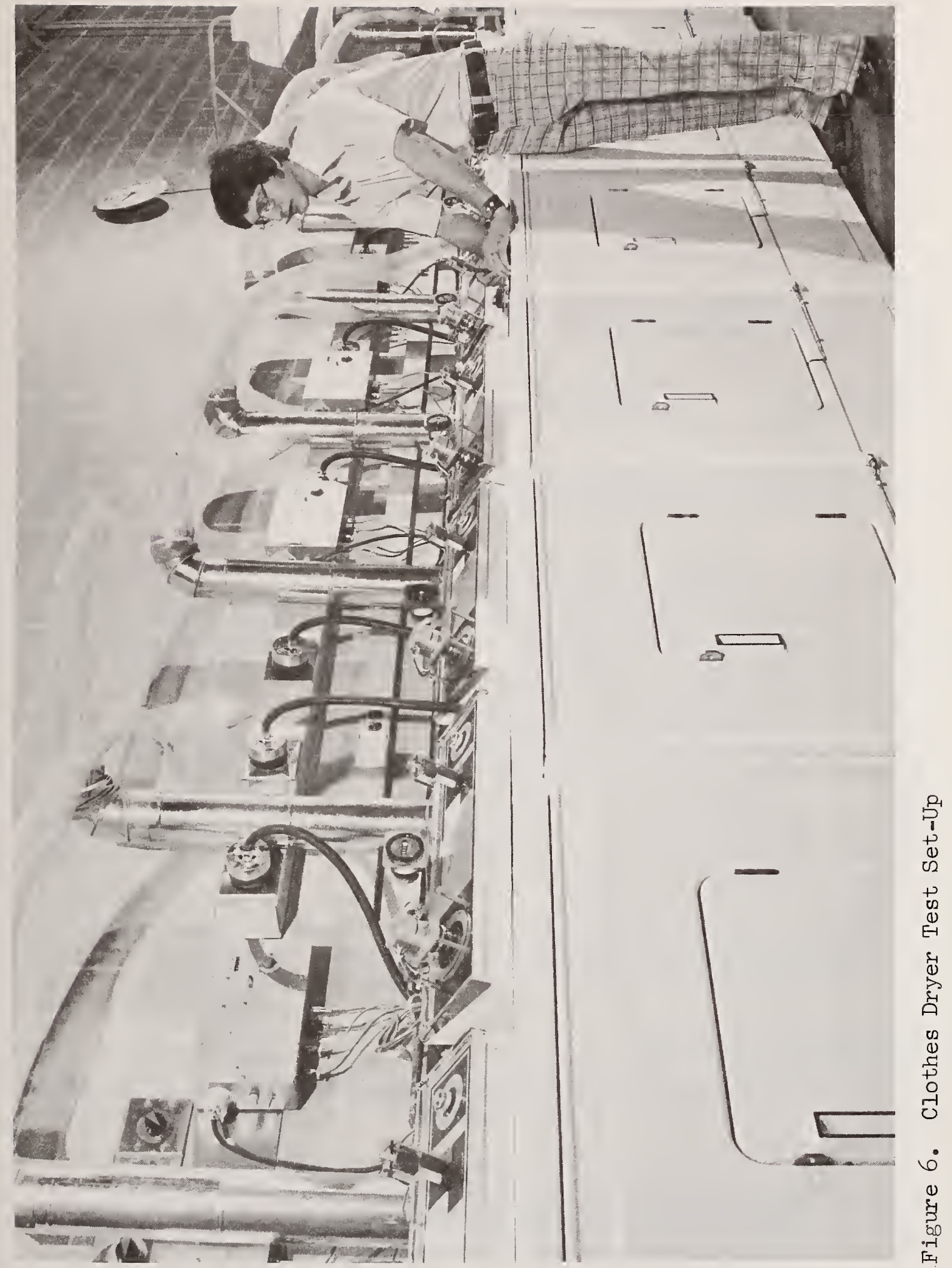




\author{
N. R. Pugh \\ Governmental and Technical Liaison \\ Sears, Roebuck and Co. \\ Department 817 \\ Sears Tower \\ Chicago, IL 60684
}

\begin{abstract}
This paper considers testing for product failure prevention from the standpoint of a laboratory in a retailing system based on "private-label" product lines.
\end{abstract}

The point of view of such a laboratory in product design evaluation and testing programs is described briefly.

Some thoughts are presented about the need for consumer product durability testing, considering the present level of product life, and the state of the art in consumer product technology.

Some of the challenges in predicting durability, and minimizing failures, through laboratory and field test programs, are explored. Examples of testing for durability evaluation are discussed. The relationship of design quality evaluation to conformance quality, both asmanufactured and after extended use, is examined. Examples of testing for durability evaluation are discussed.

The interaction of factual information and consumer receptivity; and the effectiveness of durability and life information, is considered.

Lastly, some opportunities for real accomplishment through better teamwork among various elements--governmental institutions, academe', and the private sector are described.

Key words: Consumer product life; durability; testing.

\title{
RETAILING AND THE PUBLIC:
}

To clarify the point of view of this paper, some points about the role of retailers in general, and Sears'merchandising system in particular, should be made.

First, retailers face the public directly and constantly, bearing the brunt of consumer dissatisfaction with many types of errors. Consumers tell us about quality errors made by manufacturers and vrong decision: 
we make on behalf of customers. We also must deal with complaints about regulatory decisions which add cost, and impair product function, without clear benefit to consumers.

Secondly, retailers act as purchasing agents for the public; through the decisions they make on what products to put on the shelves.

Third, a private labeler must get involved with a much broader array of products than the typical manufacturer, and must work closely with a wide variety of manufacturers, both large and small.

Lastly, it is necessary that private-labelers make "trade-off" decisions for consumers, based on knowledge of consumers' vishes and sense of values--and we must be right at least more of ten than we are wrong. In the intensity of today's competition, a retailer who tries to offer more of any product characteristic than customers wish to pay for, is penalized--as much as the merchant who does not offer enough.

These factiors help to explain why we have developed a special view of the new challenges to the consumer product field -- broad, complex problems of an unfamiliar kind.

An underlying factor in many cases is the enormous impact of improvements in communication. Events which only a generation ago would be known to only one locality, can now recelve nation-wide attention, almost immediately. This phenomena has not been lost on politicians, whose survival depends on sensitivity to public reactions. As a result, solving consumer product related problems requiring excellent technology is often unnecessarily complicated by political input.

In fact, we are concerned because too many such problems are approached more on a political/dramatic basis than in a genuine problem solving mode.

In a merchandising organization, we are conscious of the importance of imagination and enthusiasm; make no mistake about that. On the other hand, we believe that there is a special need for the MFPG, and similar groups, to promote valid techniques of problem solving, even though it is not easy to accomplish.

For a start, we suggest a close examination of where typical consumer product life stands today, in relation to consumer wants, needs and long-range interests.

We believe that learning how to prevent fallures, and building longer life into products, justifies considerable effort. At the same time, it seems important to recognize also, that the private sector, 
responding to consumers wishes, has provided a pretty good level of product durability and life, in most products.

For example, with reasonable care most automcbiles will go 100,000 miles or more. Carpeting is being offered which wears on and on, even in relatively hard service. Many textile products are discarded, not because they have become unserviceable, but because they are no longer "in style".

In other words, it seems clear from the record that consumer products generally provide a reasonable level of durability, overall. For example, the MIT studies on "Servicing of Products" and "The Real Cost of Consumer Appliances", documented impressive improvements in reliability and life, for some products.

In our own experience, we find that a very large percentage of sales do not result from failure of the current product, but because that product has become obsolete through the improved functions, features and style, of fered in today's products.

This is not to say that there is little more to accomplish through the application of sound engineering principles to consumer products. We will talk more of that a little later. The point is, however, there is a need to keep a sense of perspective about current demands for longer product life.

One important technical challenge lies in developing a discipline to determine which components of products are most vulnerable, to zero in on the weakest link in product construction. In the Sears Laboratories, this is an ongoing process, but we are quick to admit that all of us in this field still have lots to learn. Along the way, however, we have developed some strong beliefs -- some might say biases.

For example, while there has been a lot written about planned obsolescence, and how easy it would be to make longer lasting products, we believe insufficient attention has been paid to the opposite side of the coin. In our observation, more components in consumer products are over-designed, than under-designed, for optimum value. That is, a more nearly optimum design would use many less expensive components and materials, with reduced, but still adequate, reliability and durability. Of course, in a truly optimum design, some components and materials (the "weak links") would probably be more costly.

There is little mystery about which are the "weak links", in the minds of the engineers who are designing consumer products, and there are constant efforts to upgrade those key items, within severe cost restraints. Belts, bearings, brakes and insulation (electrical and 
therma1), are examples of parts which often limit durability.

Improvements in durability through selection of more expensive components is usually possible, but the trade-off of extra life for more cost may not be rewarding in the competitive marketplace. On the other hand, in particular designs, these same components may be over-designed in comparison to other parts of the product. Often, it isn't that much more expensive to get a better quality component, and the extra reliability and durability of that component may be excessive in comparison to the total.

The key to optimum design is balance and consistency. However, a great deal of high-quality research will be needed in order to provide an information base adequate to the purpose. Such formal research as has been done so far is unimpressive, for a variety of reasons. One of the most important is that seemingly simple questions in this field almost invariably turn out to be difficult to answer.

Furthermore, the life cycle of many products extends well beyond major changes in state-of-the-art, "obsolescence by improvements." For example, there are a lot of ranges in excellent condition which are quite obsolete in comparison to the self-cleaning oven, the. microwave oven, the smooth-top range, and induction cooking, for today's homemakers. In retrospect, consumers might ask: "Why were ranges made that lasted so long?"

Next, we should consider the effect of serviceabllity on total life cycle costs. Service costs are escalating, mainly from the more expensive equipment and more highly trained people required to service today's complex products. For many products, it seems that rather than emphasizing component durability, future minimum life-cycle cost designs should emphasize improved maintainability and serviceability.

Admittedly, the picture is complicated by unpredictable extremes of use. Many products are subject to harm because people who are not part of the design system make sub-optimizing decisions. For example, a person whose primary responsibility is to get the snow off the street as fast as possible after a heavy snowfall, does not have the incentive to make a thoughtful trade-off in corrosion damage to automobiles. Similarly, an untrained serviceman can do great harm to a product which otherwise might seem to be of excellent design.

In summary, this overview section has attempted to raise some questions which are irportant, but may not have received enough attention to date. 
Sears Laboratories' efforts in this field emphasize engineering design analysis and "testing by exception". That is, a Sears product engineer is expected to have a thorough knowledge of their product lines--the current technology, future trends, and customer usage in general. Furthermore, he vill usually have had input in the product development stage, so that he is familiar with important design changes.

Also, he is aware of the many kinds of trade-off decisions that have to be made in bringing a product to market. For example, how it is necessary at times to back off from some choices that might improve durability, because they would add unduly to cost, or reduce convenience, or interfere with basic function. Similarly, he is aware of the great impact of variability, in product characteristics and in type of use. Furthermore, he is extremely sensitive to the interaction of engineering design with the manufacturing facilities that will be involved.

As an illustration, recently one of our senior product engineers reviewed the results of tests on an important, new product. The test results looked good. Many of the components and materials were relatively well-known, and proven in use. Yet, when the product engineer applied his experience to analysis of the engineering design, he recognized that the design was such that it required extreme care and precision in manufacturing, to prevent reliability problems and heavy service costs. On that basis, the laboratory recommended that the design be greatly modified before production, which was done.

\section{CONFORMANCE TESTING:}

As far as testing is concerned, in most cases we are very much aware that we are not duplicating consumer use over an extended period very well. In that connection, before ve consider some details of testing of particular products, let us look at a total matrix of testing for long-range consumer satisfaction.

In analyzing the elements of product durability, we find it necessary to think in terms of quality of design versus quality of conformance to design intent, as manufactured. A Cadillac is engineered for longer life through quality of design than a Chevrolet, for example--but the conformance to design intent may be poor on some individual Cadillacs.

Similarly, there is an extensive list of characteristics that affect product life, including those characteristics that determine consumer satisfaction after extended use. The current state of the quality control art copes much more comfortably with the former, than with the latter. 
If we put these aspects in matrix form, it looks like this:

\begin{tabular}{|l|l|l|}
\hline \multicolumn{2}{|l|}{ Quality of Design } & Conformance Quality \\
\hline $\begin{array}{l}\text { As Received } \\
\text { Performance } \\
\text { After Use }\end{array}$ & $\begin{array}{l}\text { Laboratory tests can } \\
\text { define reasonably } \\
\text { well. }\end{array}$ & $\begin{array}{l}\text { Inspection, Quality } \\
\text { Assurance testing } \\
\text { can define fairly } \\
\text { well. }\end{array}$ \\
\hline $\begin{array}{l}\text { Some predictive } \\
\text { value. }\end{array}$ & $\begin{array}{l}\text { Currently cannot } \\
\text { be defined well at } \\
\text { reasonable cost. }\end{array}$ \\
\hline
\end{tabular}

The lower right hand entry points out the fact that a manufacturer cannot be certain wich of (or whether) the many things he did differently today will affect the long-range characteristics of the product. Fortunately, with reasonable care, serious problems from this cause can be minimized.

\section{DURABILITY TEST PROGRAM EXAMPLES:}

In specific product test programs, let us begin with mattresses. By experience, we know that while we do not duplicate consumer use exactly, if the mattress passes certain laboratory tests, it is likely to meet customer expectations. Our awareness of sales results and consumer complaints gives a reasonable base of such judgements on product durability and life.

By the use of a heavy roller which provides cycles of heavy loading and unloading of the mattress, followed by visual inspection after teardown, we think we get an adequate handle on durability. We recognize that the test does not completely account for aging of the foam, nor does it take into account the effect of specific "high-pressure points" (knees and elbows), which might require more elaborate test apparatus.

Similarly, in testing chairs, we emphasize structural integrity in the test program. We recognize structural tests do not take into account such factors as the aging of the plastics, the corrosion of metal, abrasion effects, nor permanent "packing down" of the cushioning material. Special tests are run for some of these aspects of long-range performance, whenever construction changes are judged likely to affect durability in an unpredictable way.

There are some synergistic long-range effects that no amount of laboratory aging tests can either duplicate or predict effectively. In other words, we must use engineering judgment on the degree to which material aging and wear will affect functional performance and consumer satisfaction. 
In carpeting, we use a practical test for durability which involves having it walked on hundreds of thousands of times in a high traffic hallway. This is the best durability test we know, but still may be in need of improvement.

For just one example, under this kind of test carpeting gets soiled more severely, so that cleanability evaluation is complicated by "deeper" cycles of soiling and cleaning.

In luggage testing, we test individually for many product characteristics that may change in different ways, and interact unpredicatably over time. For example, we use drop tests, tumble tests, handle-lift tests and abrasion tests, in addition to many others. Again, we must concede that the results must be subjected to highly knowledgeable interpretation, and have not always been correlated well with real-life results.

For further examples of complications in predicting product 1ife, consider an automatic washing machine. Suppose we have data on the life of all components and sub-assemblies, under some "typlcal" conditions of use.

We should start our process by defining, or assuming, the range of environmental conditions and type of use. In this case, we can visualize that one unit of a certain model might conceivably be purchased to clean the washing rags in a car-wash situation. Another might be purchased by a retired couple. The number of hours use, the loading, and the environment (dry/cool v.s. steamy/wet) would be extremely different for the two.

Any specific figure, therefore, would be quite arbitrary, unless the usage factor would be well understood and the degree of variability defined. Suppose any one of us were to try to predict how long a washing machine would last in our home, given the following information:

"When used under conditions of severe heat and humidity, and with heavy loading this machine will last three years. It will last 30 years under favorable environmental conditions and light duty."

Would you be able to tell where your particular family usage would fit into this product range?

To complicate the picture still further, consumer products are evolving rapidly in many ways, particularly in the use of new materials and new applications of electronics. This introduction of unknown elements greatly influences the reliability. Similarly, in many cases changes in purchased components and materials are not accompanied by engineering information on the likely effect of the change on product durability. 
We are not suggesting that it is necessary or desirable to put product design in "stop-motion" while we develop highly precise tests and analyses. We do want to emphasize the need for investigation of likely side consequences of changes.

CONSUMER USE OF DURABILITY INFORMATION:

One of the underexplored fields of consumer product marketing and technology is consumer use of information.

For just one example, any life rating is likely to be confused with a guarantee. This is further complicated by the FTC emerging policies and rules on implied warranties.

Another danger is that once consumers develop reliance on a life rating, there will be strong pressures on manufacturers to get into a "horsepower race" on claims for product life. This will lead to problems on how claims should be verified--which brings us back to the starting gate!

Similarly, if we look at the history of warranties and guarantees effectiveness, lifetime guarantees have had mixed results. At times, it has made a dramatic difference, particularly with replacement items, such as automobile mufflers. When applied to characteristics that are not high on consumers' priorities, it is likely to be ignored.

In children's play clothes, we have found that mothers rate durability extremely high. In fact, they will trade off quite a bit of comfort and appearance for durability.

Extended life guarantee was successful in the introduction of the steel radial tire, where the increase in tire life was dramatic, and the miles per dollar represented increased value.

On the other hand, both automobiles and television receivers have had some unhappy results with extended life guarantees.

Part of our concerns include consumer awareness of the true economic impact, or efforts to increase product life. Someone has to pay the bill. There does not seem to be sufficient consumer awareness that most of the increases in desirable characteristics, such as product life, safety, etc., involve complex, trade-off decisions involving other desirable characteristics.

For example, the FTC requires that lamp bulbs be rated as to lumens of light output, and hours of life. Both illumination needs and life expectations vary dramatically with operating conditions, such as applied voltage and visual task. How can the typical consumer be expected to evaluate "long life" bulbs versus "standard" bulbs--partic- 
ularly parameters of pover consumption, light output and price. If you had to replace a bulb in a relatively inaccessible hall stairway light, how would you choose among these three alternatives:

\begin{tabular}{|l|l|l|l|}
\hline Wattage & Lumens & Hours 1ife & Price \\
\hline \hline 60 & 870 & 1000 & $30 c$ \\
\hline 60 & 770 (1ess 1ight) & 2500 (1ong 1ife) & $75 c$ \\
\hline 75 (more power cost) & 1170 (more 1ight) & 750 (shorter 1ife) & $35 c$ \\
\hline
\end{tabular}

Would you make the same choice for one of the bulbs in the dining room chandelier? Or don't you care about the labels on lamp bulbs?

FUTURE DIRECTIONS :

In previous parts of this paper, we have emphasized the complications and difficulties in product life testing and durability prediction. This was intended to help prevent effort wasted by underestimating the complexity of the task.

However, we feel optimistic about progress that can be made. In that spirit, we are suggesting some specific directions for government, industry, and academe' to consider and explore.

These, then, are suggestions to the attendees at this conference:

First: CHALLENGE TO GOVERNMENT:

Our most important suggestion is to recognize the enormous potential in the directions of motivating industry efforts, and in informing the public. We believe that attempts to influence, regulate, or predetermine fine details of technical action are unrewarding. As Congress expressed in the legislative history of the Consumer Product Safety Act, technical knowledge about consumer products resides primarily among manufacturers, and effective action requires good utilization of that knowledge.

This motivation effort will require careful thought and planning, in the absence of regulatory power--and we think the history of the CPSC shows how counter-productive regulatory power can be when full utilization of the knowledge of producers is disregarded.

We suggest that another useful activity for government is to encourage applied research in this field. The National Science Foundation's RANN Program has made an excellent beginning, although there may be need to shift emphasis towards specific applied research. Other programs are needed. 
Next, government could inform and educate consumers in appropriate ways. For example, the National Bureau of Standards has had enormous credibility with the public that is both a great opportunity and a sobering responsibility.

The Sentry/Harris Report seems to indicate that the public favors a government technical function to represent their interest in product safety. As we have already mentioned, we think the history of the CPSC shows that regulation has not proven to be an effective means for such representation. We are convinced, however, that information and education does have an enormous potential for the future, both in product safety and product durability.

Along this line, certain research results provide some clues. For example, there is a trend for more disclosure of important kinds of information. The public has indicated that it favors an approach which is straight-forward and informative. Our research in catalog copy indicates that such directness is appreciated and favored by our customers.

There will be some honest disagreement how extensively and in what depth disclosure should be done, but this, too, is amenatle to research. Similarly, consumer information and education might help with some market considerations. Research shows that only one out of three consumers for big ticket consumer items repurchases the same brand if he is in the market again. This lack of brand loyalty for expensive items suggests product satisfaction alone won't bring back a customer. Advertising is necessary to keep the product in mind. The report speculates that possible reasons are high emotional and personal involvement in the purchase of expensive items, the search for information, and the option to delay purchase.

This research has real-world implications concerning product life improvement. How can the public be made aware that rewarding brands for product satisfaction can help to increase the level of general satisfaction, whereas a low correlation between product satisfaction and rewards, discourages manufacturers' efforts?

One way that the government can provide extremely useful services would be to set up an information center for consumer product life data.

One would hope that we all can learn from the disappointing experience of the CPSC with the use of NEISS data. For one thing, we would admonish against proceeding too far and too fast with an over-idealized system which might be suitable for an aerospace program but does not face the realities of consumer marketing. On the other hand, we are extremely enthusiastic about the potential contribution of such a data center if it is carefully planned, started on a modest scale and constantly improved through feedback of actual results. 
Perhaps one of the most important suggestions to industry in this field is to take a longer range view, recognizing the changing "rules of the game". For example, the full impact of life-cycle-cost awareness will apply in the not too distant future to products made today.

In other words, while there has been an emphasis on meeting consumer wants in the marketplace, it has been based primarily on sales. It is probably time to add an awareness of delayed consumer dissatisfaction, such as from the service costs. In other words, industry needs to recognize the need for high quality of engineering for customer satisfaction over the full life cycle of the product.

Furthermore, industry should be aware that it is not necessarily more expensive to have an excellent quality of engineering in the design of consumer products. In fact, with the help of government and the academic world, it can be very rewarding in the future to be able to design for more reliable products which are easier to service.

\section{CHALLENGE TO ACADEME':}

The academic community can contribute greatly by attempting to develop techniques that allow better application of current knowledge to consumer products, in a marketing-realistic way. For example, there needs to be better research techniques on consumers' usage of products. Some valuable work has been done, but does not seem to have received the attention it deserves. Frank Gryna's pioneering use of surveys paid careful attention to front end analysis, in order to determine the "vital few" factors that should be targeted for research. This technique should be used far more extensively, and improved on by use.

Similarly, there needs to be research on the way products respond to extremes of use. Some products are "forgiving" of extremes of use. Others are quite unforgiving, and even quite punishing, of any departure from the type of use built into the design assumptions.

And next, we suggest research into improved techniques of technology transfer, techniques which take a realistic view of consumers, consumer products, and technology. For example, there is a misconception that a great deal of aerospace "high technology" can be transferred directly to consumer product technology. There are some, but not as many as there would be, if those engaged in developing the art of technology transfer made the effort to better understand the interaction of technology with marketing considerations. 
Lastly, the academic world needs to develop better techniques to train engineers in the art of mathematical modeling of engineering design. Individual product samples submitted for laboratory testing may not be completely representative of total production, and may even be carefully produced prototypes. There is a need for much research work, before we can predict the quality of engineering design after use. Mathematical modeling will also require data related to the statistical distribution of important product characteristics. Advantages will not suffice.

We should also emphasize that this modeling must be balanced by good judgment and an excellent grasp of how basic assumptions have to be used for an optimum design. There is a danger of "paralysis by analysis" which all of us concerned with consumer products must keep in mind. In other words, the challenge is to balance the amount of analytical work against the need to meet reasonable deadlines. This requires the ability to know when it is time to stop gathering and ana1yzing data and make judgment decisions. 


\author{
Dr. L. E. Bensch \\ Fluid Power Research Center \\ Oklahoma State University \\ Stillwater, Oklahoma 74074
}

\begin{abstract}
The hydraulic pump is one of the most critical components in any fluid power system. It is also generally thought to be one of the most sensitive to abrasive wear. The Fluid Power Research Center has been investigating accelerated test methods for evaluating pump contaminant sensitivity for several years. An associated wear theory has also been developed for predicting long-range pump contaminant service life based upon these accelerated tests and field operating conditions. During the past two to three years, a number of tests have been performed to verify the contaminant life predictions by conducting extended life tests under controlled contaminant environments. Tests were conducted over a broad range of service lives, ranging from 22 to 1430 hours utilizing both gear and piston pumps.
\end{abstract}

This paper presents the results of this extensive research investigation, including details of the life evaluation methods. Also included are brief descriptions of the accelerated test methods and contaminant life prediction techniques. The paper discusses the expected accuracy of the life predictions revealed by the test results.

Key words: Contaminant wear; hydraulic pump wear; accelerated wear testing; service life, abrasive wear, contaminant tolerance

Introduction: In any fluid power system, there are a number of individual components which affect the performance as well as the resultant reliability of the system. The hydraulic pump is generally considered one of the most important components because it provides the hydraulic power necessary to operate the remaining components. It has been recognized for a number of years that hydraulic components (in particular, the pump) are sensitive to contaminant-induced wear. Most hydraulic component manufacturers specify that their products should be protected by filtration; however, they have not had any proven method upon which to base these filter specifications.

Because of the deleterious effects of contamination upon hydraulic components, an entire area of investigation commonly called contamination control has developed. The Fluid Power Research Center (FPRC) has been active in this area for the past two decades, and a number of associated theories and test methods have resulted for most fluid power components. The accelerated pump contaminant sensitivity test method is one of the most advanced of the techniques developed and has been adopted as a standard by the National Fluid Power Association [1]. An associated contaminant wear theory was also developed 
[2] for interpreting the accelerated test data with respect to extended life in field environments. Until recently, the wear theory had not been rigorously verified; however, the results have been successfully applied in field applications.

During the past two years, the FPRC has been involved in a program under the sponsorship of the U.S. Army MERADCOM which has resulted in a more complete verification of the wear theories. A number of extended life tests were conducted under controlled contamination conditions, and comparisons were made of the results of these tests and predictions made from accelerated tests conducted on identical pumps. The following sections of this paper present a brief description of the accelerated test method and the wear theory. Then, the test technique and results of the extended life tests are presented. Finally, comparisons are made of the actual and predicted performance.

Accelerated contaminant sensitivity test: In order to estimate the length of time a given pump will operate in a given contaminated environment, it is necessary to conduct testing under contaminated conditions. When considering the effects of contaminant wear on a hydraulic pump, the output flow rate is generally utilized as the performance appraisal parameter. The pump life is, thus, determined by the operating time during which the output flow rate is above some specified level. When flow rate is used as the appraisal parameter, the other operating conditions - speed, pressure, and temperature - are held at a constant value. The accelerated pump test procedure [1], originally formalized at the FPRC under U.S. Army MERADCOM sponsorship [3], utilizes these concepts for evaluating the pump contaminant sensitivity.

The accelerated test method is designed to progressively expose a pump to increasing sizes of contaminant while monitoring the output flow rate. The test facility utilized is illustrated in Fig. 1. To enhance both the repeatability and reproducibility of the test, the volume of the test fluid in the circuit is maintained at a constant value equal to onefourth the rated volume flow of the pump per minute. The control or clean-up filters utilized reduce the contamination level of the fluid between injections to less than 10 $\mathrm{mg} /$ litre. The procedure specifies the use of single-cut (e.g., $0-5,0-10,0-20, \ldots, 0-80$ micrometres) contaminant classified from AC Fine Test Dust base stock. The contamination level maintained in the test system during each injection is $300 \mathrm{mg} / \mathrm{litre}$. The test method calls for the test fluid to be selected by the pump manufacturer; however, most tests at the FPRC are conducted with Mil-L-2104, Grade 10 , hydraulic fluid at $65.5^{\circ} \mathrm{C}$.

After an extensive break-in period, the actual contaminant sensitivity test is initiated by injecting a slurry of 0-5 micrometre test dust to create a $300 \mathrm{mg} /$ litre system level. The pump is then run at rated conditions and output flow rate is monitored. After the flow rate has stabilized for ten minutes or a total of 30 minutes has elapsed (whichever occurs first), the contaminant is filtered from the system and the final flow rate for that injection is measured and recorded. Subsequent injections of $0-10,0-20, \ldots, 0-80$ micrometres contaminant are then made, and the final flow rate is recorded after each injection. The test is terminated after the $\mathbf{0 - 8 0}$ micrometre injection or after the flow rate has dropped to less than $70 \%$ of its original value. 
Data analysis and life prediction: In order to provide an interpretation of the results of a contaminant sensitivity test in terms compatible with filter specifications or allowable contamination levels, a contaminant wear theory has been proposed [2]. The entire development of the model is presented in Ref. [2] and will not be repeated in detail here.

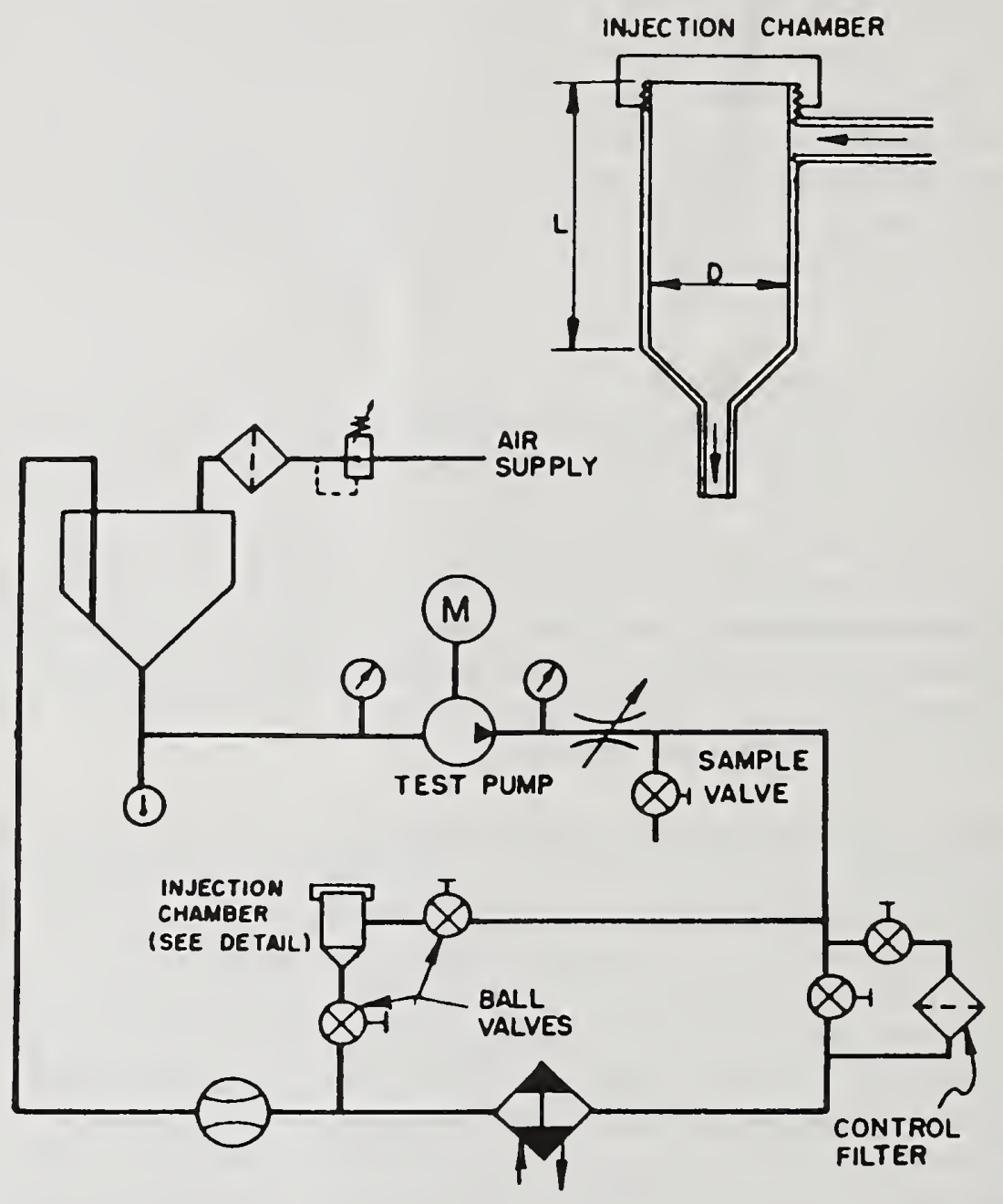

Fig. 1. Test Circuit for Pump Contaminant Sensitivity Test.

The contaminant sensitivity model is based upon the contention that, for every critical size particle that passes through or is exposed to the pump, there is a finite amount of damage which reduces the output flow of the pump. Thus, the rate that the flow degrades $(\mathrm{dQ} / \mathrm{dt})$ depends upon the sensitivity $\left(\mathrm{S}_{\mathrm{i}}\right)$ of the pump at size interval (i) and the rate $(\mathrm{dN} / \mathrm{dt})$ at which particles of size interval (i) are exposed to the pump. This relationship is expressed by the following equation: 


$$
\mathrm{dQ} / \mathrm{dt} \quad=\quad-\mathrm{S}_{\mathrm{i}}\left(\mathrm{d} \mathrm{N}_{\mathrm{i}} / \mathrm{dt}\right)
$$

By considering the facts that: (1) the sensitivity coefficient is a function of both particle size and concentration, and (2) the contaminant exposure is not only related to particle concentration but also to the flow rate of the pump, an expression for flow degradation for a given particle size can be obtained as follows:

$$
\mathrm{Q}(\mathrm{t}) \quad=\quad \mathrm{Q}_{\mathrm{O}} \mathrm{e}^{-\frac{\left(\alpha \tau \mathrm{n}_{0}{ }^{2}\right)\left(1-\mathrm{e}^{-2 \mathrm{t} / \tau}\right)}{2}}
$$

where:

$$
\begin{array}{ll}
\mathrm{O}_{\mathrm{O}} & =\text { initial flow rate } \\
\alpha & =\text { contaminant wear coefficient } \\
\mathrm{n}_{\mathrm{O}} & =\text { initial particle concentration } \\
\tau & =\text { particle destruction time constant }
\end{array}
$$

It should be pointed out that the contaminant wear coefficient, $\alpha$, is constant for a given pump and operating conditions but varies with particle size. The influence of each particle size range is evaluated by a single injection of contaminant which is continuously circulated during the test. Test results have shown that the contaminant (or at least its ability to cause wear) is destroyed during a test, and such destruction must be considered in the mathematical analysis. The contaminant destruction is accounted for in Eq. (2) by the use of the time constant, $\tau$.

In using the results of a contaminant sensitivity test for estimating field operating characteristics, it is assumed that, under field conditions, contaminant is continually being ingressed or generated and subsequently filtered from the system. This continuous interchange of new particles results in a relatively constant contamination level, $n$, determined by the ingression and filtering characteristics, and Eq. (2) for field operation becomes:

$$
\mathrm{Q}=\mathrm{Q}_{\mathrm{o}} \mathrm{e}^{-\alpha \mathrm{n}^{2} \mathrm{t}}
$$

Solving Eq. (3) for time and allowing the full particle size distribution to be reflected gives the following reference contaminant life equation:

$$
T=\frac{-\ln \left(\mathrm{Q}_{\mathrm{F}} / \mathrm{Q}_{\mathrm{o}}\right)}{\sum_{\mathrm{i}=1}^{i_{\max }} \alpha_{\mathrm{i}} \mathrm{n}_{\mathrm{i}}{ }^{2}}
$$

where $\mathrm{Q}_{\mathrm{O}}$ and $\mathrm{Q}_{F}$ are, respectively, the initial and final flow rates and $\mathrm{T}$ is the contaminant service life. The $\alpha_{i}$ 's are the reference contaminant wear coefficients evaluated from the laboratory test, and the $n_{i}{ }^{\prime} s$ are the particle concentrations for the various size intervals which describe the particle size distribution of the field fluid. 
The contaminant life equation can be utilized to calculate the pump contaminant life for any given particle size distribution. In order to allow system filters to be selected for the protection of a given pump, it is desirable to determine the maximum particle size distributions which would result in a specific contaminant life. In order to provide this information, the contaminant tolerance profile was developed [2]. The calculation of the profile requires the iterative use of Eq. (4). Ideally, any contaminant particle size distribution which is below the contaminant tolerance profile would result in a service life equal to or greater than the reference life associated with the profile.

Contaminant life verification testing: In order to verify the accelerated sensitivity test and the accuracy of the wear relationships for predicting field service life, a number of extended wear tests were conducted. The procedure utilized for these contaminant life tests consisted of the following basic steps: (1) Conduct contaminant sensitivity test on subject pump; (2) calculate contaminant tolerance profile for pump; (3) determine contamination level to result in desired life; (4) select proper filter and ingression rate to produce required contamination level; (5) conduct life test; $(6)$ compare results of life test to prediction.

The test circuit utilized for most of the test work is illustrated in the schematic shown in Fig. 2. The pump test system was a recirculating loop, consisting of a load valve, flowmeter, clean-up filter, and automatic temperature controller. The contaminant conditioning circuit included a 26 lpm pump and "conditioning filter." The two systems used a common fluid reservoir with a volume of approximately 40 litres. A separate recirculating

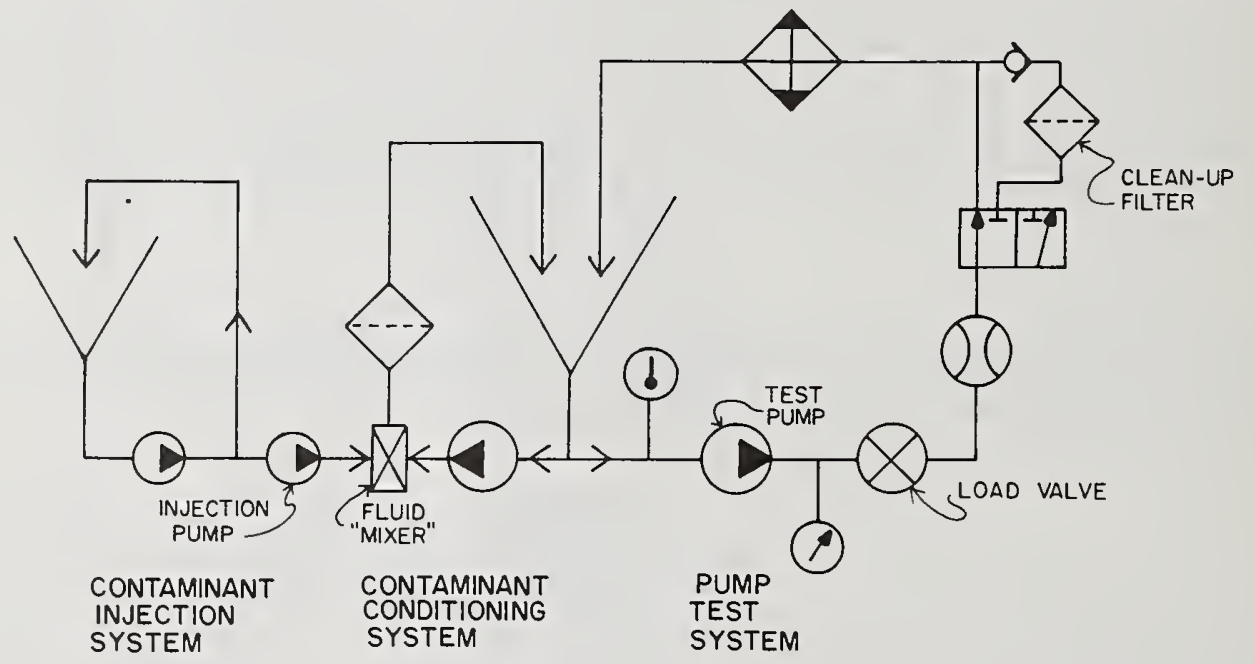

Fig. 2. Pump Contaminant Life Test Circuit.

system continuously injected fresh AC Fine Test Dust contaminant into the conditioning circuit upsteam of the filter. Automatic controls and shut-down features controlled pressure and temperature and provided for shut-down due to low or high pressure, high 
temperature, low fluid level, or high filter differential pressure. Periodic measurements of output flow rate were made during testing, and fluid samples were extracted for particle count analysis. The test configuration was selected to result in longer filter life while retaining an approximation to a realistic field system. The pumps used for testing were contributed by pump manufacturers and included both gear and piston pumps. All tests were conducted at $1800 \mathrm{rpm}, 138$ bars (2000 psi) and $65.5^{\circ} \mathrm{C}$, using Mil-L-2104, Grade 10, hydraulic fluid. A total of nine tests were completed on four different pump models with rated flows in the $60-80$ lpm range.

Reference [4] includes a complete summary of the verification test results. Therefore, only the condensed highlights are presented here. Typical contamination levels encountered in tests on pump numbers $243 \mathrm{~B}$ and 243E are illustrated in Fig. 3. The number refers to a specific pump model, and the letter suffix signifies a particular pump from that lot. A 1000-hour contaminant tolerance profile for Pump 243 is also shown in Fig. 3. The contamination level exposed to Pump 243B was well above the 1000-hour profile, while the level for Pump 243E was approximately tangent to the profile curve. The flow degradation curves calculated for Pumps $243 \mathrm{~B}$ and $243 \mathrm{E}$ are shown in Figs. 4 and 5. The actual flow degradation values (actual flow divided by initial flow) are also shown on Figs. 3 and 4 for direct comparison to the calculated values. In both instances, the results are exceptionally close. Similar curves were obtained for the remaining pumps, but space limitations do not allow presentation of all curves in this paper. The calculated flow degradation values were actually determined in a stepwise manner versus time. Because the particle count levels changed somewhat during testing, the actual counts were used in the calculations, along with the pump contaminant wear coefficients determined from a standard pump contaminant test. The particle counts used for a given time period were an average of the counts obtained at the beginning and end of the time period.

Comparison of actual and predicted life: A convenient method to verify the accuracy of the contaminant wear theory (besides a direct comparison of actual and calculated flow degradation curves) is to compare the actual time required for designated flow degradation to the calculated time for the same degradation. Table 1 presents the results of life comparisons to a flow degradation value of 0.800 , or $20 \%$ degradation. For situations in which the flow did not degrade below $80 \%$ of the initial value, the final flow rate at the conclusion of the test was used as the comparison point, and a life calculation to that flow rate was made. The life for Pump 242D was not calculated because the degradations were so minute $(0.5 \%$ maximum) that large errors can result in life estimations. The flow degradation ratio at the conclusion of the test on Pump 242D (0.995) was actually less than the calculated value, but only by a factor of 0.001 , or $0.1 \%$. Because contamination levels were not known past the test termination of 163.8 hours, the estimated life past that point could not be determined.

The average ratio of actual to calculated life for the eight pumps considered in Table 1 was 1.58 , with a standard deviation of 0.32 . This ratio implies that the average pump life is 1.58 times greater than that predicted using the contaminant wear theory. In every instance, except pump 242D, the actual life was in excess of the calculated value. Figure 6 


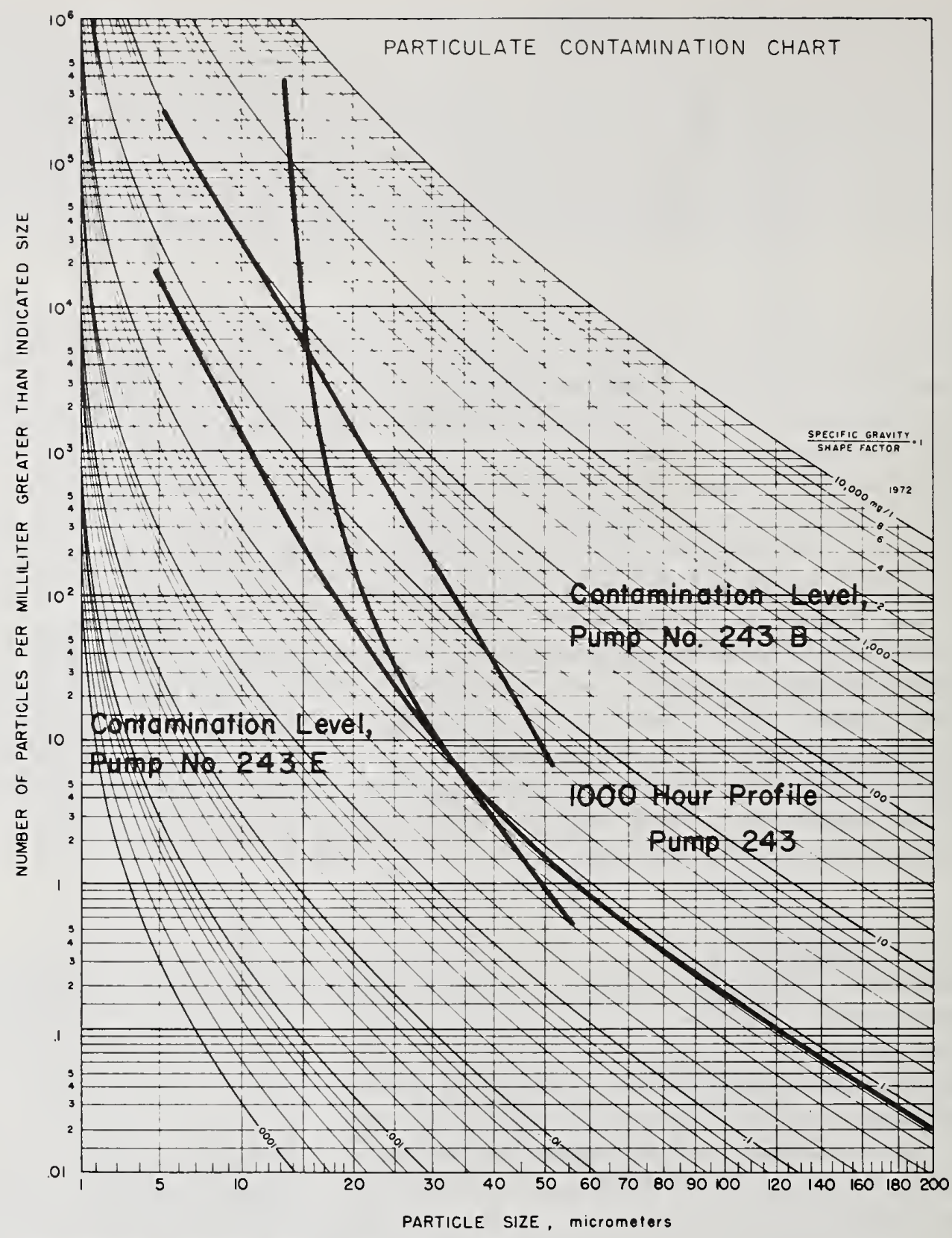

Fig. 3. Contamination Levels for Pump 243 Life Tests.

is a graphical representation of the life ratios listed in Table 1. A histogram was constructed using ranges of life ratio equal to 0.25 . The "normal" curve superimposed on the histogram emphasizes the mean life ratio of 1.58 . 


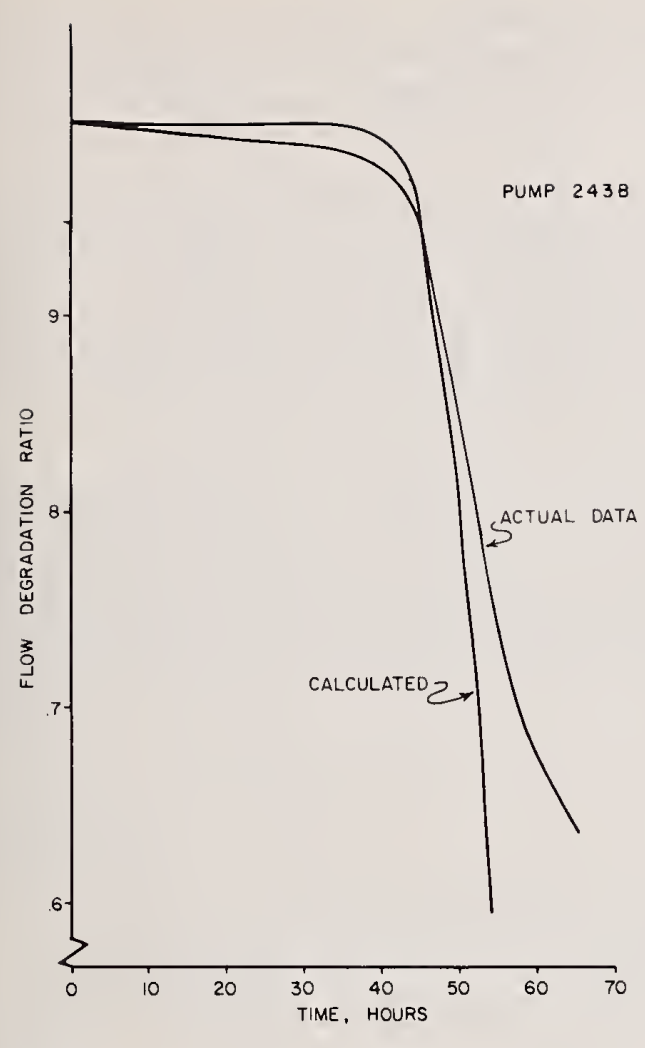

Fig. 4. Comparison of Actual and Calculated Degradation for Pump 243B.

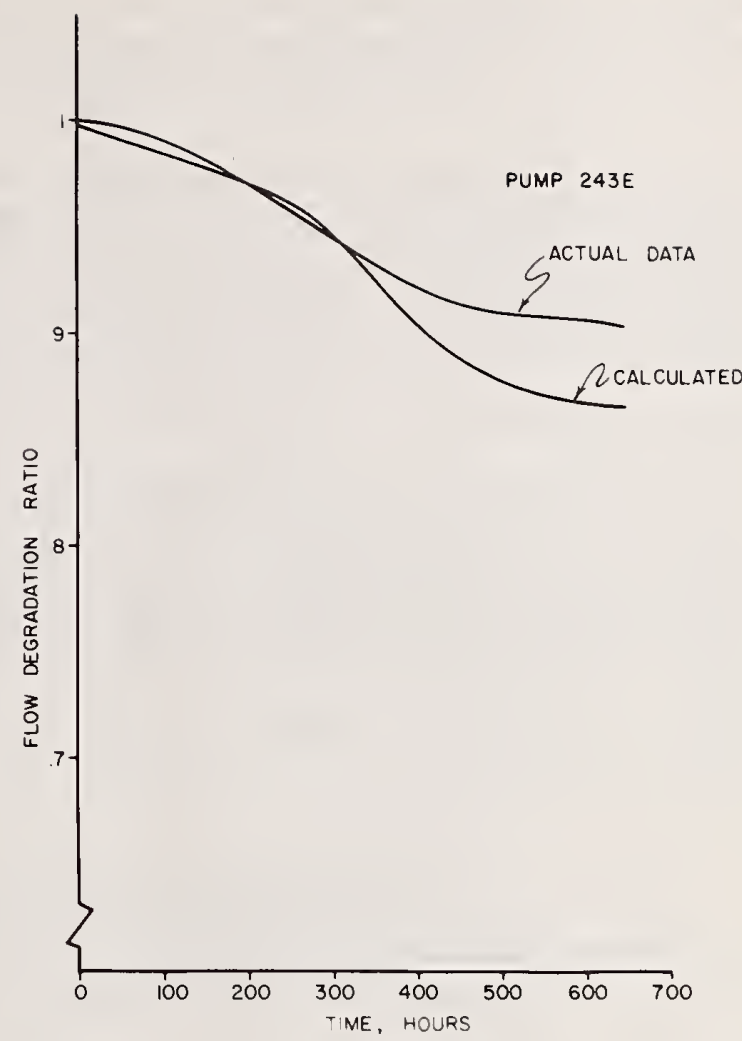

Fig. 5. Comparison of Actual and Calculated Degradation for Pump 243E.

Conclusions: A total of nine life tests were conducted on various hydraulic pumps, and the data are summarized in Table 1 . The tests on both gear and piston pumps ranged in length from approximately 12 hours to 1,431 hours. The average ratio of actual to calculated pump life was 1.58 , with a standard deviation of 0.32 or $20 \%$ of the mean. The low standard deviation implies that the life calculations are consistent but deviate from the actual by an average factor of 1.58. In all but one instance, the actual life was in excess of the calculated value; and, in this case, the actual and calculated flow degradations differed by a maximum of only $0.2 \%$. Because of the conservative nature of the estimations, the contaminant wear theory and interpretations can be used with confidence directly, as presented in Ref. [2].

The primary reason for the discrepancy between the actual and calculated lives is believed to be caused by the omission of "particle destruction" characteristics in the field wear expressions. In reality, the contaminant is not totally destroyed, but its abrasive characteristics are probably altered (sharp edges rounded, etc.) by the wear process. Current studies are being conducted to gain actual evidence to support this contention. Preliminary photographs taken through a scanning electron microscope have revealed that many of the sharp edges on the silica particles are rounded after several minutes of exposure to the 
TABLE 1. ACTUAL VERSUS CALCULATED PUMP LIFE SUMMARY.

\begin{tabular}{|l|l|c|c|c|c|}
\hline $\begin{array}{l}\text { PUMP } \\
\text { 1.D. }\end{array}$ & $\begin{array}{l}\text { PUMP } \\
\text { TYPE }\end{array}$ & $\begin{array}{c}\text { FLOW DEGRADATION } \\
\text { RATIO }\end{array}$ & $\begin{array}{c}\text { Actual Life } \\
\text { (hours) }\end{array}$ & $\begin{array}{c}\text { Calculated } \\
\text { Life (hours) }\end{array}$ & $\begin{array}{c}\text { Rátio } \\
\text { Actual / Calc. }\end{array}$ \\
\hline $242 D$ & Piston & 0.995 & 163.8 & $x \times$ & $x \times$ \\
\hline $242 C$ & Pistor & 0.840 & 276.0 & 158.1 & 1.75 \\
\hline $243 B$ & Piston & 0.800 & 52.2 & 50.6 & 1.03 \\
\hline $243 E$ & Piston & 0.903 & 646.1 & 396.1 & 1.63 \\
\hline $247 D$ & Gear & 0.800 & 11.7 & 8.0 & 1.46 \\
\hline $247 E$ & Gear & 0.800 & 385.3 & 273.4 & 1.41 \\
\hline $241 C$ & Gear & 0.990 & 1430.6 & 852.2 & 1.68 \\
\hline $223 \mathrm{~A}$ & Gear & 0.800 & 108.0 & 72.0 & 1.50 \\
\hline 252 & Gear & 0.800 & 123.0 & 57.0 & 2.16 \\
\hline & & & & & \\
\hline
\end{tabular}

Averaqe Ratio (actual/calculated life) $=1.58$

Standard Deviation $\quad=0.32$

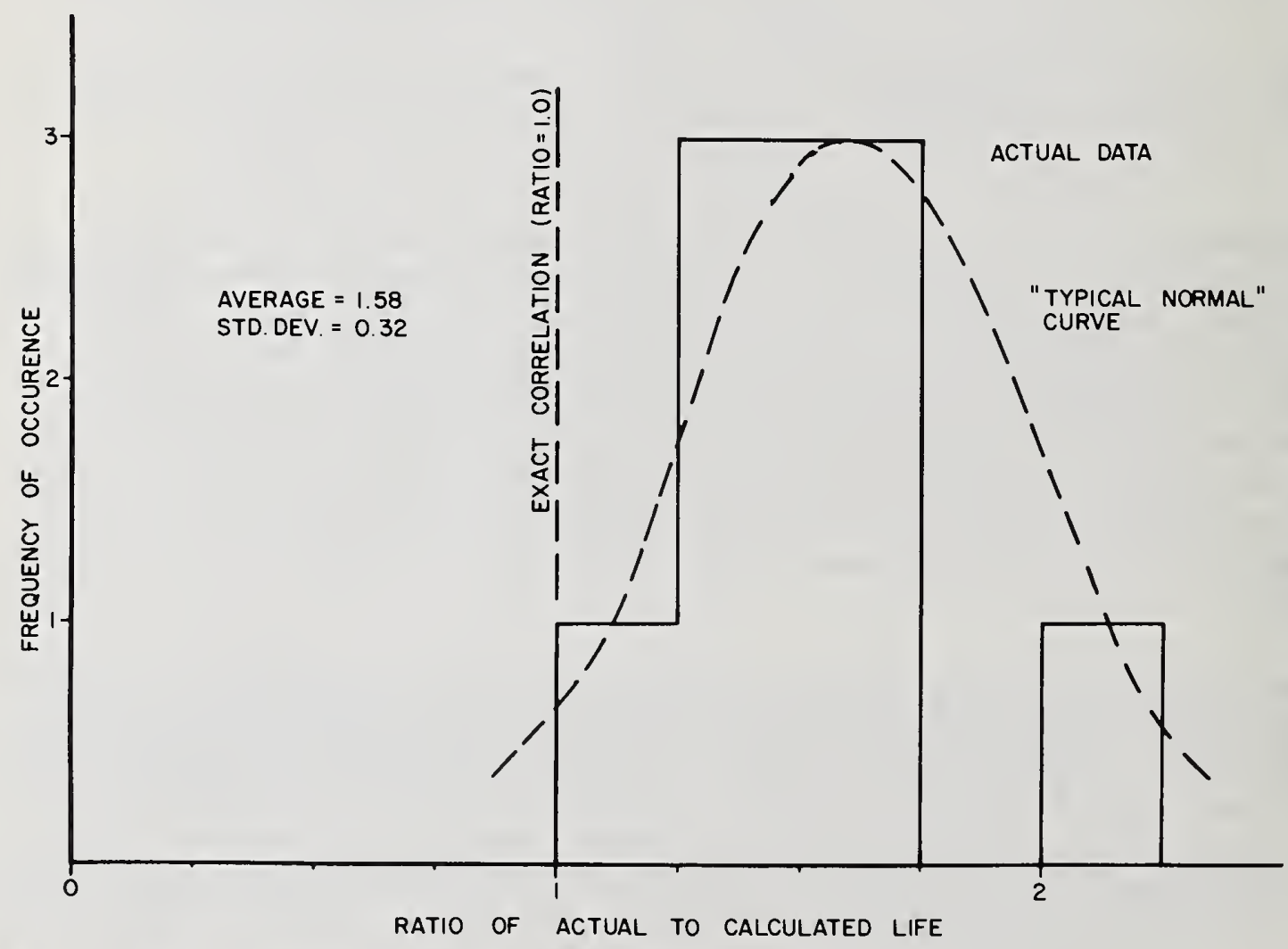

Fig. 6. Actual Vs. Calculated Pump Life Characteristics. 
wear process. A detailed report on the findings of this study will be available in the near future. It can certainly be concluded from these studies that it is necessary to continuously inject fresh contaminant in any realistic field-simulated experiments.

Although the contaminant wear theory is not totally accurate without the inclusion of terms describing "particle destruction" (This would include filter and ingression characteristics.), it appears to be sufficiently accurate for routine application. Based on the data shown, proper application of the contaminant wear theory results in sufficient protection for a hydraulic pump and assures adequate contaminant service life.

Acknowledgments: The author wishes to express his appreciation to the U.S. Army MERADCOM for sponsorship of this project, to the pump manufacturers who contributed the test pumps, and to Pall Corporation for their assistance in performing the preliminary scanning electron microscope analyses of the silica contaminant during the various wear stages.

\section{References:}

1. "Method of Establishing the Flow Degradation of Hydraulic Fluid Power Pumps When Exposed to Particulate Contaminant," NFPA Recommended Standard T3.9.181976, National Fluid Power Association, Milwaukee, Wisconsin, 1976.

2. Bensch, L. E., and E. C. Fitch, "A New Theory for the Contaminant Sensitivity of Fluid Power Pumps," Paper No. P72-CC-6, Sixth Annual Fluid Power Research Conference, Oklahoma State University, Stillwater, Oklahoma, October 1972.

3. "Hydraulic Specification (Phase I)," Final Report to U.S. Army MERADCOM, Contract No. DAAK02-70-C-0093, Oklahoma State University, Stillwater, Oklahoma, November 1970.

4. "Pump Contaminant Tolerance Verification," Section VI, MERADCOM/OSU Hydraulic System Reliability Program, Annual Report, Contract No. DAAK02-75-C0137, Oklahoma State University, Stillwater, Oklahoma, February 1977. 


\author{
Andrew W. Dorney \\ American Standard Inc. \\ P. 0. Box 2003 \\ New Brunswick, NJ 08903
}

\begin{abstract}
Manufacturers often find that even though their products have been processed utilizing stringent manufacturing controls, their customers are still receiving and reporting poor quality. The function of an independent Reliability Section is discussed covering its relationship with Design, Manufacturing and Quality Control. This section does not fully utilize the statistical aspects of Reliability, but controls the quality of the design as required, by determining the end use of the product and testing accordingly. Responsibility for the design and manufacturing in the various stages is discussed as is the testing and decision making associated with it. A typical consumer product is followed from Marketing concept through acceptance for shipment to the customer.
\end{abstract}

Key words: Product failure; product testing; quality control; quality of design; reliability.

Why is it - we never take the time to do the job right, but we always take the time to do it over? As manufacturers, we have all been made painfully aware of a shortcoming in our product by the most important inspector, the customer. Somehow, the press of meeting deadlines, the potential sales and profits, and the desire to just get the task completed, results in taking short cuts, risks, and in many cases, making errors of commission and, more importantly, of omission, causing the production of a poor quality product.

When the customer informs us that the product has failed, our first inclination is to be defensive, raising the usual questions. Is the product really unsatisfactory? Is the customer being too fussy? Is it only one lot, or one area of the country? Has anyone seen any bad ones? Should we stop production and shipment? Most times, the product is defective upon inspection and so the wheels of correction activity are set in motion and the job is done over and, possibly over again, since sometimes the corrective actions are not adequate and more problems are generated. There is not only added engineering, manufacturing, and inspection expense, but expenses for returning and reworking defective product, and shipping new product, but also damage to our image as a reputable manufacturer. In addition, faulty product may pose a potential consumer hazard, and if this is the case, then we must follow 
the procedures of the Consumer Product Safety Act and report the potential hazard to the Consumer Product Safety Commission. They must be furnished information on the extent of the problem, what is being done to correct and/or recall defective product, and what corrective measures are being taken to assure no hazard on future product. How much better it would have been to utilize this time, effort and money to do the job right!

Doing the job right - what is the job? The job is to design and manufacture a quality product. This entails controlling the quality of the design and controlling the quality of manufacture. We are all well-acquainted with controlling the quality of manufacture; this is our Quality Control Program, with the assigned task of making the product to print or, in other words, the Quality of Conformance. It does not do any good, however, to have an excellent Quality Control Program without having a proven design. This then is the area of prime importance, the control of the quality of the design.

Reliability, the quality of the design, is defined as assuring that the product will perform acceptably for the planned life in the intended environment. The primary assignment of this responsibility must be to an organization, generally called Reliability, which is a completely independent entity from manufacturing, design engineering or quality control. It must have the basic authority to approve or reject designs, or design changes, wholly and solely based upon the results of their testing and investigations. Experience has shown that rationalization of test results by well-meaning management eliminates the possibility of continual good judgment and weakens the future activities undertaken by this section. Lack of support by management, especially in negative decisions, will soon render the entire function useless; however, enthusiastic backing through a few new products or design changes, should prove its effectiveness.

At American-Standard, Reliability is part of a multi-discipline department which supplies technical expertise to our manufacturing organization which no plant or group of plants could economically justify. The primary responsibility of this Engineering Services Department is to assure that al1 newly designed or redesigned product will perform as intended and/or product limitations are recognized beforehand. In order to do this, a system has been set-up whereby Engineering, Manufacturing, Marketing and Reliability collectively coordinate design and production activity; however, Reliability, having the responsibility for performance and testing, is generally the controlling factor.

The system as set-up is a formal one requiring each group to perform and report on functions associated with their area. For example, when engineering has completed their design on new product, they must, in conjunction with manufacturing, confirm that they are able to produce the design successfully, at the cost price agreed upon, within the 
appropriate time interval, and with the assigned inventory. Marketing responsibility is to confirm that they will realize the planned selling price and volumes. On redesigns, the situation is similar; however, in requesting a design change, the reason and cost must be specified when the request is made. The request is submitted to each department, in turn, and all must approve before the change can be implemented. When the change requires a print revision, all signatures must appear on the request document before this is done. No production may take place without a revised print; therefore, in cases where testing and further approvals are necessary all parties must sign the document and it must be stamped with the notification that the product may be produced but may not be shipped prior to official approval.

Design changes are generally undertaken for three basic reasons, correction of field problems, substitution of materials, or cost reductions. The intent and necessity of the first two is apparent but the third, while important, often results in problems. The control of cost reduction changes must be extremely stringent, since many of them result not only in cost reduction, but in product degradation, by reducing the effectiveness of the product in one way or another.

Even though Reliability has the authority to approve designs or design changes, based upon its own activities, it must avail itself of all of the other disciplines, as appropriate. Questions regarding installation and compatibility are referred to Roughing-In, review of aesthetics are referred to Industrial Design, material evaluations and approval for use are assigned to Materials, regulatory agency and appropriate code and standard conformance is checked by Codes, and adequate packaging is designed and/or tested by Packaging. Even though all these disciplines are extremely competent and the decisions made in each area are technically sound, the ultimate value of the effort is directly proportional to the calibre of the person responsible for operation of the Reliability Section. This position can make or break the entire design control activity, since it many times finds that designs are not acceptable and therefore not suitable for use. The easily badgered or non-confident individual, who is unwilling to face higher levels of management, with unpopular decisions, will render the entire program valueless, and it will be nothing more than a paperwork exercise. The make-up of the Reliability Section is extremely important. It must have the fundamental disciplines available, such as, mechanical and electrical engineering, and statistical expertise, but by far the most critical item, an indepth, exploring, sensitive, investigative, practical approach to product design evaluation. When planning the evaluation, not only the normal functioning and environmental exposure of the product must be covered, but also the foreseeable possibility of misuse and overload characteristics, including damage. It is important here that past experience be utilized in setting up design evaluation tests or procedures, but it must be remembered that past results, even in similar tests or products, should not color the thinking or analysis of the problem at hand. 
Initiation of the control of design occurs when Marketing submits a request to have a product designed. They spell out the important characteristics of the product, with material limitations, if any, the comparable products on the market, whether in-house or competitors, and the target selling price. The design engineer, with the parameters defined, formulates his ideas into sketches and functional models. This phase of development then proceeds to some performance testing and perhaps some minimal life testing. The depth of testing required to qualify a design is obviously a function of not only its complexity but the environmental conditions to which it will be exposed, in addition to al 1 the normal performance requirements. A careful assessment of the performance test results, both as they affect basic design and materials selection, can save many hours of duplicated testing later on, so it is important that this testing be as rigorous as possible.

The importance of standard tests and the requirement of full compliance is critical to design control. Occasionally, it is necessary to field test a product to further insure a design's effectiveness, since all the functional and environmental variables cannot be reproduced to the extent necessary within a laboratory. For the most part any critical characteristic associated with time can only be estimated, and only actual time in use will provide the necessary answers. It is imperative the field testing be kept to a minimum and, therefore, a very detailed plan regarding quantities, distribution, and follow-up, must be made. A comprehensive list of defects must be made defining a design failure and, any failures associated with the design constitutes rejection of the design.

It is important to note, at this time, that a test plan covers both standard and uniquely developed tests formulated to check for design capability. They are documented procedures prescribing detailed methods, equipment and conditions, including time or usage characteristics; however, they do not include acceptance criteria since it is expected that no design attributable failures are allowed. All designs and redesigns in which test plans require the use of the documented procedures are done under the same conditions and are required to pass them successfully. Unique tests are generally developed in response to design changes associated with material usage; for example, the compatibility of rubber and plastics in close contact, to assure that migration from the rubber does not cause deterioration of the plastic. Also important in plastic applications is the effect of household cleaners on the parts, as installed. Many plastic materials under stress, are attacked by these cleaners, resulting in cracking or other physical changes, such as staining.

Responsibility for all testing activity is assigned to Reliability; however, in the development phase, the control of the intent and amount of testing is given to the Design Engineer. He stipulates tests, data, and conditions to be utilized and may at any time, depending upon the results obtained, change direction. When the design 
engineer is satisfied with the performance of the product, the initial sketches and specifications are converted to complete engineering drawings. At this point, Reliability reviews the drawings and coupled with their previous exposure in the development testing, formulates a test plan to determine acceptability of the design.

This Design Review also covers the evaluation of materials used in each component. The specification for each material, coupled with its use, is checked for completeness; that is, will the specification provide material selection, most notably in rubber and plastics, in how to determine and define their selection. Often formulations are given for rubber and, in many cases, the tradenames of plastic material are utilized. Unfortunately, once the selection has been made on this basis, the responsibility of the performance of the materials is with the purchaser. To preclude incorrect or marginal material selection, a system has been developed, whereby performance characteristics are specified, utilizing ASTM tests for evaluation. While this is a step in the right direction, it too is still deficient in that the tests performed are on laboratory produced configurations rather than on the part itself; however, these tests coupled with actual performance tests of the product, provide a great deal of protection.

One of the shortcomings in testing, which is very difficult to overcome, is the changes which occur due to aging. The passage of time can be approximated by certain accelerating conditions; however, there is no real substitute for actual time in service. If there is any question as to the validity of the results, it may be necessary to conduct a field test to confirm the results obtained. Field testing may be conducted in one of two ways; the low volume, highly, detailed test, or utilization of the "shotgun" approach with an extremely large quantity of production. Results in the first case are dependent on the performance and close scrutiny of each and every piece installed in a known location, while the second approach is more easily evaluated by waiting for complaints from the field, if any. The field test must be documented as completely as possible when new materials or old materials in new applications are being tested, as it may be necessary to use this documented data to convince Municipal, State, or Federal Administrative Authorities to allow the product to be used.

After the development phase and subsequent Design Review, prototype parts are produced and assembled using manufacturing tools, conditions and methods, whenever possible, utilizing temporary tooling only as necessary. The Manufacturing Department is responsible for assuring that this production conforms to the design since all testing is done on an "as received" basis, and only after failure or completion of test are dimensions confirmed and/or noted as to the change or wear which has resulted. During this phase of testing, two very significant items are reviewed. The first is an evaluation of any failures or potential failures, which could occur, to determine the completeness of the specification; that is, have all the necessary characteristics of 
materials and components been adequately identified and controls instituted for protection? The second is the type of ultimate failure to be expected; that is, what will the failure mode be when the planned life of the product is exceeded? This must be non-catastrophic! Using the test plan, the prototype production is evaluated and upon successful completion, final production is authorized.

This authorization begins with final engineering drawings which represent the product accepted in the prototype evaluation to a large extent, obviously though, it must cover tolerance ranges and combinations of tolerance stack-up not previously encountered. It is imperative that the approval of the design, covers to the maximum extent possible, the combinations of dimensions and manufacturing variables which could be encountered in long range production. To do this on a planned basis is not feasible, so the random approach to the various combinations is utilized by requiring a production quantity based upon the complexity of the design. This production run is controlled by manufacturing and quality control, utilizing the same activities that would be in place as required by this design. Samples representing the production are selected and tested using the same test plan previously used and upon successful completion, further production and shipments are authorized. This final stage is repeated whenever design changes are required which necessitates Reliability testing approval.

Control of product design, therefore, is fundamental to the manufacture and sale of any product. All the possible contingencies must be explored to the fullest extent so that when the design has been finalized, no surprises are upcoming. Product use must be simulated and utilized as the test method, and in most cases, the conditions extrapolated to the maximum expected. The failure modes must be known, and any possible malfunctions, due to misuse, must be taken into account. Detailed methods for product use, and instructions for installation are a must, as is adequate protection for the product, until delivered for use.

To summarize, product failure may be attributed to either quality of conformance or quality of design. As in the case of love and marriage, "you can't have one without the other," if you expect a happy ending. 


\author{
W. David Conn, Carol Inge, \\ Biswapriya Sanyal, and Elaine Warren \\ School of Architecture \& Urban Planning \\ University of California, \\ Los Angeles, California 90024
}

\title{
Abstract
}

A possible method of reducing solid waste (to alleviate problems of solid waste management, resource depletion, and environmental degradation) is to increase the lifetimes of durable products. Recognizing that in practice these lifetimes are determined not only by the physical durability "built in" by the manufacturers but also by a variety of other factors, an NSF-sponsored research project at UCLA is currently seeking information to assist government decision-makers in developing cost-effective waste reduction policies. Consumers have been surveyed to obtain data about their acquisition and disposal of small household appliances (such as irons, toasters, etc.); manufacturers have been asked about their actions affecting product lifetimes; and the nature and extent of second-hand markets have been examined. Preliminary results are presented.

\section{$\underline{\text { Key Words }}$}

Product lifetime; durability; solid waste management; waste reduction; small household electrical appliances, consumers; second-hand markets.

\section{Introduction}

Extending the lifetimes of durable products (and thereby delaying the need for replacements) has been suggested as a means of conserving natural resources, lessening environmental impacts, and reducing solid

\footnotetext{
*This paper is based on a study entitled "Factors Affecting Product Lifetime: A Study in Support of Policy Development for Waste Reduction", supported by the National Science Foundation. Marian Burke, J. Eugene Grigsby III, Richard A. Kentro, Thomas H. Hale, Mary Hruby, and Richard J. Lutz have contributed to the research. Any opinions stated herein are those of the authors alone and do not reflect an offical view of the National Science Foundation or of the University of California.
} 
waste management costs $(1,2,3)$. Careful examination of the 1 ikely effects of product lifetime extension on materials and energy flows has shown that the outcome is not always predictable, and that it could be counterproductive with respect to the stated objectives (4). For example, an automobile could almost certainly be built that would last considerably longer than present models, but it might also weigh considerably more and consume much greater quantities of gasoline.

Nevertheless, it does seem likely that many situations exist in which an extension of product lifetime would indeed serve the intended objectives. Given that such an extension might be desired (for this or any other reason), policy-makers face the question of how it might be achieved. Many policy measures proposed in the past, such as durability standards, product labeling, and requirements for longer warranty periods, seem to have been aimed at persuading the manufacturers, directly or indirectly, to produce products that are physica11y more durable.1 However, it is not at all clear that the physical durability built in by a manufacturer is necessarily the sole or even a major determinant of a product's lifetime in use. The latter appears to be influenced by the decisions and actions not only of the manufacturers, but also of the distributors, repair industries, taxing and regulatory authorities, and (perhaps most important1y) the consumers themselves.

In order to assist policy-makers in this poorly understood area, a research project sponsored by the National Science Foundation has been seeking information on "Factors Affecting Product Lifetime". This paper presents preliminary results from the study, which is currently nearing completion.

\section{Nature of the Study}

The study has been exploratory. It has covered a selected set of products, namely small household electrical appliances, as listed in Table 1. It has been conducted in a limited geographic area, namely, in and around the City of Santa Monica, California. Although this City has a mix of population, ethnic, income, housing, and other characteristics that is thought to be reasonably representative of many major communities throughout the U.S., it is recognized that the findings of the study may have a regional bias; for example, the prevalence of certain second-hand markets, such as garage sales, might be influenced by climatic factors.

The study has been conducted in three parts. In the first part, consumers have been asked directly a variety of questions concerning their acquisition, use, and disposal of the products under investigation, as

1. This may not necessarily be true in every case. For example, product labeling may simply have the purpose of improving market efficiency by producing consumers who are better informed; it may not be intended specifically to influence behavior. 
Toasters

Toaster ovens

Blenders

Coffee-makers

Can-openers

Frypans/skillets

Irons

Blow hair-driers

Bonnet hair-driers

Vacuum cleaners

Radios

Black and white portable TVs

well as about relevant attitudes. In the second part, manufacturers have been asked for their perceptions of consumer responses to some of the questions previously mentioned, as well as for information regarding the feasibility and desirability of a number of possible policy approaches aimed at extending product lifetimes. The third part has consisted of an investigation of second-hand markets, on the grounds that these provide an opportunity for the transfer of products from owners who no longer use them to potential new users.

The findings regarding second-hand markets have already been reported in a separate paper (5) and will merely be summarized here. The responses obtained from manufacturers have not yet been fully analyzed, and therefore will not be discussed in this paper. Instead, the primary focus will be on the preliminary findings from the survey of consumers.

\section{Second-Hand Markets}

Due to limitations on resources, no attempt was made to conduct a fully comprehensive investigation of second-hand markets; rather, efforts were directed primarily at:

(i) identifying market channels for the products covered in the study; (ii) gaining a reasonably reliable estimate of the volume of products transfered via these channels; and

(iii) understanding the principal factors and constraints affecting the operation of these markets.

The information was obtained by means of interviews with market participants and other interested parties, reviews of tax records, printed advertisements, and other pertinent documents, and field observation.

Table 2 lists the markets that were examined. However, it is recognized that in addition, certain stores selling new appliances will accept used products in part-exchange; furthermore, some stores offer for sale rebuilt or reconditioned appliances. The principal findings of the investigation can be summarized as follows:

(i) The volume of small household electrical appliances transfered via 
the second-hand markets studied is small, numbering in the tens or hundreds of appliances per month within the Santa Monica area, compared with the thousands of new appliances sold monthly in the same area. (ii) The second-hand markets are frequently inter-related, in that products bought at one market (e.g., a garage sale) may subsequently be sold at another (e.g., a swap meet). Discards that have not sold in other markets may be "dumped" on the charitable organizations such as Goodwill Industries and the Salvation Army, qualifying the donor for a tax deduction. As a last resort, some products are sold "as is" to dealers from South of the U.S. border, where their useful lifetimes may be extended further.

\section{TABLE 2 Second-Hand Markets for Small Electrical Appliances}

Garage sales

Swap meets

Private sales via classified advertisements

Privately operated thrift stores

Charitably operated thrift stores

Consumer Survey ${ }^{2}$

In the initial phase of the consumer survey, a randomly selected sample of 3291 households were screened by telephone to identify those that had disposed of one or more of the products under investigation during the past 12 months. "Disposing" in this context did not necessarily mean "throwing away" but rather refered to the termination of a product's useful life within the household. Table 3 lists the options that fell within the definition of "disposal" for the purpose of the study. Respondents who qualified in the telephone screening were asked to participate in home interviews. A total of 311 interviews have since been completed.

TABLE 3 Disposal Options Considered in the Study

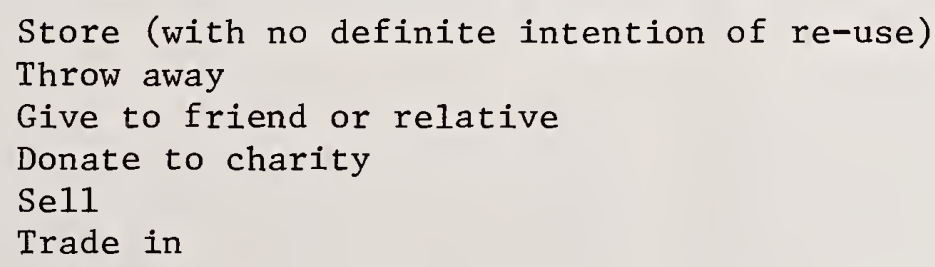

The frequency distribution of the various disposal options is given in Table 4. It is significant that the two most frequently chosen options (stored and thrown away) can be considered the most "wasteful" since they correspond to non-use of the product; the other four options entail a greater likelihood of further use. The primary reasons given for the choice of each option (as listed in Table 5) are consistent with intuitive expectations. An interesting observation is that those

2. The survey itself was conducted under contract by The Planning Group, Inc. 
options providing some monetary gain to the disposing household (i.e., donated, sold, traded in) appear to have been chosen by middle-income families.

TABLE 4 Frequency of Choice of Disposal Options

$\begin{array}{lr} & \% \\ \text { Stored } & 41 \\ \text { Thrown away } & 21 \\ \text { Given away } & 18 \\ \text { Donated } & 11 \\ \text { Sold } & 7 \\ \text { Traded in } & \frac{.2}{100}\end{array}$

TABLE 5 Primary Reasons Given for Choice of Disposal Option

Stored: "Couldn't decide what else to do with it" (given by $30 \%$ of those who stored products)

Thrown away: "Damaged and too costly to repair" (30\%)

Given away: "A friend or relative needed one" (40\%)

Sold: "Needed the money" (25\%)

Donated: "To support Goodwill or the Salvation Army" (30\%)

Traded in: "To get a price cut" (43\%)

Table 6 indicates the frequency with which products needed repair at the time of disposal, in aggregate and by disposal option. It is significant that nearly half of the products did not need repair when the household stopped using them, although it does appear that many of these products in working order were passed on, in one way or another, to other potential users.

TABLE 6 Products Needing Repair at Time of Disposal

Tota1

$\%$

54.2

By disposal option

$\begin{array}{ll}\text { Thrown away } & 95 \\ \text { Donated } & 63 \\ \text { Traded in } & 57 \\ \text { Stored } & 53 \\ \text { Sold } & 24 \\ \text { Given away } & 15\end{array}$

Of the households whose products needed repair, only $46 \%$ considered doing so. Cost and inconvenience were cited as the main reasons for not repairing. Since the likelihood of having a broken product repaired would be expected to depend largely on the relative cost of repairing versus buying a new product, it is important to note that the products investigated in the study had generally been fairly inexpensive when 
purchased; the average price (of those that were remembered) was $\$ 43$, while the median was $\$ 21$. Furthermore, $95 \%$ of the products thrown away and $70 \%$ of those stored had cost less than $\$ 30$. In contrast, it was determined in another part of the study that the cost of repairing one of the same products typically falls in the range of $\$ 7-15$. Responding to an attitudinal question posed elsewhere in the survey, more than half of the respondents said that they would not hesitate to throw away a product costing less than $\$ 20$ if it broke down. The responses to other attitudinal questions relating to repair are given in Table 7 ; they provide further insight as to why a breakdown often signals the end of a product's useful life.

\title{
TABLE 7 Consumer Views on Repairing Small Electrical Appliances
}

$\%$ in agreement

\author{
"Items should be easier to repair" \\ "Some products are not worth repairing" \\ "Getting items repaired is unconvenient" \\ "It is often cheaper to buy a new product \\ than to repair an old one"
}

98

80

73

70

The patterns of acquisition of the products disposed of and their replacements (where acquired) are indicated in Table 8. It is interesting that many products which were originally received as gifts were subsequently replaced by direct purchases. The survey revealed that $90 \%$ of all products were acquired new, and that most of those acquired used came through informal channels (e.g., from a friend or relative) rather than through a second-hand market such as a garage sale or thrift shop.

TABLE 8 Sources of Acquisition

old products (those that had been disposed of)

$\begin{array}{lr}\text { Purchase } & 56.3 \\ \text { Gift } & 39.5 \\ \text { Other } & 4.2\end{array}$

New products (acquired as replacements)

When asked about the importance attached to various criteria when the original product was purchased, performance, reliability, and durability were most commonly rated "important" or "extremely important" by the respondents (as indicated in Table 9). However, although durability rated highly on this question, it is interesting to note that almost one-third of the respondents had not known how long their products were expected to 1 ast.

Table 10 lists some general statements regarding product satisfaction, with which many respondents "agreed" or "strongly agreed". Although care was taken in designing the survey instrument to avoid "loading" the questions, it is significant that these expressions of discontent 
$\%$ considering important

or extremely important

More important criteria

Performance $\quad 99$

Reliability 98

Durability 88

Less important criteria

Terms of warranty 50

Ease of repair 50

Appearance 40

shows a lack of consistency with the response to another question, in which $80 \%$ of respondents claimed that they were satisfied with the particular products being discussed.

TABLE 10 Consumer Views on Product Satisfaction

Products are not built the way they used

$\%$ in agreement

to be

I am often disappointed with the products

I buy

Products break down too soon

I would gladly pay more for more durable

products

\section{Future Output From the Study}

Most of the findings reported above have emerged from a preliminary analysis of responses to the consumer survey. Little or no attempt has been made in this paper to explore the implications of these findings; this will be done once the data have been subjected to more extensive scrutiny, using a variety of analytical techniques. As mentioned earlier, the primary objective of the study is to provide policy-makers with information that will assist them in efforts to extend product 1ifetimes; for this purpose, it is important both to understand the factors that influence the pertinent decisions by consumers and others, and to anticipate the likely responses to different policy approaches. Early indications are that the study will indeed shed light on some of the key issues involved.

\section{$\underline{\text { References }}$}

1. U.S. Environmental Protection Agency, Office of Solid Waste Management Programs, Annual Reports to Congress: Resource Recovery and Waste Reduction, U.S. Environmental Protection Agency, Washington, $1974-77$. 
2. Wah1, D., Reduce - Targets, Means and Impacts of Source Reduction, League of Women Voters, Washington, 1975.

3. Conn, W.D., ed., Proposed Policies for Waste Reduction in California, California State Solid Waste Management Board, Sacramento, 1976.

4. Conn, W.D., "Consumer Product Life Extension in the Context of Materials and Energy Flows" in Pearce, D.W. and Walter, I., eds., Resource Conservation: Social and Economic Dimensions of Recycling, New York University Press, 1977.

5. Conn, W.D. and Sanyal, B., "The Significance of Second-Hand Markets for Small Electrical Appliances", Discussion Paper, UCLA School of Architecture and Urban Planning, 1977. 



\section{SESSION III}

\section{DURABILITY TECHNOLOGY}

\section{IN INDUSTRY}

CHAIRMAN: A. W. RUFF

NATIONAL BUREAU OF STANDARDS 

S. K. Rhee

Bendix Research Laboratories

The Bendix Corporation

Southfield, Michigan 48076

Abstract: Automotive and truck friction materials are described, and their wear characteristics are discussed. The wear rates of these friction materials are dependent upon many independent and dependent variables such as brake temperature, brake pressure, deceleration rate, weight, terrain, climate, engine conditions, drivers, traffic conditions, road dust, dust shield, surface roughness of the rotor and others. Test methods are described, and an equation is given for determining wear rate of automotive friction materials at a given temperature. The paper concludes by noting the difficulties of developing standardized techniques for durability testing of friction materials.

Key words: Automotive friction materials; brake wear; friction material test methods; friction materials wear; wear equation; wear mechanisms.

During a stop or deceleration a brake converts a substantial portion of the kinetic energy of the moving vehicle or machinery into heat, absorbs the heat, and gradually dissipates it to the atmosphere. The sliding friction couple in the brake consists of a rotor (drum or disc), and a stator on which is mounted a friction material (lining, pad, or block). The friction material is the expendable portion of the friction couple which converts to brake wear debris and gases in use. There exist many types of brakes, varying in size from a small brake on a bicycle or small machine to large brakes on the jumbo-aircraft. The scope of this paper will be limited to the discussion of automotive and truck brakes. However, general principles described in this paper will be generally applicable to other brakes and clutches as well.

There are numerous kinds of friction materials, different in composition as well as in configuration. The most familiar are lining materials for automotive drum brakes and pad materials for automotive disc brakes. Usually, these materials consist of an asbestos-reinforced polymer (commonly phenolic resin or rubber) filled with various friction and wear modifiers. Friction materials of this type are conventionally called "organic" friction materials [Refs. 1-5]. For extreme heavy-duty applications such as aircraft, rapid transit and occasionally race car brakes, copper or iron matrix materials, reinforced with steel fiber and filled with various ceramic and metallic property modifiers, are used. Materials of this type are called "Cerametalix", cermet or sintered friction materials [6-8]. When the asbestos-reinforcement in "organic" friction materials is replaced by steel fiber, and other fillers such as 
iron and graphite powder are added, the material is called "semimetallic" [9]. "Semimetallic" friction materials are used for passenger car and truck disc brakes, when "organic" friction materials are found to be inadequate.

Desired properties common to these automotive and truck friction materials include high, constant friction; low wear rate and no noise; no sensitivity to water; and little or no wear of the drum or disc; all under varying service conditions. Gray cast iron is the most commonly used drum or disc material. There are two separate pieces of linings in a drum brake: primary and secondary linings. Both of them may be of the same composition, but frequently they are found to be of different compositions and different sizes. The primary lining must provide high and stable friction while the secondary lining provides stable friction and wear resistance. Similarly, a pair of disc pads is used for a disc brake and the two pieces of the pair may or may not be of the same composition and size.

Friction materials can be tested in the laboratory or in the field. Laboratory testing usually uses the Friction Assessment Screening Test Machine (FAST machine) [10], Friction Materials Test Machine (sometimes called the Chase machine) [11], and/or inertial dynamometer [12, 13], while field testing uses an actual vehicle such as a passenger car or truck. The FAST machine employs a 1/2-inch square sample of friction material rubbing against the flat face of a 7-inch diameter cast iron disc which rotates at a constant speed. The heat generated by the rubbing action raises the temperature of the disc as the test proceeds. In the case of the Chase machine a 1-inch square sample of friction material is slid against the internal surface of an 11-inch diameter cast iron drum, and a heater-blower system can be used when desired for controlling the drum temperature. These two machines are more suitable for evaluating the consistency of friction materials rather than for predicting the performance of friction materials on a vehicle. In other words, these two machines are quality control tools, and results obtained from these two machines do not correlate very well with vehicle data [14]. In contrast to these two machines an inertial dynamometer employs full-size brakes and linings (or pads). Brake drums (or discs) are linked to inertial steel discs, which are bolted together and rotated to simulate the vehicle weight and speed. The single-end inertia dynamometer utilizes only a single brake while the dual-end inertial dynamometer uses one front brake and one rear brake. The quadruple inertial dynamometer uses all four brakes. Since the coefficient of friction of friction materials changes depending upon service conditions, there is a continuous load transfer between the front and rear brakes during braking. This makes it highly desirable to evaluate friction materials using the dual-end dynamometer or quadruple dynamometer. These inertial dynamometers produce test results which are usually in fair agreement with vehicle test results. One major disadvantage of these inertial dynamometers, however, is their high initial cost. The reasons for the fair agreement rather than excellent agreement are many. A brake system 
mounted on a dynamometer cannot fully duplicate a brake system on a vehicle in terms of air flow, vibration, road dust and other factors. For example, one may find differences in wear rates between an inner disc pad and outer disc pad when tested on a dynamometer, while vehicle tests indicate no differences. This difference is due to the fact that vibration of a moving vehicle assists disc brake shoes to retract from the rotor when the brake hydraulic pressure is released, while a rigid inertial dynamometer provides no significant vibration to the brake, so that one of the two pads tends to hang and slide continuously against the rotor.

There are many dynamometer and vehicle test procedures for evaluating the friction, friction stability, noise, wear, sensitivity to water, and rotor wear. These include wear-versus-temperature, SAE (Society of Automotive Engineers) Fade, FMVSS (Federal Motor Vehicle Safety Standards) 105-75, Detroit Traffic, Los Angeles Traffic, Jennerstown Mountain, Davis Dam and Pikes Peak. Generally speaking, dynamometer tests are used to screen candidate friction materials, and then, dynamometerscreened friction materials are always vehicle-tested on the road for each type of vehicle before release to the public.

If a fixed amount of work (or braking) is performed under the conditions of fixed normal load (or torque) and sliding speed, the wear rate of automotive and truck friction materials remains fairly constant with respect to rotor temperature up to approximately $220^{\circ} \mathrm{C}$ and the rate increases exponentially thereafter [15-18]. At low temperatures below $220^{\circ} \mathrm{C}$ (rotor temperature), the wear rate may remain constant or increase slightly with increasing temperature, depending on the composition of the friction material. The wear at these low temperatures has been attributed to the abrasive and adhesive wear mechanisms [19]. The exponentially increasing wear rate at high temperatures is due to the thermal decomposition of polymeric ingredients present in friction materials $[15,16]$. In other words wear rates of polymer-matrix friction materials can be very sensitive to brake temperatures. The wear rate at low temperatures is also very much dependent upon the surface roughness of the rotor. In general, the low-temperature wear rate increases with increasing roughness of the rotor friction surface [18, 19]. of course, the roughness of the rotor surface is influenced by the mating friction material itself as well as road dust.

The wear rate at a given temperature of automotive friction materials is related to the normal load ( $p$ ) and sliding speed (v) in the following manner:

$$
\mathrm{W}=\mathrm{k} \mathrm{P}^{\mathrm{a}} \mathrm{V}^{\mathrm{b}} \mathrm{t}^{\mathrm{c}}
$$

where $W$ is the amount of wear; $k, a, b$ and $c$ are constants characteristic of a given friction pair; and the sliding time [15, 16, 20]. This wear equation is also found to be applicable to the sliding wear of 
ceramic materials [21]. As a general rule, a and b are different from each other, being substantially different from unity, and $c$ is usually unity. In other words, the wear rate is not a linear function of the normal load or sliding time. Thus doubling the normal load may not raise the wear rate by a factor of two, but doubling the sliding speed may raise the wear rate by more than a factor of two.

Apparent from the discussions given above is the complex nature of testing a friction material for its durability or life. The durability is dependent not only on the brake temperature, but also on the brake pressure and deceleration rate. Furthermore, each type of vehicle tends to have its own brake design or designs; usually front brakes are different from rear brakes. Some brakes may have dust shields, thus lowering the three-body abrasive wear, but raising brake temperatures. Rear brakes may run hotter than front brakes because of the heat generated by the engine in the front. Inner disc pads may run cooler than outer disc pads because of different air flow rates, or vice versa. In addition to all of these variables, there are a few more; weight (heavy vs. light), terrain (mountainous vs. flat), weather (hot vs. cold), engine conditions (different engine deceleration), different drivers (different driving habits), and traffic conditions. Also, brake linings and disc pads tend to wear out unevenly (tapered). In a case such as this, the average volume wear rate may be more meaningful to scientists than to consumers. From a practical point of view consumers are more interested in the maximum thickness wear. Because of all these variables, it is not unusual to replace brake drum linings or disc pads after 60,000 or 70,000 miles in one case, versus only after 20,000 miles or less in another case. Because of the many variables, it is difficult to compare friction materials by road tests alone. Controlled testing has been recently done by simulating the Detroit Traffic Road Test for a specific vehicle, using an inertial dynamometer. Those tests exhibited considerably more consistent results than actual road tests.

In conclusion, if a "typical" vehicle (or brake) and "typical" service conditions can be defined, the durability of friction materials can be more readily determined. However, one must question if there are such things as "typical" vehicle and "typical" service conditions. In addition, the durability evaluation has to be coupled with other property evaluations: friction, friction stability, noise, rotor wear, and water recovery. Also, friction materials of one composition found suitable for one brake system may turn out to be unsatisfactory for another brake system. Thus, it must be said that if durability testing is to be standardized for friction materials, a tremendous amount of preparatory work will be needed to generate a reasonably satisfactory and acceptable set of test procedures. This task will prove to be extremely complicated and difficult. 
References

1. R. E. Spokes and E. C. Keller, "Friction Element", U.S. Patent No. 2,428,298, September 30, 1947.

2. R. E. Spokes, "Friction Elements and Methods of Making the Same", U.S. Patent No. 2,685,551, August 3, 1954.

3. B. W. Klein, "Friction Controlling Means", U.S. Patent No. 3,007, 549, November 7, 1961.

4. S. B. Twiss and E. J. Sydor, "Friction Elements and Methods of Making the Same", U.S. Patent No. 3,007,890, November 7, 1961.

5. F. W. Aldrich and M. G. Jacko, "Organic Friction Materials", Bendix Technical Journal, Vol. 2 (No.1), p.42 (1969).

6. A. W. Allen and R. H. Herron, "Friction Article", U. S. Patent No. 2,948,955, August 16, 1960.

7. N. A. Hooton, "Metal-Ceramic Composites in High-Energy Friction Applications", Bendix Technical Journal, Vol. 2 (No.1), p.55 (1969) .

8. K. Aoki and J. Shirotani, "The New Tokaido-Line Bullet Train", Bendix Technical Journal, Vol.6 (No. 2) p.1 (1973/74).

9. S. K. Rhee and J. P. Kwolek, "Sponge Iron Friction Materials", U.S. Patent No. 3,835,118, September 10, 1974.

10. A. E. Anderson, S. Gratch and H. P. Hayes, "A New Laboratory Friction and Wear Test for the Characterization of Brake Linings", SAE Paper No. 670079 (1967).

11. A. J. Burkman and F. H. Highley, "Laboratory Evaluation of Brake Lining Materials", SAE Paper No. 670510 (1967).

12. D. W. Howard and J. L. Winge, "An Automatically Programmed Quadruple Dynamometer for Vehicle Brake Testing", SAE Paper No. 670144 (1967).

13. D. Sinclair and W. F. Gulick, "The Dual Brake Inertial Dynamometer -A New Tool for Brake Testing", SAE Paper No. 488C (1962).

14. J. D. Preston and R. J. Forthofer, "Correlation of Vehicle, Dynamometer and Other Laboratory Tests for Brake Friction Materials", SAE Paper No. 710250 (1971).

15. T. Liu and S. K. Rhee, "High-Temperature Wear of Semimetallic Disc Brake Pads", Wear of Materials, edited by W. A. Glaeser, K. C. Ludema and S. K. Rhee, ASME, New York, p. 552 (1977).

16. T. Liu and S. K. Rhee, "High Temperature Wear of AsbestosReinforced Friction Materials", Wear, Vol. 37, p.291 (1976).

17. S. K. Rhee, "Wear Mechanisms for Asbestos-Reinforced Automotive Friction Materials", Wear, Vol. 29, p.391 (1974).

18. S. K. Rhee, "Influence of Rotor Metallurgy on the Wear of Friction Materials in Automotive Brakes", SAE Transactions, Vol. 80, p. 992 (1971).

19. S. K. Rhee, "Wear Mechanisms at Low Temperatures for MetalReinforced Phenolic Resins", Wear, Vol. 23, p.261 (1973).

20. S. K. Rhee, "Wear of Metal-Reinforced Phenolic Resins", Wear, Vol. 18, p.471, (1971). 
21. J. E. Hines, Jr., R. C. Bradt, and J. V. Biggers, "Grain size and Porosity Effects on the Abrasive Wear of Alumina", Wear of Materials, edited by W. A. Glaeser, K. C. Ludema and S. K. Rhee, ASME, New York, p.462 (1977).

22. H. W. Schwartz and S. K. Rhee, "Brake Dynamometer Evaluation of the Detroit Traffic Road Test", SAE Paper No. 770026 (1977). 


\section{Frank E. Kalivoda}

Copeland Corporation

Sidney, Ohio 45365

Abstract: Refrigeration, heat pump and air-conditioning compressors are expected to have long operating lives and low failure rates. Accelerated tests are, therefore, a practical necessity, but, care must be taken not to introduce extraneous failure modes. This paper discusses a test plan used to qualify these compressors and some of the complexities which must be considered.

\section{Introduction}

A large scale program to evaluate and improve the reliability of our refrigeration and air-conditioning compressors was initiated in 1973. An independent group was set up for this purpose and equipped with over 250 life test stands for testing compressors under a variety of operating conditions (1). Since that time, we have been testing compressors at the rate of about 700 per year. The program is proving its merit particularly at this point in time when requirements for performance and service are undergoing dynamic change.

The tests performed in this program have, in many cases been verified by field results. Areas have also been found, however, where the tests themselves can be improved. The purpose of this paper is to describe the tests which are being performed and the areas requiring further refinements.

\section{Discussion of the Problem}

A refrigeration compressor is an electromechanical device operating in a hermetically sealed environment with two fluids-lubricating oil and refrigerant. Residual materials and moisture can also be present. Electrical problems, wear of bearings, rods, and pistons or breakage of valve reeds, discharge tubes or other components are failures that can occur.

Temperature is a major variable, defining as it were both the operating conditions and system stresses including reactions among the lubricant, refrigerant, and the materials used in the compressor such as motor insulations. Normally, these materials are selected to have very low reactivities with screening tests of new materials being performed in sealed tubes (2). Erdman has indeed used the chemical half life theory which states that for each $18^{\circ} \mathrm{F}$ rise in temperature the rate of a 
There are, of course, temperatures which must not be exceeded if conditions such as lubricant or insulation breakdown are not to occur too rapjdly and invalidate the test completely. Our normal ljmits are $230 \mathrm{~F}$ for the 011 sump, $250 \mathrm{~F}$ for the discharge 1 ine, $270 \mathrm{~F}$ for the motor and $330^{\circ} \mathrm{F}$ for the valve plate.

Another unusual attribute of the system is that $0 i 1$ and refrigerant 22 have limited solubility with one another. For example, at $-15^{\circ} \mathrm{F}$, a single phase will exist between $\mathrm{R} 22$ and one of the common refrigeration oils when the concentration of $0 i 1$ is between either 0 and $3 \%$ or between 75 and 100\%. The actual concentration will depend on the pressure. Between these two concentration ranges, two phases will exist (4). This has two effects. The first of these is a decrease in the viscosity of the lubricant. A 32 centipoise viscosity oil, for example, is reduced to 5 centipoise by dilution of $25 \%$ refrigerant (5). Bearing lubrication is, therefore, directly affected.

The second effect is less obvious. A refrigerant can separate from the oil whenever the pressures change rapidly such as during system start up. If these conditions are not considered in design, vapor binding of the lubrication system or perhaps even a complete loss of lubricant could result. Crankcase heaters are one means used to protect the compressor during this type of condition (6). Proper oil pump venting arrangements and selection of oil solubilities are other ways of avoiding problems.

The compressor also experiences other unusual operating conditions. Although designed as a vapor compressor, it can be suddenly subjected to large quantities of liquid refrigerant during periods such as the defrost cycle of a heat pump particularly if the system is not designed with the proper accumulators. This can lead to valve breakage and bearing surface washout. And finally, there are conditions where failure of other system components can produce high stresses on the compressor.

These conditions must be factored into test plans which must also account for operating life expected from compressors. Table I shows operating hours and cycle targets for 10 years of operation for airconditioning, heat pump and commercial applications. Operation of a compressor on a test stand on a 24 hour day basis provides about 8,000 running hours per year. To qualify a heat pump compressor for 30,000 hours on that basis would require $33 / 4$ years. This is obviously too long for new product development, and some form of accelerated testing is required.

\section{Reliability Tests}

The types of reliability tests we run are of two general types: bench 
and life test. Ideally, bench tests can be used to qualify each component. Components such as valve plates and discharge tubes can be strain gaged, for example, and the design adjusted so that the stresses are kept below the fatigue limits. One problem, however, is in designing the test rig to simulate the actual operating conditions. Then too we have the physical size of the strain gage itself, and the difficulties in locating the gage exactly at the point of maximum stress. Furthermore, in cases of components such as valve reeds, the effect of combined stresses involving impact make the actual failure mechanism difficult to determine. With bearings, there are difficulties simulating lubricant conditions. Therefore, these tests must be used with careful evaluation and interpretation.

One advantage of testing compressors in the smaller sizes is that they are relatively inexpensive compared, for example, to something like a large engine. Thus, the compressor itself becomes a relatively inexpensive test stand or dynamometer, although costs can exceed $\$ 1,000$ apiece for early prototypes. Then too, al1 of the variables involved in the compressor, its manufacture and operation are covered directly in statistically planned system tests.

Life tests involving complete compressors can be of two different types. First we test directly in complete heat pump or refrigeration systems. This can provide excellent correlation to field data. For our purposes, however, where we supply a variety of compressors to many different system manufacturers, there are problems with cost, flexibility, and reliability of other system components. Units are absolutely necessary for the performance of certain tests such as blocked fan, but we do the greatest part of our life testing in specially designed water cooled life test stands which can be set and monitored for various operating conditions.

Setting up the test conditions is fairly complex. Cole and Pietsch presented an excellent discussion of the variables and stress zones involved in testing heat pumps (7). Our conditions shown in Figure 1 and Table II have been developed along the same general 1 ines.

Figure 1 shows typical compressor operating regions for cooling and heating on a chart of condensing and evaporating temperatures. These are the basic temperatures mentioned before as those which establish the service conditions of the compressor. There are four general zones in this chart: one a high load zone with resulting high bearing loads; another a high flow zone where the valve reeds are stressed to their fullest extent; third, a high compression ratio zone where the running gear is stressed at high operating temperatures; and finally, a low flow area where the motor cooling can be a problem. The normal operating regions for a compressor in the cooling and heating modes are shown on this graph. The boundaries of the regions are established either by maximum temperatures or by standard use. 
The rating point for cooling, point 1 and for heating, point 2 , can be seen to be comfortably within these areas. Life tests performed only at those conditions would leave unanswered the compressor durability when operated across the whole range of conditions. One objective is to test the compressor to values at the extremes of the operating zones without exceeding catastrophic failure conditions. Conditions 4, 5, and 6 fulfill this requirement for high load, high density flow, and high compression ratio conditions.

Point 7 is a heat pump operating condition. It can be encountered in operation since our policy is to let the compressor operate during periods of cold outside ambients. If, however, the compressor were allowed to operate with the normal superheat, valve plate temperatures would get much too high-about $380 \mathrm{~F}$. For this reason, we recommend that the system flood liquid back to the compressor at this condition to keep the compressor operating at reasonable temperatures (8). A typical recommendation is for $8 \%$ dilution of the $0 i 1$ with liquid refrigerant. This can be accommodated readily in systems, but does lead to problems in controlling life test stands because of the solubility characteristics of refrigerant and oil. A careful job of instrumentation and control is required. Thus, another test variable requiring close measurement of 011 temperature and shell pressure is added to the test requirements.

Other conditions are shown in Table II. A stop/start test stresses the compressor suspension and electrical components. A defrost test where liquid is repeatedly introduced into the compressor while it is operating stresses the valves. A flooded start test causes the compressor to be started with various amounts of liquid in the shell. Finally, a blocked fan test is imposed on the compressor in an actual system to simulate a system problem involving a blocked condenser or failed fan. In this case, the head pressures rise opening an internal pressure relief valve and causing the motor protector to break the line current.

Al1 ten of these tests are used in the qualification of new compressor designs. For qualification, conditions one and two are run 6,000 hours, and the remaining conditions from 2,000 to 4,000 hours each on various compressors in a statistical test plan involving as many as 60 compressors. The first seven are normally used in the audit of production compressors to ensure ongoing product reliability. For the audit test, we use a test sequence involving about 1,000 total hours of testing. These tests are, incidentally, preceded by a transit test (shake and impact) to simulate shipment.

The chemical half life theory can be used to help evaluate the severity of a test. In the condition shown in Figure 1 for point 7 which is a heat pump test, the valve plate temperature measured with $18^{\circ} \mathrm{F}$ superheat at that condition on a typical compressor would be $380 \mathrm{~F}$, whereas normally, we would not want this to exceed $330^{\circ} \mathrm{F}$. This would, therefore, show an acceleration factor of about two cubed or 8 . In going from 
$330^{\circ} \mathrm{F}$ to the $240^{\circ} \mathrm{F}$ experienced under the rating condition, we would have an additional acceleration factor from a chemical standpoint of two to the fifth power or 32 . The overall acceleration between point 7 and point 2 would, therefore, be an enormous 256 from a chemical standpoint.

The acceleration factors are further complicated in some of our compressors such as those used for low temperature refrigeration by the fact that they already operate under severe conditions to just about the limit of operation on a 24 hour day basis. The maximum compression ratios for the air-conditioning tests shown in Table II, for example, are about 8.6 to 1 . For a refrigeration machine, operating with a $-40^{\circ} \mathrm{F}$ evaporator and a $130^{\circ} \mathrm{F}$ condenser, the compression ratio, however, is about 18 to 1 . If we attempt to further accelerate the test by reducing the evaporator temperature to $-50 \mathrm{~F}$, we would increase the compression ratio to 23 to 1 which could lead to catastrophic failure since at these high compression ratio conditions, we do get high values of temperature as can be calculated from thermodynamic fundamentals (9).

\section{Correlation with Field Data}

The correlation of results from this type of test is underway with field failure statistics, and in many cases good correlation has already been found. Another approach that we're taking is through a large scale field test now underway on heat pump systems. Thirty of these units have been placed in residences with records kept on operating hours and cycles of operation. Six of these systems have also been very heavily instrumented with field data system incorporating a microprocessor.

This system measures 15 system operating temperatures and two pressures every 30 seconds while the unit is in operation. This data is transferred to our IBM 360 computer for analysis, and we will have more and better information on the operation of such systems than currently available.

\section{Conclusions}

Accelerated testing of compressors is a practical necessity for high volume production compressors with expected long lives. In order to have validity, however, such tests must be performed carefully with a great deal of attention to detail.

References

1. F. E. Kalivoda and K. W. Yun, "Modeling Mechanical System Accelerated Life Tests," Proceedings of the 1976 Annual Reliability and Maintainability Symposium, IEEE, p. 206. 
2. H. M. Parmelee, "Sealed Tube Stability Tests on Refrigeration Materials," ASHRAE Transactions, Vo1. 71, Part I, 1965, p. 154.

3. F. G. Erdman, "Compressor Application Life Testing," Proceedings of the 1972 Purdue Compressor Technology Conference, Roy C. Herrick Laboratories, p. 142.

4. R. C. Downing, "Freon Refrigerants \& Lubricating 0i1s," E. I. DuPont deNemours and Company, Wilmington, Delaware, June 1971, Fig. 11.

5. ASHRAE Handbook \& Product Directory 1976 Systems, American Society of Heating and Air-Conditioning Engineers, New York, 1976, p. 32.13.

6. R. E. Cawley and S. A. Parker, "Evaluation of Crankcase Heater and its Effectiveness with a Hermetic Compressor," Proceedings of the 1972 Purdue Compressor Technology Conference, Roy C. Herrick Laboratories, p. 475 .

7. M. H. Cole and J. A. Pietsch, "Qualification of Heat Pump Design," ASHRAE Journal, July 1973, p. 43.

8. Application Engineering Bulletin, AE-1243-R3, Copeland Corporation, July 15, 1977.

9. ASHRAE Handbook of Fundamentals. American Society of Heating Refrigeration and Air-Conditioning Engineers, New York, 1976, p. 9. 


\section{TABLE I}

Reliability Targets

\begin{tabular}{lcrr}
\multicolumn{1}{c}{ Application } & Life & Hours & Cycles \\
Air-Conditioning & 10 Years & 15,000 & 75,000 \\
Heat Pump & 10 Years & 30,000 & 150,000 \\
Commercial & 10 Years & 58,000 & 350,000
\end{tabular}

TABLE I I

Life Test Conditions

Test

1. Design Condition Heating

2. Design Condition Cooling

3. Stop/Start

4. High Load

5. High Density Flow

6. High Compression Ratio

7. Heat Pump

8. Defrost

9. Flooded Start (Approx.)

10. Blocked Fan (Approx.) \begin{tabular}{c} 
Head \\
(PSIG) \\
\hline
\end{tabular}

130

110

360

550

170

360

226

300

250

700 $\begin{array}{r}\text { Suction } \\ \text { (PSIG) } \\ \hline\end{array}$

45

30

80

100

100

50

13

24

60

200
Suctign Temp. $_{F}$

20

10

65

65

$59(\operatorname{Max}$.

65

0 to -10

20(Min.)

60

Varies 


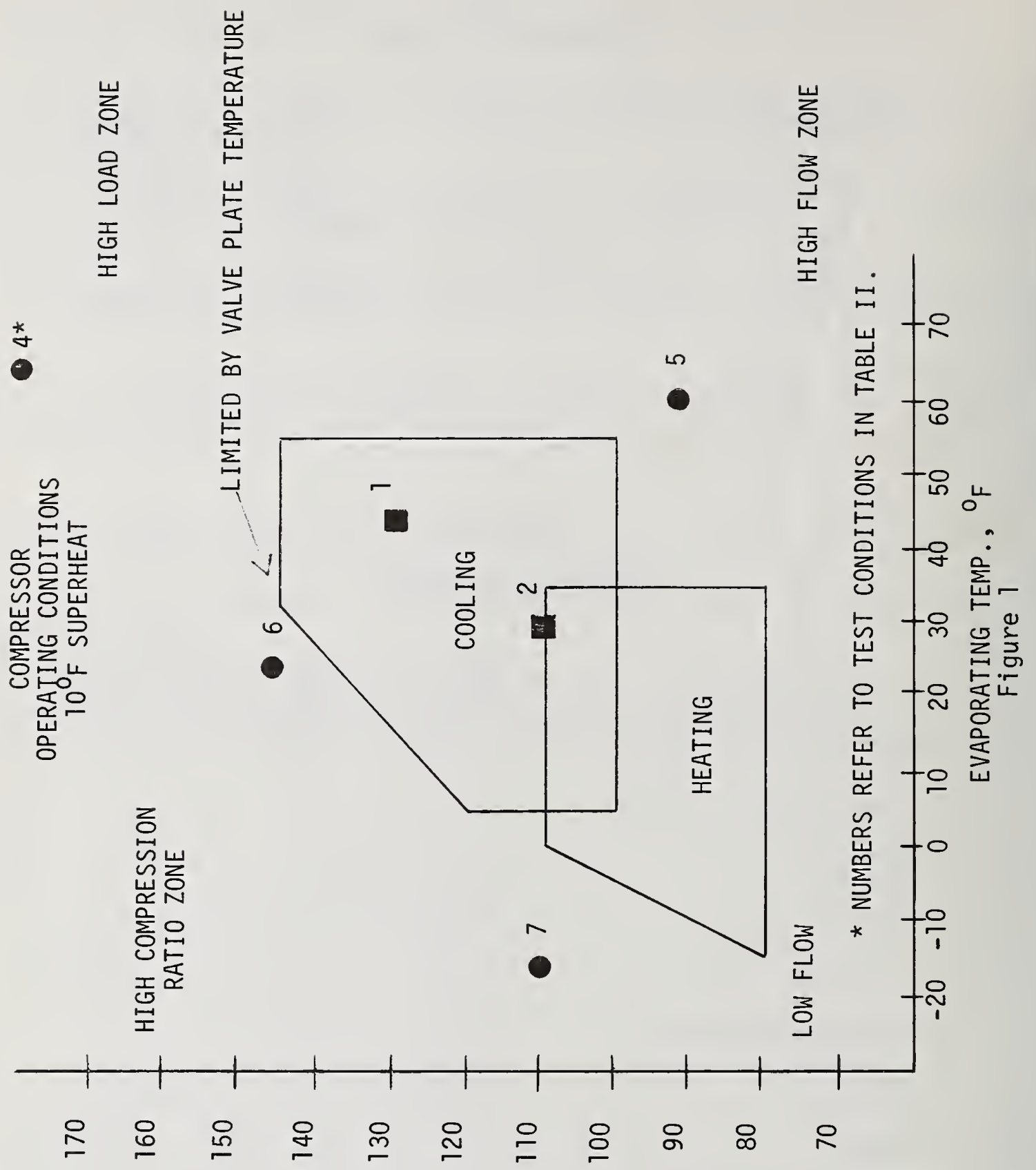




\author{
C. J. Brady \\ General Motors Corporation \\ Engineering Staff. \\ Warren, Michigan 48090 \\ H. W. Larsen \\ General Motors Corporation \\ Engineering Staff \\ Milford, Michigan 48042
}

Abstract: The automobile industry is designing and testing vehicles to meet increasing requirements for durability, safety, emission control, and fuel efficiency. Recent technical developments at General Motors have provided previously unavailable quantitative information on usage of vehicles by customers. This presentation discusses an electronic field data collection program and the way General Motors is combining the resulting information with modern design analysis and test methods to estimate the service life of vehicles.

Discussion: When we examine U.S vehicle registrations, we find that about $93 \%$ of the vehicles are still in service in five years (Figure 1). Presumably, the others are no longer registered because of collision, fire, theft, or export. About half of the vehicles are still in service after ten years, and about $11 \%$ are still registered after 15 years.

These numbers, obviously vary year to year, but these figures represent the general population of passenger cars over several model years. We see from this that vehicles have potential durability upwards of 15 years. Vehicles that do not receive reasonable maintenance and are exposed to more abusive operation go out of service early. 


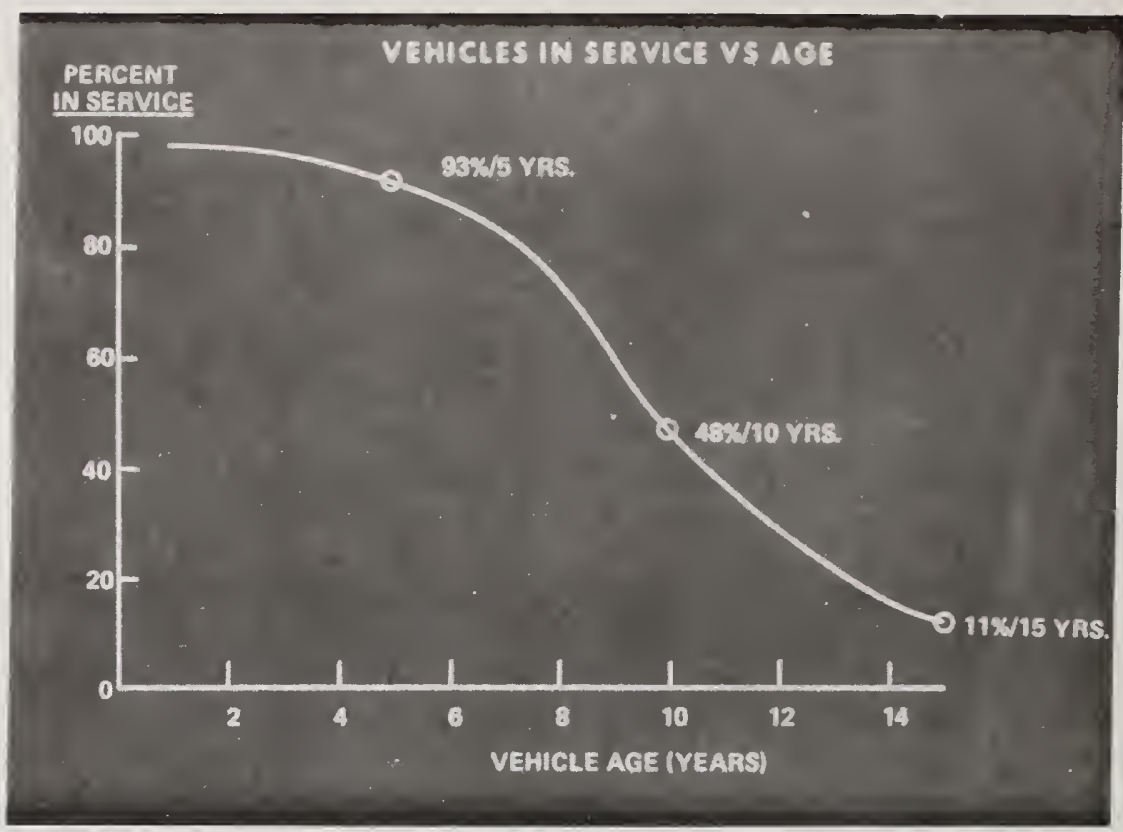

Figure 1

The domestic automobile industry is presently engaged in a major redesign of passenger cars to meet the national requirements for emission control, fuel conservation, and safety. It is General Motors' plan to produce cars that meet those requirements with as much utility and durability as possible.

To design, test, and develop vehicles to have a long, useful life, we need to know some things about the way the whole spectrum of customers uses our products.

A few years ago, we prepared some cars to record a variety of temperatures, pressures, forces, and motions (Figure 2). Data from this program were then combined with other available information such as government road statistics and past test versus field durability data. At that time, our road test schedules were modified to better match customer vehicle usage. This early work also gave us insight into some of the concepts and philosophies which would later be employed to more precisely define the customer usage spectrum.

This method of data collection tells us much about traffic patterns in general but not enough about individual car usage over extended time periods. 


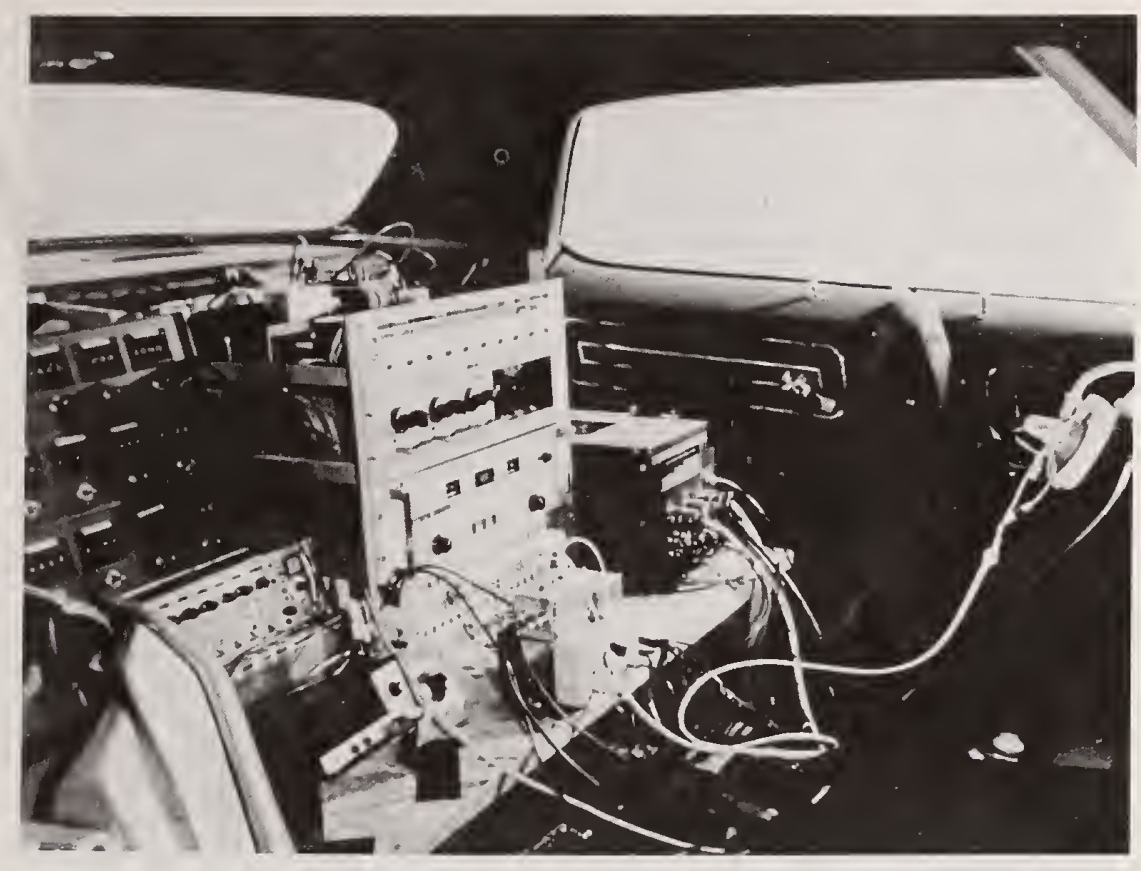

Figure 2

In order to determine how the whole population of vehicles is used we decided to measure the vehicle usage of randomly selected customers over extended time periods. Certain vehicle performance parameters and system or component loads and motions would be used to characterize vehicle usage.

This has become practical with the advent of micro-electronics. To monitor individual car usage, we have developed some instruments that can be installed in customers' cars and operate unattended for several months.

Figure 3 illustrates a complete instrumentation system to record steering linkage forces. These instruments contain their own power supply, signal conditioning, and data reduction electronics. This complete package concept allows data storage capacity for up to 10 million bits of data that can be produced in a few months of customer operation. A similar setup to record dynamic front suspension loads is shown in Figure 4. 


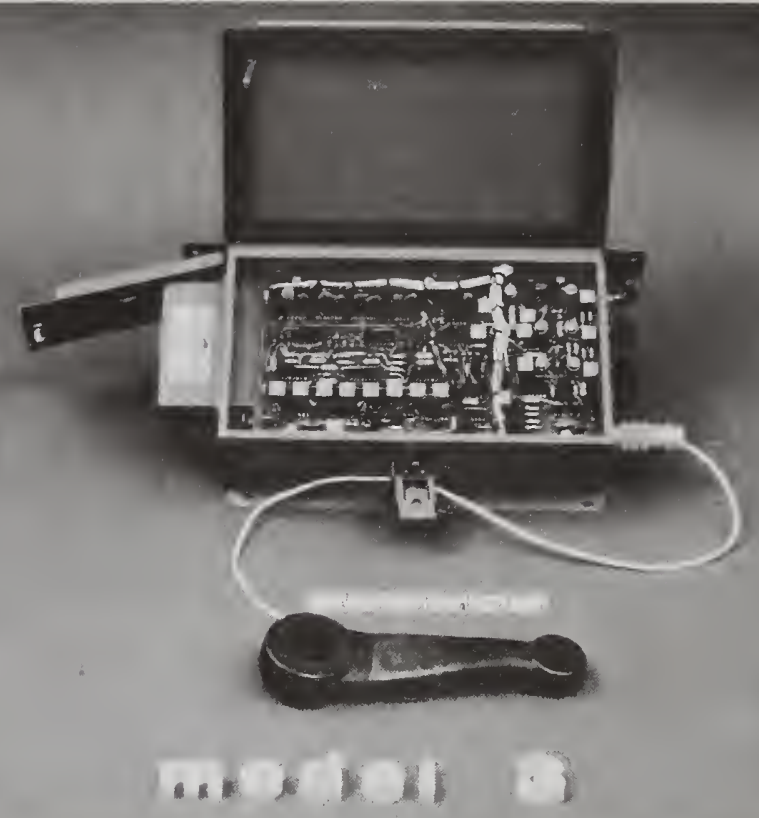

Figure 3

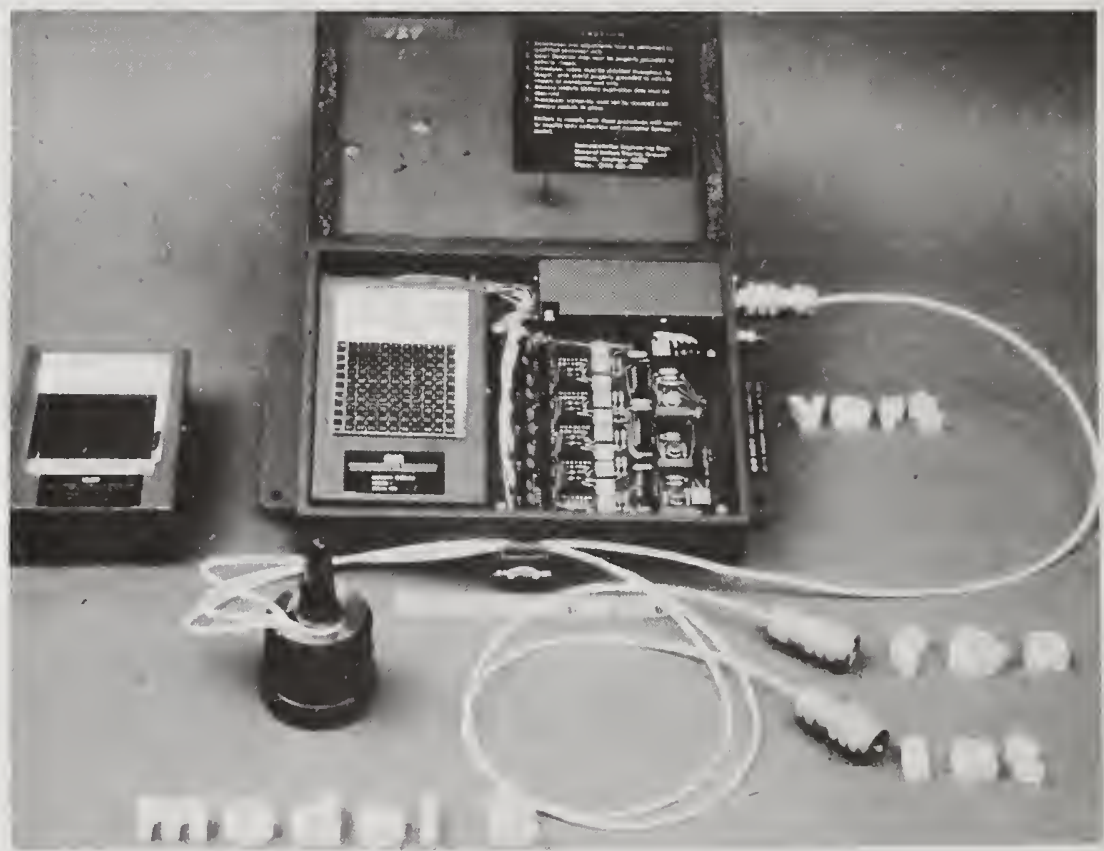

Figure 4 
It is important to us that the owner use the vehicle just as he would if the devices were not present. The owners are generally not told the details of the measurement until the data collection is complete. These devices are installed in the customer's vehicle so they do not interfere with his vehicle usage in any way (Figure 5).

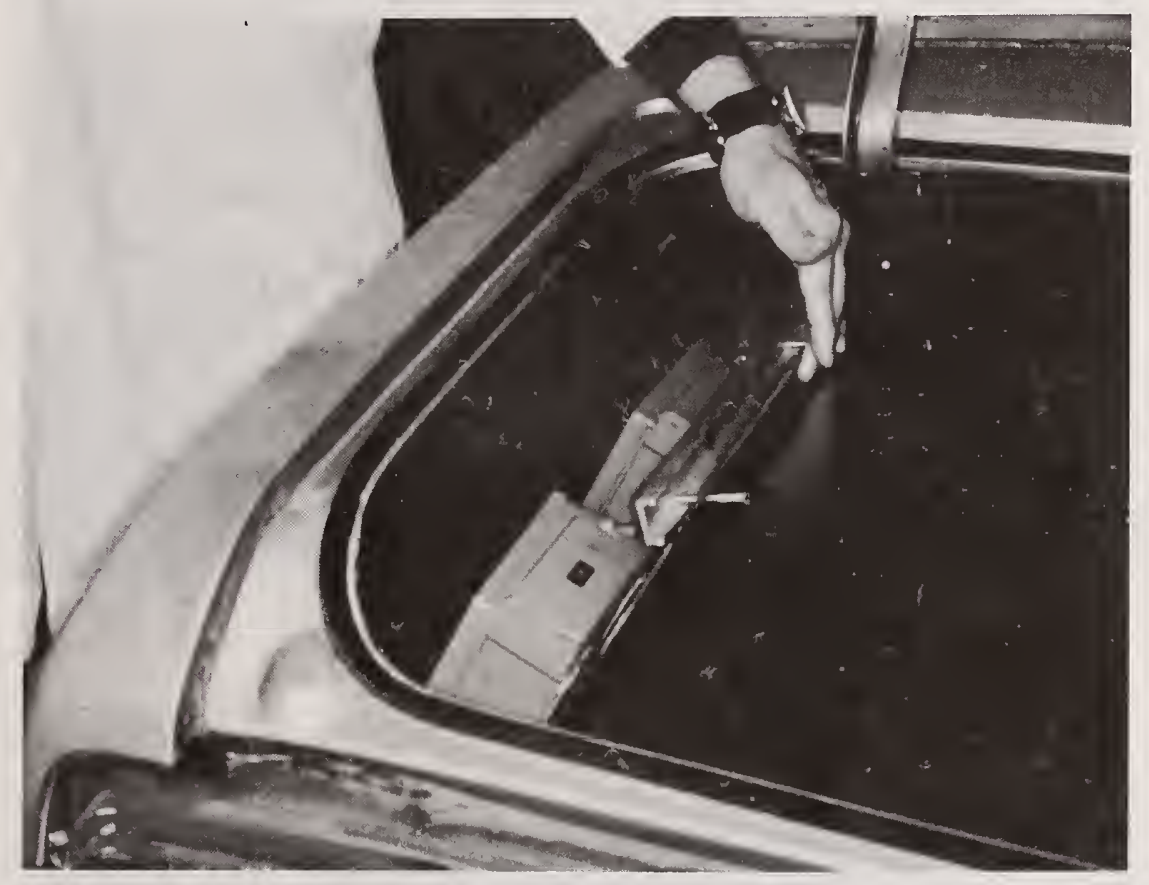

Figure 5

The locations of some randomly selected owners of one model of vehicle with suspension force recorders is shown in Figure 6.

In many cases, we continue with the instrumentation with the second, and sometimes third owner, since our objective is to measure the vehicle activity over an extensive portion of the service life. In almost all cases, we have found the owners of these vehicles to be enthusiastic and willing to participate in this type of program (Figure 7).

An example of typical data resulting from this program is shown in Figure 8. Specifically, this shows variation in front suspension forces experienced by just 5 of the 20 customers used in this particular project.

Figure 9 shows another example. Here we have determined the average miles driven in various speed ranges by a randomly selected group of 20 1973 intermediate car owners over a 2-year period. 


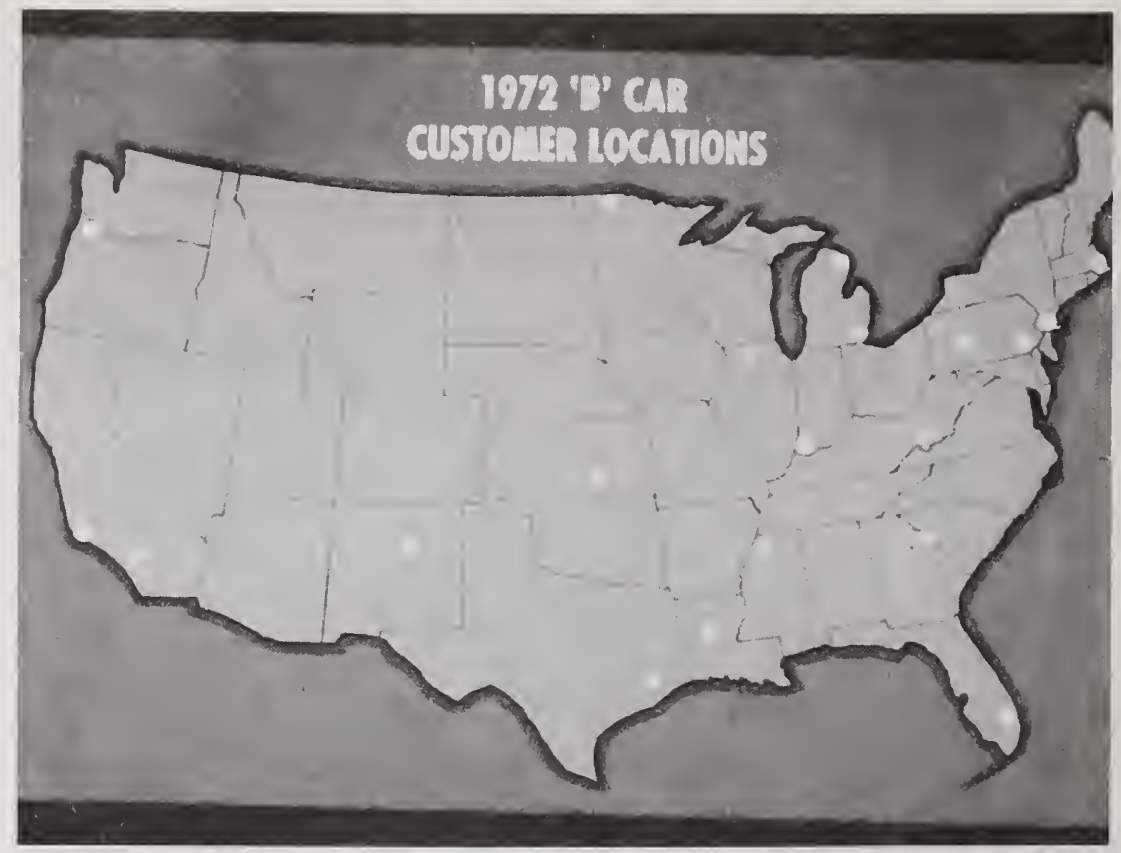

Figure 6

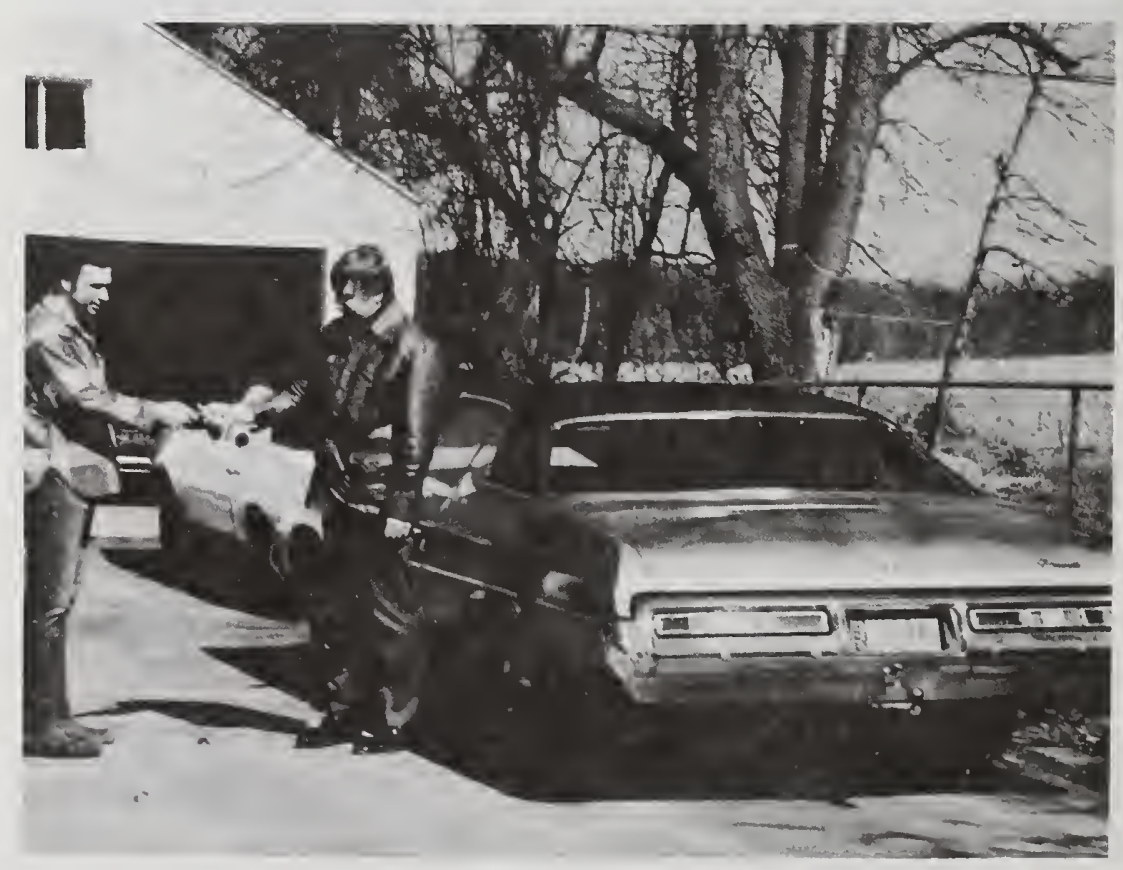

Figure 7 
RANDOM U.S. CUSTOMERS

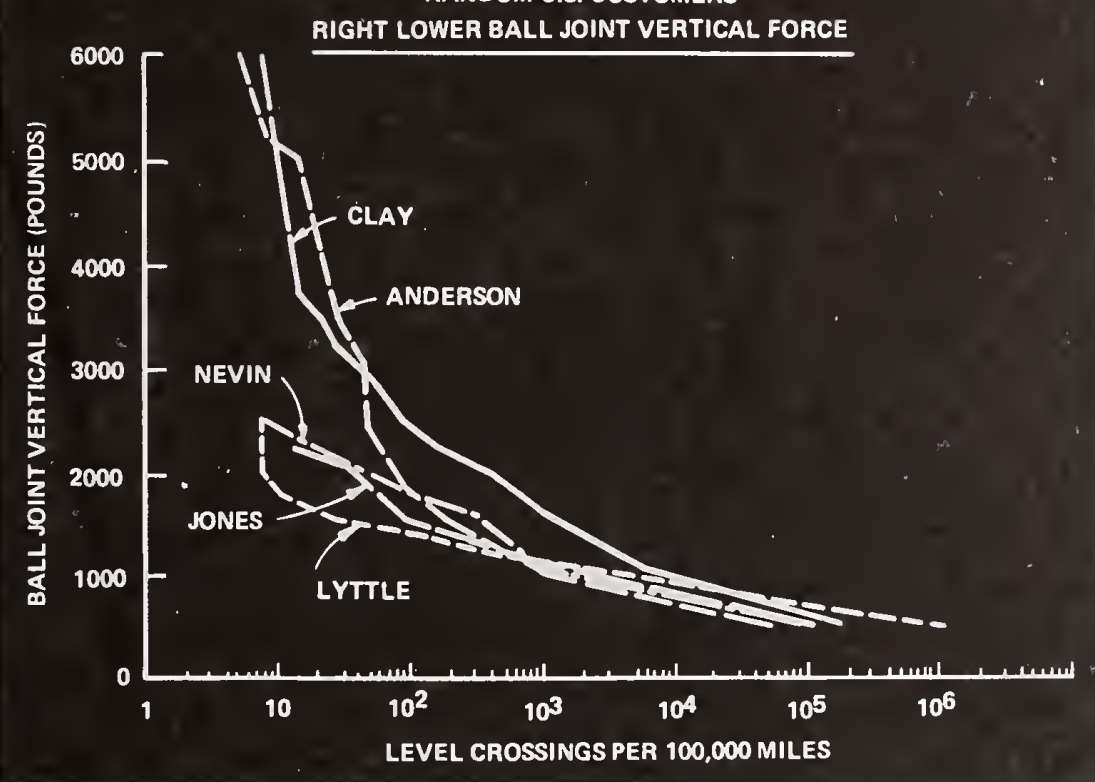

Figure 8

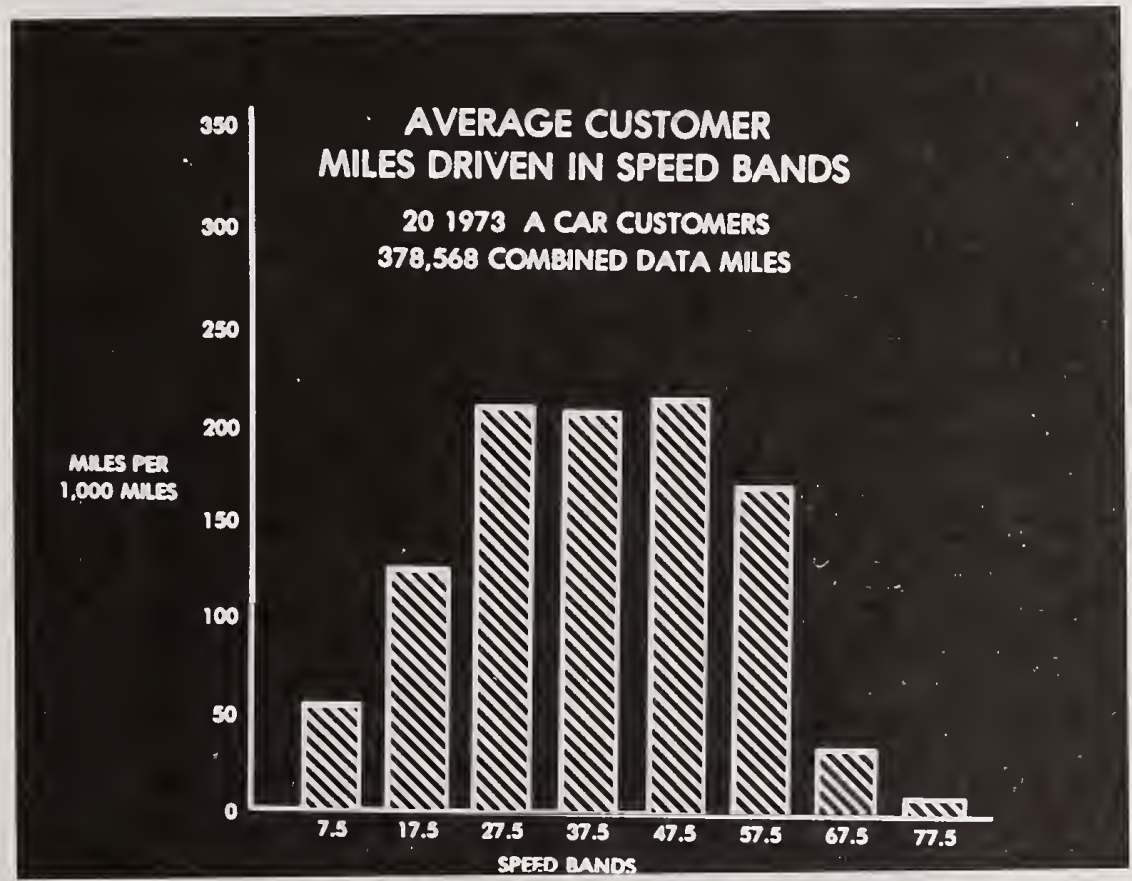

Figure 9 
In Figure 10, the data has been analyzed to provide a statistical estimate of the number of brake stops in various kinetic energy bands that the 80th percentile vehicle will experience. This statistical estimate, based on a rather small sample, indicates that $80 \%$ of the customer population makes fewer brake stops in each kinetic energy range than the graphed values.

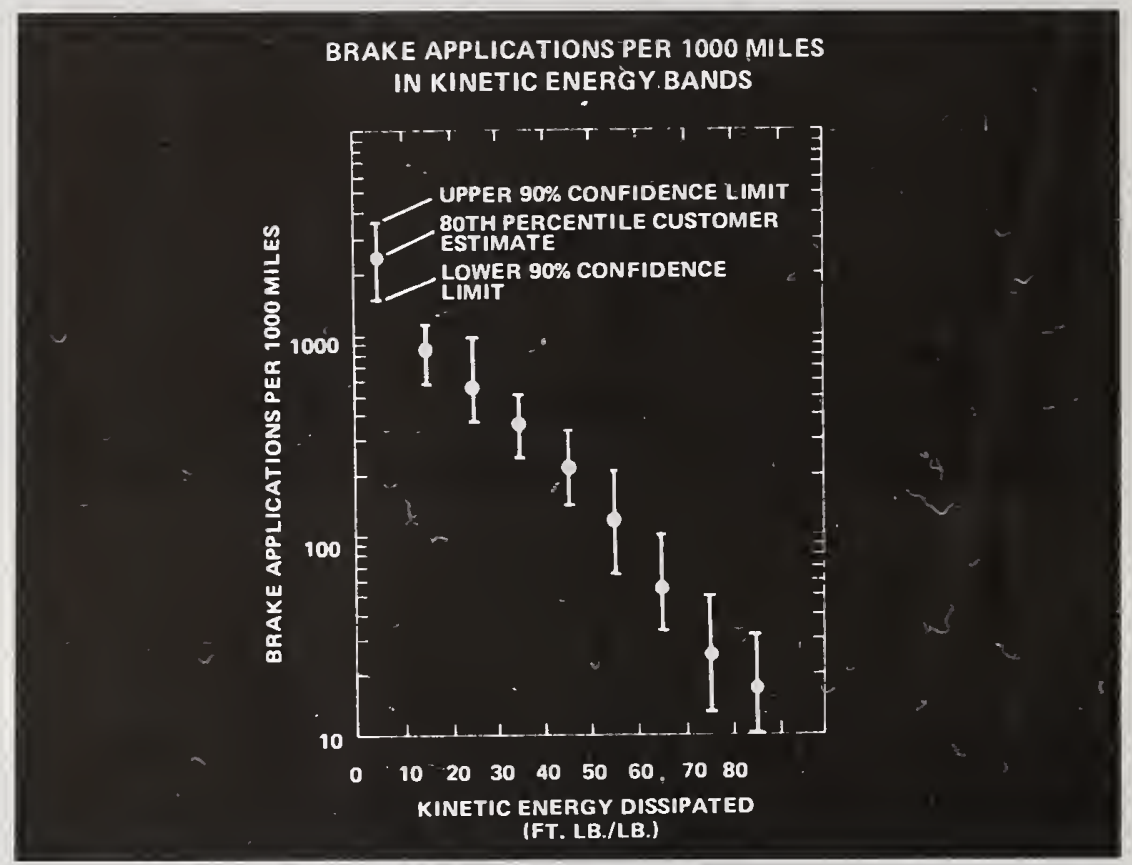

Figure 10

Since beginning this type of program in late 1973, 757 channels of this type of instrumentation have been installed in over 100 different randomly selected customer vehicles throughout the country. over this period, more than 2.5 million vehicle miles of data have been collected, analyzed, and used to design and develop products to have durability that is well matched to the customers' needs. These data are the basis for various laboratory tests and design analysis.

In addition to the direct instrumentation measurements, surveys and inspections of customer vehicles are frequently conducted to add to our understanding of vehicle usage in the hands of the customer.

For example, recently we conducted a survey to determine how brake pads and shoes wear on customer vehicles. To accomplish this, we replaced the brake pads and shoes (Figure 11) on 200 customer owned, randomly selected 1974 and 1975 cars. The friction materials remaining on their pads and shoes were measured, and from measurements and mileage on the vehicle, we were able to project the mileage at wearout. 


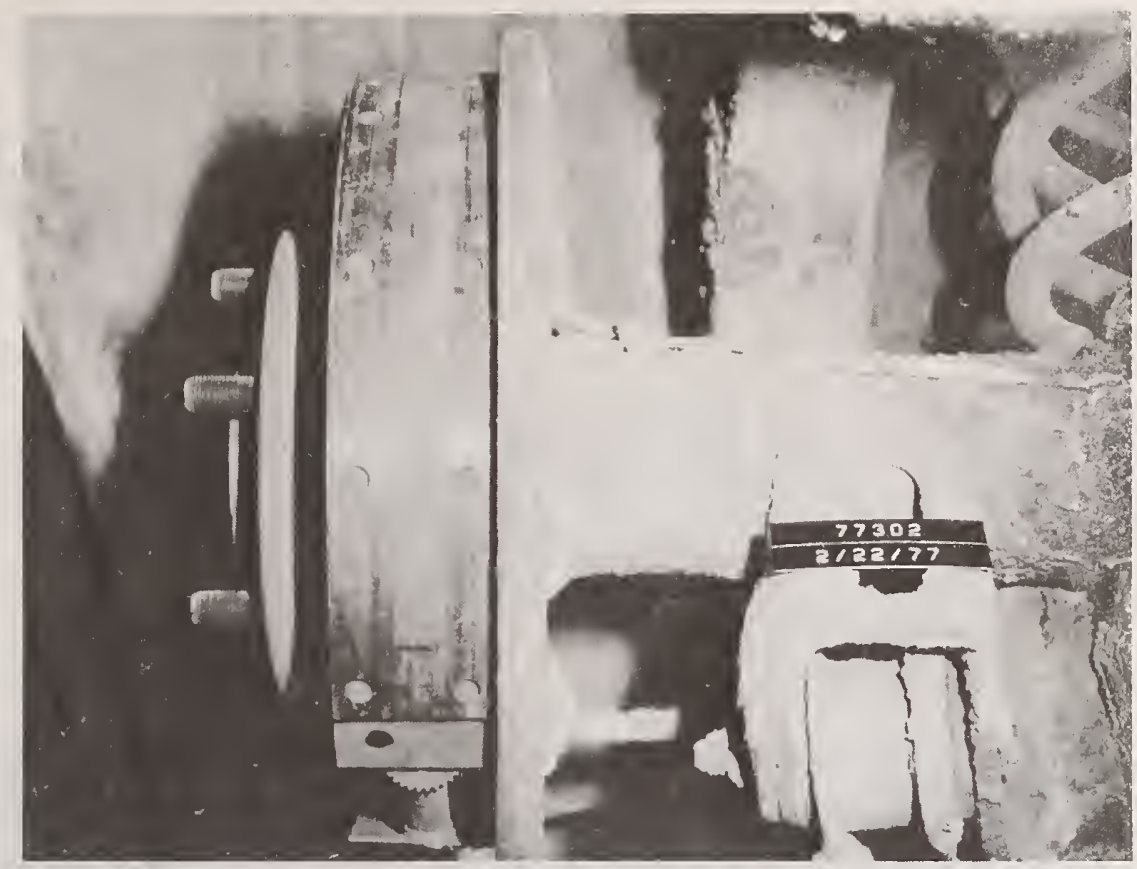

Figure 11

The distribution of projected wearout life from this sample of 200 car owners is shown in Figure 12.

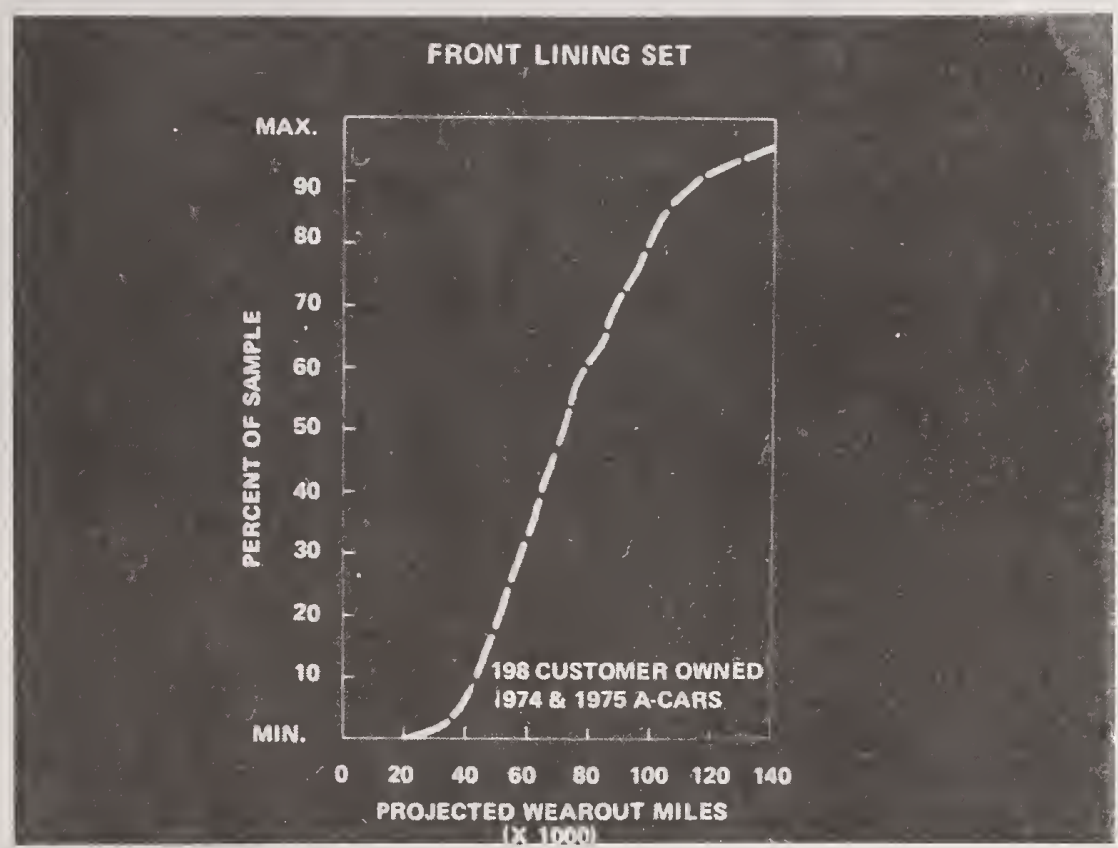

Figure 12 
We have also made similar friction material measurements on vehicles where we are measuring their brake usage with instrumentation in order to determine the variables that are related to brake wear.

The relationship between projected brake wearout mileage and the average kinetic energy dissipated per mile by a sample of 1973 "A" car customers is shown in Figure 13.

Using these data, we now design vehicles with an improved understanding of the operation they will be exposed to by the customer, and we now have a family of passenger car durability schedules that are factually related to customer usage and allow prediction of the product endurance in the hands of the customer.

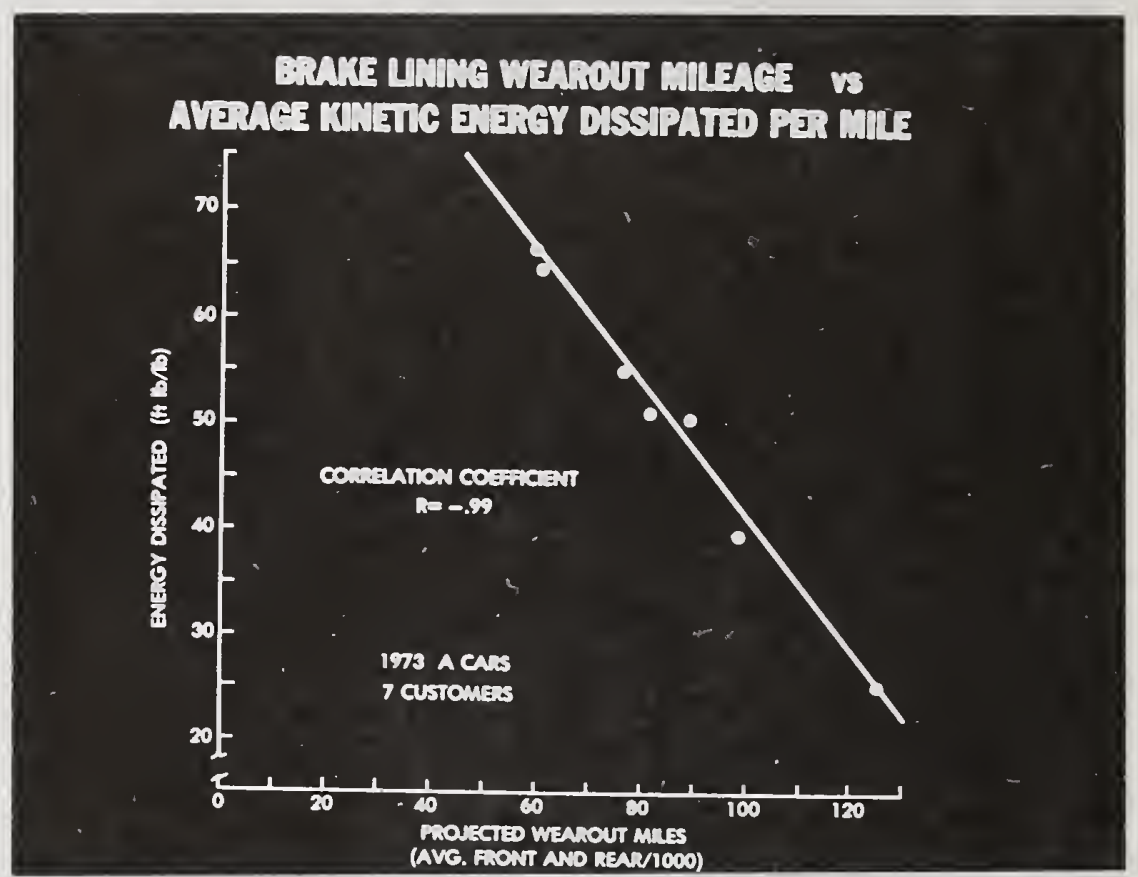

Figure 13 
The load spectrums measured on customer vehicles are used in the finite element design of new vehicle structures to achieve a desirable balance of stress distribution with the least massive structure (Figure 14). Estimates of production process variations that affect component strength must be included in these analyses. When prototypes of the new design are available, the presumed load spectrum and calculated strain values are refined with road test measurements on the customer related Proving Ground durability schedules.

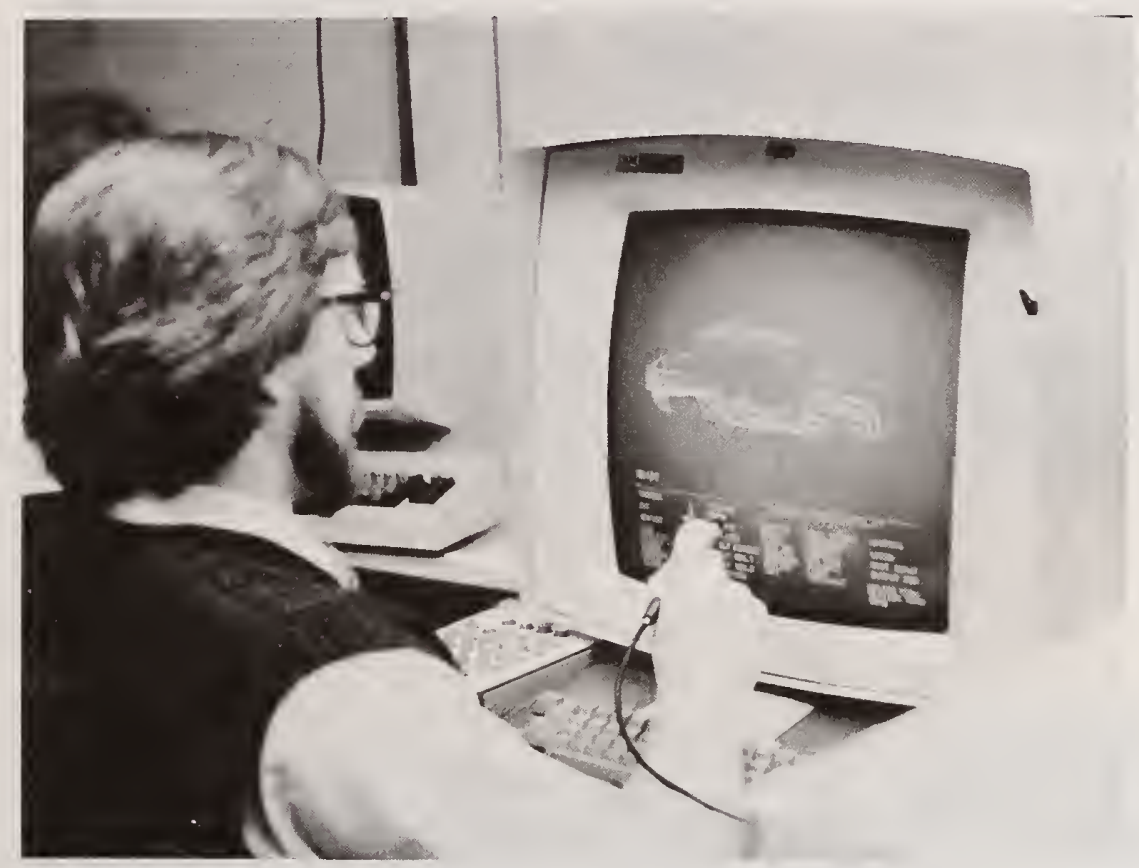

Figure 14

Corrosion and other aging processes are difficult to evaluate in a short test time simply because they are time dependent chemical processes; however, an approximate precursor of customer vehicle corrosion has been reasonably successful.

Vehicle and component corrosion rates are accelerated by exposing them to the road salt and mud comparable to the northeastern United States, and periodically placing them in a warm, humid chamber to speed-up the chemical processes (Figures 15-17).

The corrosion of test vehicles and standard steel corrosion coupons attached to them (Figure 18) has been correlated with similar customeroperated vehicles also with corrosion coupons in various United States and Canadian locations. 


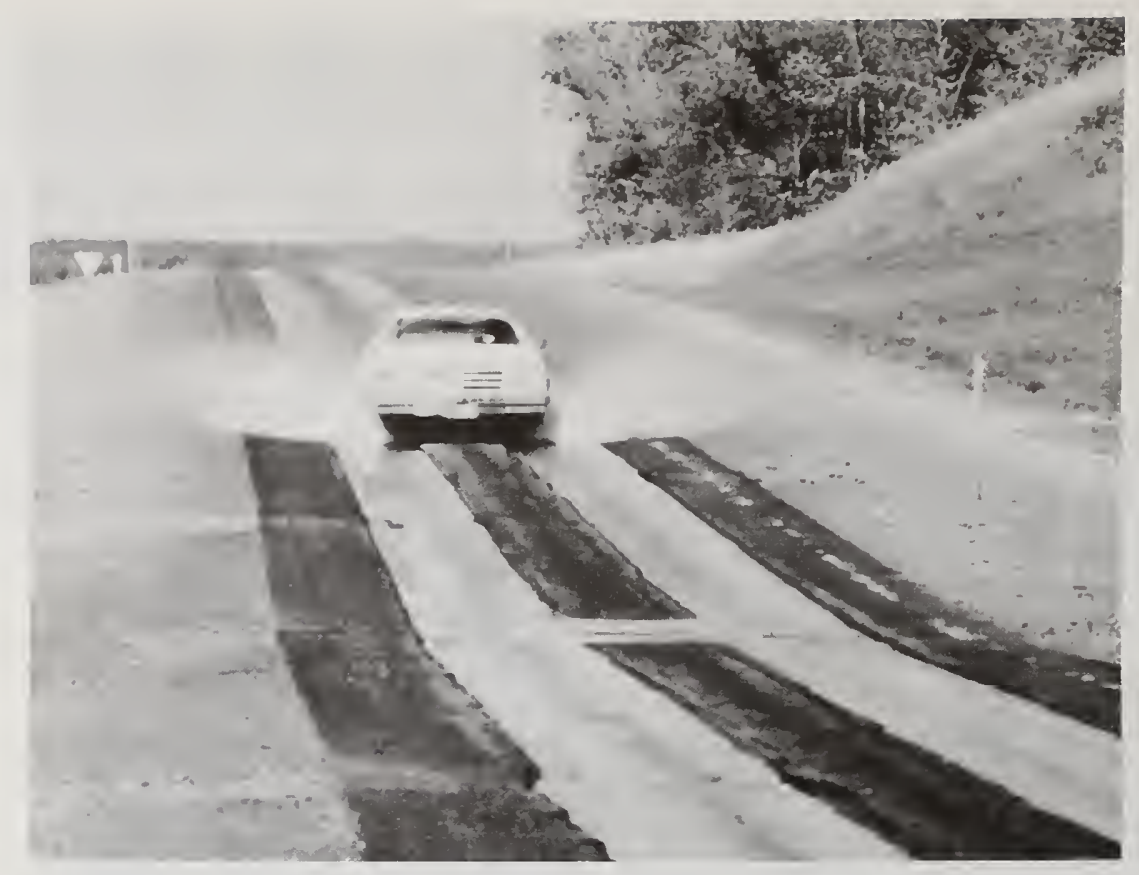

Figure 15

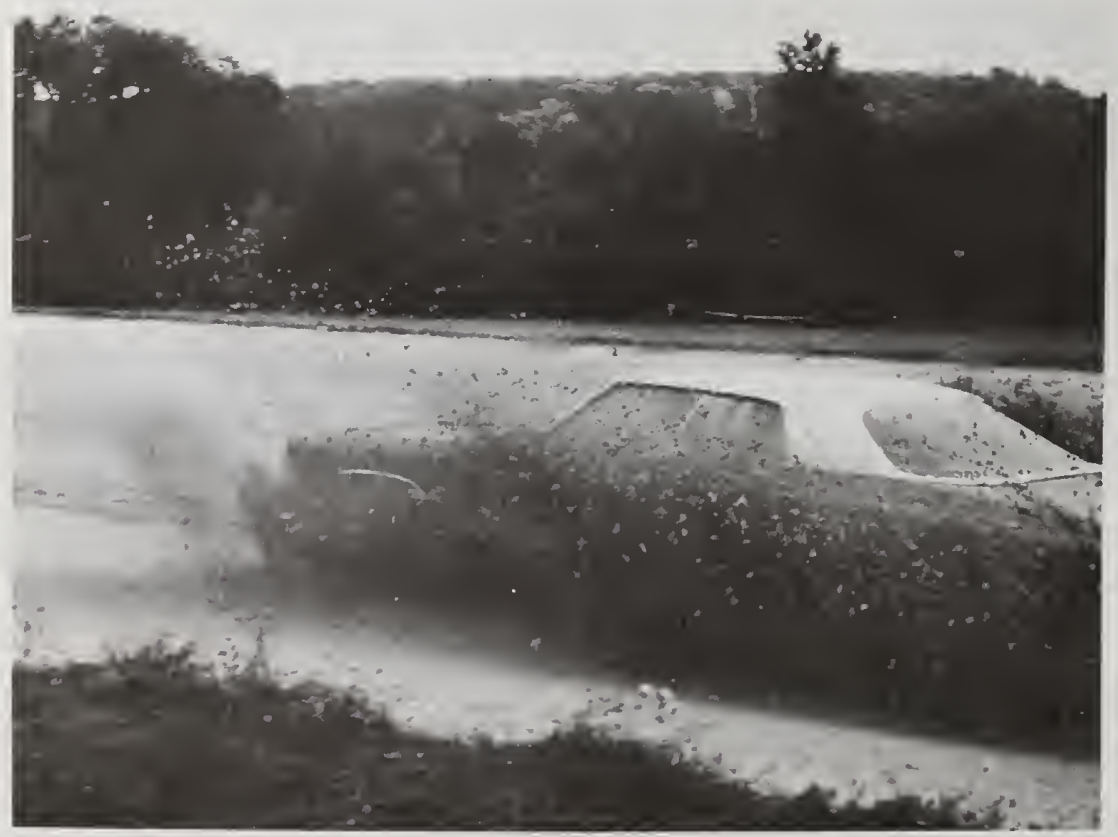

Figure 16 


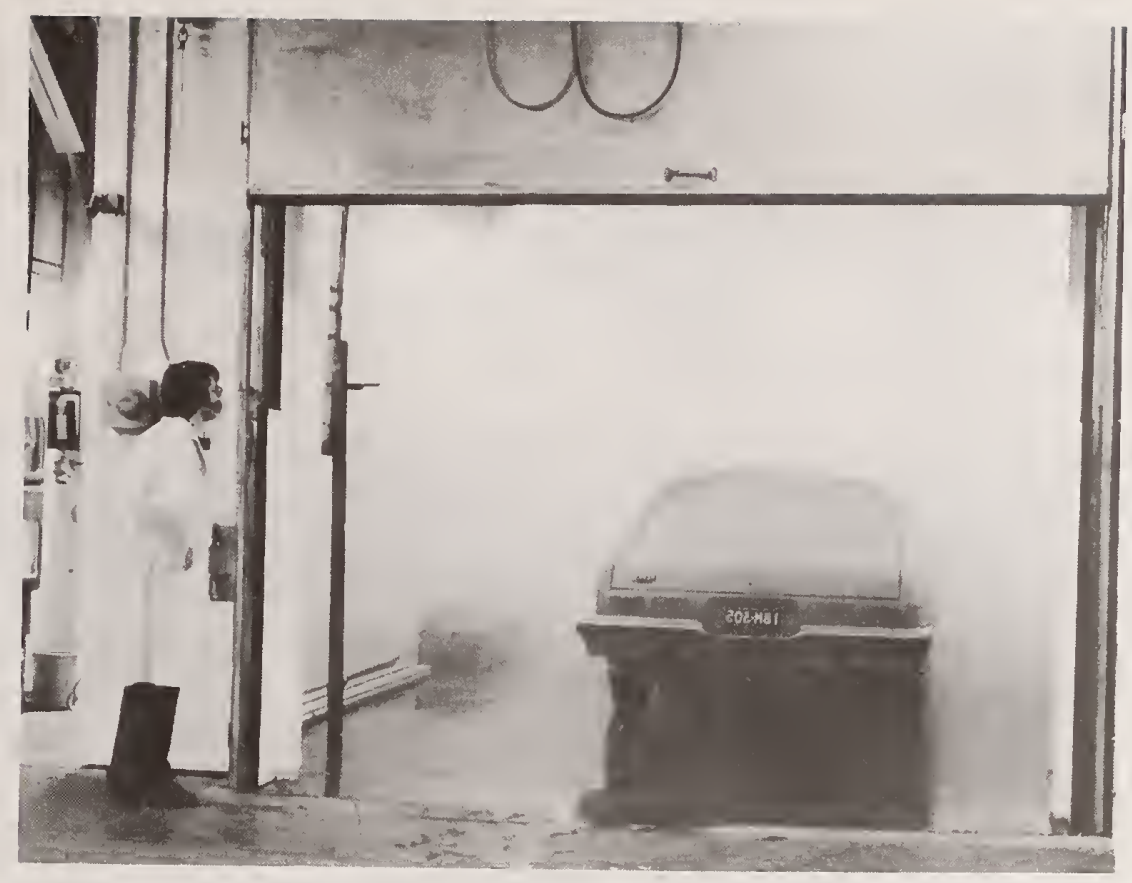

Figure 17

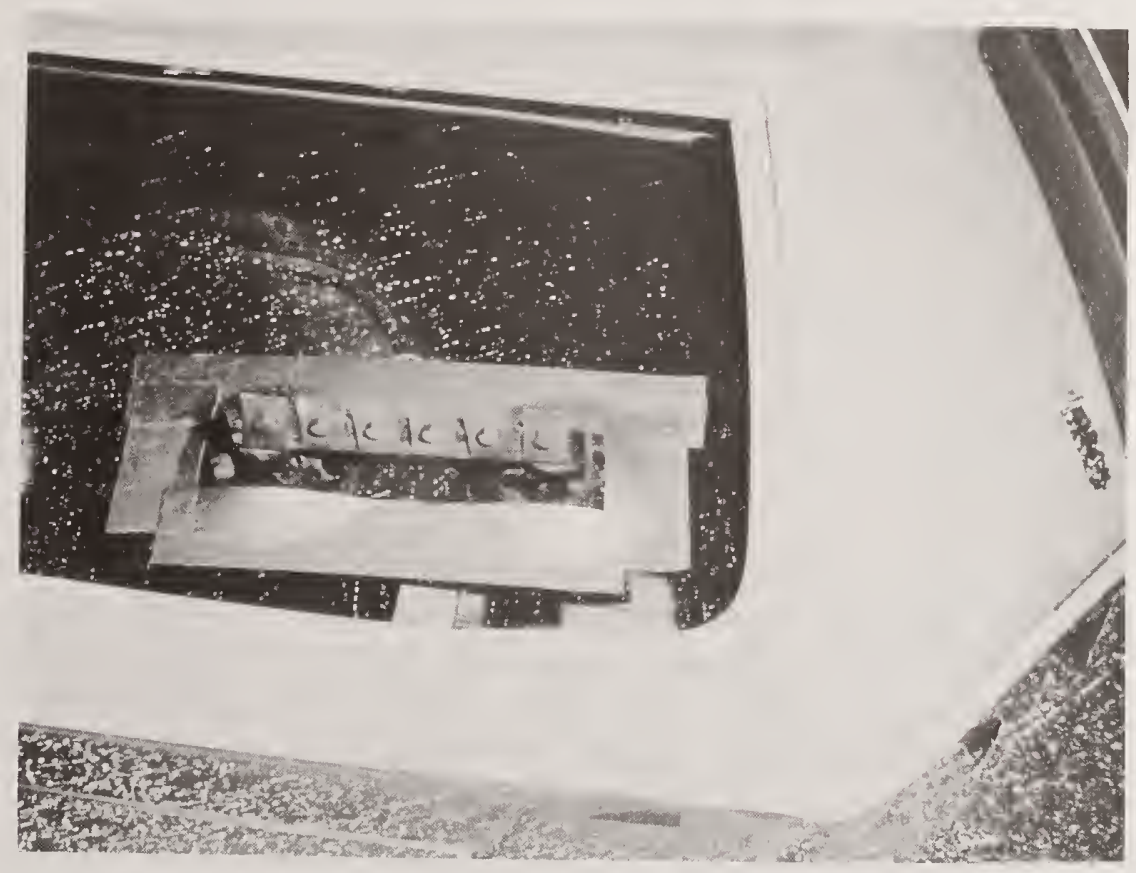

Figure 18 
You are no doubt aware that General Motors has removed several hundred pounds from many of the vehicles in the past two model changes to improve fuel economy. My discussion indicates the extent of the engineering that went in when the pounds came out.

I suspect many of the techniques we are using today, such as cumulative damage analysis and finite element analysis, were pioneered by people attending this symposium. We appreciate these new tools; they enable us to do a more precise job of engineering durability into our products today than was possible a few years ago.

It is General Motors' plan to apply all available technology that will make it possible to produce vehicles that have a balance of emission control, fuel efficiency, durability, utility, performance, safety, comfort, and convenience that is acceptable to the regulators, and desirable and affordable to the consumer. 


\author{
P. A. Engel \\ IBM Corporation \\ System Products Division \\ P.O. Box 6 \\ Endicott, NY 13760
}

Abstract: In many input-output devices, such as printers, impact combined with sliding between mechanical components is the chief cause of wear. This paper first describes the phenomenological aspects of this type of wearing and then analytical formulation is discussed. Wear prediction for industrial design purposes hinges on the recognition of the wear mechanism and on the determination of the wear parameters by simple tests. Computation of the contact loading intensity and of the wear formation geometry are the analytical aspects of the wear prediction process.

Introduction

The input-output devices used in business machines (such as computers) have stringent requirements for durability and long wearlife. As a result they place special requirements on the mechanical designer. Two of the principal types of designs that are involved are classified as (1) printer and (2) carriage (shifting) mechanisms. Carriage devices operate primarily on rolling and sliding bearing elements, with various gear-type transmissions. In these devices, hydrodynamic or boundary lubrication is often possible, loads are usually moderate and predictable, and a choice of materials can be made by more-or-less conventional wear-test methods.

In mechanical printers the tribological (relating to friction, wear, and lubrication) problems tend to be unique. Impact loads, aggravated by associated sliding, abound. Lubrication is often severely limited or excluded. The contact geometry, typically confined with in narrow limits, gives rise to large local (contact) stresses. A variety of wear mechanisms have been noted depending on the materials that are used.

The success of a wear design is dependent on recognition of the correct wear mechanism in the prototype and on simulation of the relevant loading parameters to be incorporated in a "robot" wear test procedure. Based on these preliminary investigations, the quantitative engineering wear predictions may be construed and eliminate the need for generating expensive prototype test data [1] .

We should consider a few of the concepts which are helpful to aid in the further discussion of wear in general. 
One-body-wear is a terminology applied to the significant wear on only one of the two repetitively impacting solid surfaces. Two-body-wear is defined as the simultaneous wearing of both surfaces.

The three basic contact modes (sliding, rolling, and impacting) are often present in hybrid (compound) forms; in fact, compound impact with sliding is the most damaging wear mode in unlubricated contacts. In comparison, pure, normal impact is often more severe than compound impact in lubricated contacts.

The wear mechanism, a physical phenomenon, usually suggests an empirical formulation, such as an equation connecting wear volume $W$ with contact force $P$ and the number of cycles $N$,

$$
W=K P^{c} N
$$

for a given range of $P$. Here, $K$ and $c$ are experimental constants.

The following descriptions are examples of a few basic cases of printer wear analysis.

\section{Type Wear Against Paper or Ribbon}

The first description is the development of a wear prediction formula and a preliminary test procedure for the typical impact wear application of metal type [2] repetitively striking against paper or ribbon. We are considering computer type that was designed for impact on paper supported on a platen. The impact occurs "on the fly" to create a faster printing operation; this wear is a compound impact-withsliding contact mode.

The impact force of this type can be measured by a transducer replacing the platen. This condition, of course, somewhat alters the impulse; however, in the test cases we could verify the fact that an approximate sinusoidal force-time relationship is produced which is unchanged as repetitive impacts create wear on the type.

The wear process results in the smoothing of the metal surface. For a metal surface to be resistant, it has to be hardened or plated with a hard layer such as chrome. The process of printing causes this hard surface to strike against a constantly changing, nominally soft paper surface, creating a "one-body wear" situation for the harder contact partner which is the metal. Close investigation indicates an abrasive wear mechanism operative, activated by occasional fibrous matter in the paper.

The following description briefly outlines the test procedure applied in our laboratory. The abrasive wear constant $K$ of the paper was found by special sliding wear tests. A large, 1.2 $\mathrm{m}$ diameter drum tester [3], with a cylindrical surface had the paper stretched over its circumference. A ball specimen of the type material was 
pressed against it with fixed force $P$. While the drum was rotated, the ball holding fixture was also given a small transverse motion so as to touch consecutively new areas of paper. The test facilitated evaluation of the abrasive wear constant

$$
K=\frac{H_{m} W}{P x} \text {, }
$$

where $H_{m}$ is the hardness of the type and $x$ is the total sliding distance.

The constant $K$ was found quite different for the various papers (in a range of two orders of magnitude) with an approximate $10^{-6}$ as an average value. This value is probably three orders of magnitude lower than that commonly encountered for metals. In addition, there is a great deal of dependence on conditions such as temperature, humidity, and others. More wear was found when the type was attached to a stiff cantilever which resisted bending in the tangential plane during impact. A freely rotating, "point-mass" style of type showed less wear.

Proceeding from the phenomenological description to the wear analysis we consider a tangentially spring-restrained type slug (containing a print character) impacting a platen-supported layer of paper. A compound impact is generated by the relative sliding speed $v$ of the platen (to which the paper is assumed to adhere) with respect to the normally approaching type. Consider an individual impact after the first contact with the paper. The type is gradually accelerated by the platen in the $x$-direction, while it slips. If the impact is of sufficient length, the horizontal momentum exchange is completed at some time $\bar{t}<t^{*}$ ( $t^{*}$ being the contact time). At this time, adherence, in the tangential sense, has occurred and slipping has stopped.

The slip during an infinitesimal time $d t$ is $d X=v$. $d t-d x,\left(0<t<\bar{t}<t^{*}\right)$. Assuming that wear is only accrued during slipping, but not in the adhering phase, the infinitesimal wear $d W$ caused by slip $d X$ can be formulated if an empirical wear mechanism equation is available. For a linear abrasive wear mechanism, such as the one involved in Eq. (2), we can write

$$
d W(t)=\frac{K P(t) \cdot d X(t)}{H_{m}}
$$

The impact force may be related to the tangential position $x$ of the slug at time t by its equation of motion. Considering the type slug as a point mass $m$, acted upon by the Coulomb friction force, we obtain the differential equation

$$
m x=\mu P(t)-k x, \quad(0<t<\bar{t})
$$


with initial conditions $t=0 ; x=\dot{x}=0$. Here $\mu$ is the coefficient of friction and $k$ is the spring restraint of the type holding member.

Integration of Eq. (4) is facilitated by the pulse shape approximation $P(t)=P_{0}$ $\sin \pi t / t^{*}$. The wear per cycle may be integrated over the impact duration, yielding

$$
\Delta W=\int_{0}^{t^{*}} d W=\int_{0}^{i} d W=\frac{K v t^{*} P_{0}}{\pi H_{m}} C(f)
$$

where $f=\pi m V / \mu P_{0} t^{*}$ is the "slip factor." For the simple case of unrestrained type $(k=0)$,

$$
\begin{aligned}
C(f) & =f / 2, \quad(0<f<2) \\
& =2(1-1 / f), \quad(f>2)
\end{aligned}
$$

It is noted that the value of $f$ is between 0 and 2 for adherence occurring during impact $\left(\bar{t}<t^{*}\right)$, while $f>2$ means continual slipping during the whole impact duration.

The linear wear model suggests that the final wear occurring after $N$ load cycles will be $W=N . \Delta W$. The depth of wear over the type character may be obtained by averaging a depth $h$ uniformly over the impacted surface area.

An examination of Eq. (5) shows that the wear is proportional to the sliding speed $\checkmark$ and, also, to the normal impulse (which, for a sinusoidal pulse is $2 P_{0} t^{*} / \pi \cdot$ ). The hardness of the type is critical, and its role is wear resistance. Of course, when a hard plating is worn off, wear resistance is dictated by the sublayer.

The above wear formulation has proven quite reliable, and it allows a rapid evaluation of various prospective materials to be used for type. The preliminary testing includes hardness test for the metal, a sliding wear test for the friction coefficient and the abrasive constant, and a relatively simple impact robot test to examine the relevant wear mechanism.

Several, similar type elements have been analyzed using this method. An example is the wire printer [1] where the wear on the thin wire tips is due to penetration slip.

The wear of metal-plated plastic type depends on the ductility of the plating and the bond strength of the metal-plastic junction [4]. When the ductility and bond strength are sufficient, the abrasive action of printing can be evaluated by the same method as for solid metal type. Numerous cases for wear are listed in Ref. 4. 
Repetitively impacting mechanical components often develop fretting wear which is a hybrid mechanism. In a simple form of this wear mechanism the metal surface would be oxidized and the oxide layer removed by successive impacts, which exposes pure metal; the process is then repeated, resulting in wear. When the tangential impact speed component is small (small oscillations are often possible due to finite sideways constraints), the oxidized debris can remain for a longer period of time in the contact area, and it assumes a protective role. A large tangentialimpact speed component tends to remove the debris that is generated. Thus, for dry contact, the conspicuous difference between normal impact and sliding impact appears to be manifested in the amount of "scrubbing action" involved. Another way of accounting for differences between normal and compound impact is to consider the shear stresses caused by the two processes. The normal impact tends to cause subsurface damage, while the compound impact yields maximal shear stresses on the surface. In addition, slipping tendencies increase with the relative sliding speed $v$. The two quantities which combine to cause wear damage are contact stress and slip.

Studies of compound impact wear tests resulted in the observation of a "zero wear limit," similar to the case of sliding wear [5]. The zero wear limit is reached in $N_{0}$ load cycles when the surface geometry has been distinguishably changed from the original. This change has been arbitrarily defined as the depth of wear corresponding to half the original peak-to-valley finish, i.e., $h_{0}=\delta / 2$.

An experimental-analytical investigation [1] found the following zero-wear formula for several steels and aluminum alloys impacted in the elastic contact stress range:

$$
N_{0}=\frac{1}{1+\beta} \quad\left(\frac{\gamma_{\sigma} \gamma}{\sigma_{\max }}\right)^{9} \cdot 2000
$$

In the above formula, $\beta$ is the relative surface damage contribution, defined as the ratio of surface damage to subsurface damage. The damage quantities are themselves time-integrals of the maximum surface or subsurface shear stress $\left(\tau_{1}\right.$ and $\tau_{2}$ respectively). $\gamma$ is a wear factor, with a value of 1.1 for those steels referred to above. $\sigma_{\max }$ is the Hertz pressure.

After the zero wear limit has been determined, one point of the impact wear curve is fixed. The curve, usually given in a double logarithmic graph of wear depth $h$ vs. cycle number $N$, can be established for the gradual wear processes with only one more constant outside of $\gamma$; this can be the parameter $c$ in Eq. (1). 
At this point wear may be considered an impact-stress-dependent geometrical process, resulting in a gradually widening wear scar. For simple indenters (e.g. sphere vs. plane) and a suitable contact theory (e.g. Hertz's), the widening of the wear scar may be mathematically related to the number of cycles. The experimental wear curves in a log-log representation show a typical slowly declining slope, and this variation can be also shown by use of the theoretical model.

It is possible to express a nondimensional geometric wear-scar parameter in terms of the number of cycles. The method found useful in the analysis of impact wear situations recognizes that the corresponding physical wear curves may be obtained by shifting the nondimensional curves with the severity of the loading.

For example, consider the one-body wear of a "softer" plane by a hard (i.e. nonwearing) sphere of radius $R_{1}$. The spherical-shaped wear scar on the plane may be described at any stage of measurable wear by two geometric data. The nondimensional geometric parameter $p=R_{1} / R$ (where $R$ is the changing meridional radius of the wear-scar curvature) may be one of the two data. Another one of the two parameters (say the crater radius) will be completely dependent on $p$ if the momentum of impacts remains constant, and the impact stress continues to follow the Hertz theory, we have the following relation for the hard ball vs. soft plane, based on Eq. (1):

$$
N=\frac{\rho / \rho_{0}}{\left(\frac{1+\rho}{1+\rho_{o}}\right)^{\frac{8+9}{5}}} \cdot N_{0}
$$

where $N_{o}, p_{0}$ are the zero-wear-point coordinates. The conversion from $p$ to "physical" wear depth $h$ is, by use of geometry and Hertz theory:

$$
h=-C_{s} \rho(1+\rho)^{-4 / 5}
$$

where

$$
C_{s}=0.77\left(V^{4} m^{2} E_{r}^{2} R_{1}^{-1}\right)^{1 / 5}
$$

and $V$ is the impact velocity, $m$ the mass, $E_{r}$ the reduced modulus of elasticity.

For the various descriptive parameters $\left(\delta, V, m, E_{r}, R_{1}\right.$, etc. involving the surface, the loading, the geometry and the material), not only is the zero-wear-point different, but, $C_{s}$ the "scale" is also changed. Therefore, the typical slowly-levelling impact wear curve can be basically shifted to the left with the increased severity of wearing conditions. With this method families of impact wear curves can be 
generated for a given industrial design situation. As a result, economically feasible, competitive designs can be selected based on a predictive theory, reducing a long and costly test period.

\section{References}

1. P. A. Engel, Impact Wear of Materials, Elsevier, New York, 1976.

2. P. A. Engel and R. G. Bayer, "Abrasive Impact Wear of Type," J. Lub. Tech., Trans. ASME, Vol. 98 (1976), pp. 330-334.

3. D. D. Roshon, "Testing Materials for Evaluating Wear by Paper," Wear, Vol. 30 (1974), pp. 93-103.

4. P. A. Engel et al., "Review of Wear Problems in the Computer Industry," ASME-ASLE Joint Lub. Conf., Kansas City, Mo., Oct. 1977; ASME Paper 77-Lub-4.

5. R. G. Bayer et al., "Engineering Model for Wear," Wear, Vol. 5, (1962), Pp. 378-391. 



\section{SESSION IV}

\section{PRODUCT PERFORMANCE \\ - WHY CARE?}

CHAIRMAN: M. R. MEYERSON NATIONAL BUREAU OF STANDARDS 


\author{
Marilyn Doss Ruffin and Katherine S. Tippett \\ Agricultural Research Service \\ U.S. Department of Agriculture \\ Hyattsville, Maryland 20782
}

Abstract: Methodology and results of USDA studies of appliance service life, under one owner, are discussed. Since the 1950's USDA has estimated the retention period of most major appliances by means of actuarial or life tables constructed from ownership and discard data obtained in nationwide household surveys. The most recent such estimates are based on a 1972 survey of 11,696 households and include seven major consumer appliances: range, refrigerator, freezer, dishwasher, washer, dryer, television. The best-known use of the actuarial or life table method is, in estimating the life expectancy of persons in the population. The advantages of this method for estimating the service life of appliances are that it minimizes the effect of trends in appliance saturation and population change, minimizes the effect of year-to-year variation in the number of units marketed, and reflects the experience of units remaining in service as well as of those that have been discarded. For life study by the actuarial method, the product must have been on the market long enough for the maximum life span to have elapsed; there must be sufficient numbers in the population to provide a reasonable sample; and the item must be of sufficient importance that the owner-user will be likely to recall the date of acquisition.

Key words: Actuarial table; clothes dryer; consumer appliance retention; dishwasher; freezer; kitchen range; refrigerator; service-life expectancy; television set; washing machine.

Since the 1950's the U.S. Department of Agriculture has published actuarial estimates of the average "service-life expectancy", under one owner, of major consumer appliances as part of a program of research contributing to the understanding of family use of resources $(1,2,3,4$, $5,6,7,8)$. The estimates represent the period of retention by the household rather than the mechanical life of the appliance and pertain only to user-owned household items. Separate estimates were made for equipment obtained new and for that obtained used. The most recent such estimates were based on a 1972 nationwide survey and include seven major appliances: range, refrigerator, freezer, dishwasher, washer, dryer, television (7).

A number of conceptual and methodological problems had to be resolved when USDA began the studies of service-life expectancy of household 
appliances: how service life should be defined: choice of method for estimating service life; and specification of population, both of households and of appliances. Following a discussion of these questions the resulting estimates and variation by household characteristic will be presented.

\section{Definition of Service Life}

The first problem was to define service life in a way that would be meaningful with respect to decisions families make about resources and in a way that would be measurable. For budgeting purposes, families need to know probable times of replacement for appliances. Families often discard an appliance before the full potential for use is exhausted, so the mechanical life of the appliance is not the piece of information that the family budget-maker needs. Families may replace or dispose of an appliance because it has ceased to function and cannot be repaired, or for a variety of other reasons: availability of new convenience features, changes in equipment needs over the family life cycle, a move to a new residence, or marginal or unreliable performance of the item. Furthermore, to determine which appliances had exhausted the full use potential and locate them and count them would be virtually impossible. The definition of service life used in the USDA studies is the expected period of retention by one owner--the time elapsed from acquisition to removal from use. Removal from use was defined either as disposal by the household or storage of the appliance with no specific plans for returning it to use. The length of the retention period can be determined by questions that are direct, simple, and factual in nature--no subjective evaluation of the future serviceability of the discarded appliance is necessary. The service life or expected retention period in the household was estimated separately for items obtained new and items obtained used. Adding the new and used retention periods will not yield the total mechanical life of the appliance, however; some appliances remain with the original owner until the mechanical life is exhausted, while others may change ownership several times. The retention period estimated by USDA pertains only to equipment owned and used by the same household, because an estimate based on family-owned items best serves family budgeting needs.

\section{Method of Estimation}

A second problem was how to make estimates that would be useful into a future period. The most direct way might be to use the average age of currently-owned appliances or of appliances discarded during the previous year. However, both methods would bias the estimate toward a lower average age if there has been a long-term increase in the number of households or in the proportion owning appliances; either increase would result in over-representation of appliances of low age in the sample. In addition, the average age of currently-owned appliances is always somewhat lower than their age when taken out of service. 
The method selected by USDA to estimate the retention period in the household is the actuarial or current life table method. The estimation procedure reflects the combined current experience of all age groups in the appliance population; it reflects the longevity of those that continue in service and of those that have been removed from service during the recall interval. The best-known use of the actuarial or current life table method is in estimating the life expectancy of persons in the population. The method also is a valuable tool for the study of consumer product data, because it minimizes the effect of long-term trends in the number of households and the percent who own appliances; minimizes the effect of year-to-year fluctuations in the number of units marketed; and reflects the survival experience of items remaining in service as well as of those that have been removed from use. The life table is a convenient method for summarizing the mortality experience of a population, providing concise measures of the longevity of that population. Basically, there are two types of life tables--the cohort life table and the current life table or actuarial table. Both methods are based on observed probabilities of surviving consecutive intervals of the lifespan. The cohort table is longitudinal, following a particular cohort (a group beginning life or other condition at the same time) from birth (or onset of the condition) to death (or termination of the condition). The resulting life-expectancy figure applies only to the one cohort observed; and, because the entire population group must have lived out its lifespan before the cohort table can be calculated, the method is useful mainly to those interested in the historic perspective. The current life table or actuarial table, which has been used by USDA to estimate the appliance retention period, is a cross-sectional method. The estimation is based on the observation at one point in time (or in one time period) of many cohorts. The "life"-expectancy estimate derived by that method reflects the combined current experience of the many cohorts that make up the population. Reference of application of the method to industrial equipment dates back many years.

\section{Study Population}

Once the questions of definition and method were agreed upon, other questions had to be resolved regarding the population of households to be surveyed and the selection of appliances to be studied. For calculation of the expected household retention period for an appliance, data are needed on the number in the appliance population that have been discarded during a recent interval of time and the number that have been retained in the household. Retention and discard information are needed for each age group represented in the appliance population distribution in order to compute age-specific "survival" rates. The survival rates are used to construct an actuarial table for a hypothetical cohort of appliances, whose total life is a composite reconstructed from the various age groups' survival of the recall interval. Life tables for the human population are constructed from census data, from public records of births and deaths, or from insurance statistics. 
Since no such sources of data are regularly available for the appliance population, special surveys must be conducted in order to construct life tables for appliances. The sample must be quite large, as only a small percentage of surveyed households (generally 5 to 10 percent) will have discarded any particular appliance during a one-year recall interval, and the actuarial table calls for discard information on all age groups in the appliance population distribution. In addition, there is wide variation in the age at which appliances are discarded. Many are discarded quite early in the life span, often in connection with a change in the household's place of residence; others are quite longlived.

For the collection of data from which actuarial tables could be constructed with reasonable reliability and which would represent the experience of all households in the country, USDA contracted with the U.S. Bureau of Census. Most recently, a questionnaire was attached to the July 1972 Quarterly Survey of Consumer Buying Expectations; 11,696 interviews were obtained. All households (renters as well as owners) were asked questions about appliances they currently owned or which they had removed from use within the past year. Even if a household did not currently own an appliance, interviewers were to ask about the past year's removals so that results would reflect the experience of all user-owned household appliances--not just discards due to replacement. An owned item was considered to be currently in inventory if it was in use in the household's main residence or was temporarily out of service but intended for future use. Landlord-owned items were not covered by the survey. For each appliance, the household respondent was asked if the household owned one; and if so, when had it been acquired. In addition, certain appliance classification information was recorded so that length of use for new and used items could be estimated separately and so that product characteristics (such as gas vs. electric, built-in vs. portable or freestanding) could be considered. Certain information about the household also was recorded.

Criteria for identifying appliances suitable for life study by the actuarial method were established through methodological studies: the product must have been on the market long enough for the maximum lifespan to have elapsed; there must be sufficient numbers in the population to provide a reasonable sample; and the item must be of sufficient importance that the owner-user will be likely to recall the date of acquisition (3). With these criteria, seven appliances were selected for study in 1972: range, refrigerator, freezer, washer, dryer, dishwasher, and television. Service-life estimates had previously been made for all but the dishwasher, but needed to be updated to reflect the considerable changes that had occurred since the 1957-61 period: marked increases in saturation levels for some appliances; the impact of innovations such as frost-free refrigerators, self-cleaning ovens, and color televisions; changes in family characteristics such as income level, mobility, and employment of wives. 
Sufficient data were obtained from the 1972 survey to develop actuarial tables and service-life estimates for 18 appliance categories $(7,9)$. The average service-life expectancy under one owner for items acquired new ranged from a high of about 20 years for freezers to a low of about 11 years for black and white television sets and for washing machines (see table).

Table -- Selected Major Appliances: USDA Estimates of Service-life Expectancy Under One Owner ${ }^{1}$

\begin{tabular}{|c|c|c|c|c|}
\hline \multirow{2}{*}{ Appliance } & \multicolumn{2}{|c|}{ Obtained new } & \multicolumn{2}{|c|}{ Obtained used } \\
\hline & 1972 survey & prior survey ${ }^{2}$ & 1972 survey & prior survey $^{2}$ \\
\hline & years & years & \multirow[t]{2}{*}{ years } & years \\
\hline \multicolumn{4}{|l|}{ Kitchen range: ${ }^{3}$} & \\
\hline Electric....... & 12 & 16 & 6 & 8 \\
\hline Gas............ & 13 & 16 & 7 & 9 \\
\hline Refrigerator...... & 15 & 16 & 7 & 8 \\
\hline Freezer......... & 20 & 15 & 9 & 11 \\
\hline Dishwasher ${ }^{4} \ldots \ldots$ & 11 & - & 7 & - \\
\hline Washing machine ${ }^{5}$.. & 11 & 11 & 5 & 5 \\
\hline \multicolumn{5}{|l|}{ Clothes dryer: } \\
\hline Electric....... & 14 & 14 & 5 & - \\
\hline 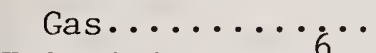 & 13 & - & - & - \\
\hline \multicolumn{5}{|l|}{ Television set: ${ }^{6}$} \\
\hline Black and white. & 11 & 11 & 5 & 6 \\
\hline Color........... & 12 & - & - & - \\
\hline
\end{tabular}

1 Indicates how long, on the average, households keep each appliance --not how long the appliance could have been made to last. New and used are not additive. Based on actuarial analysis of household survey data.

2 Survey years: kitchen range, 1959; refrigerator, 1960; freezer, 1961; clothes dryer, 1961; washing machine, 1957; television set, 1960.

3 Freestanding only.

4 Built-in and portable.

5 Automatic.

6 Excludes portables under 12 inches. 
For items acquired used, the freezer again had the longest retention period and the washing machine had the shortest. Although figures suggest that gas ranges may have longer household service-life expectancy than electric ranges, and that electric dryers may be kept longer than gas dryers, tests of significance did not reveal any differences significant at the .05 level. Neither a pattern of lengthening nor of shortening retention period was observed when results from the 1972 survey were compared with earlier USDA surveys. Estimates for four of the seven items acquired new for which comparison was possible were about the same as the most recent previous estimate. Two items--gas and electric ranges--appeared to have a shorter retention period than previously, and one item--the freezer--appeared to have a longer one; however, these apparent differences were not significant at the .05 level. All items acquired used for which comparisons with earlier years were possible had slightly lower service-life expectancies than previously. However, these apparent differences were generally within the range of 2 standard errors, and therefore individually not significant; nevertheless, such uniformity in the direction of change may indicate a trend toward a shortening period of use of used appliances by one household.

\section{Explaining Variation in Product Retention}

The estimates from the 1972 survey that were published in 1975 (7) are averages for all households in the population, and of course conceal considerable variation among families. The actual length of time that individual families held on to their various appliances ranged from less than 1 year to about 40 years. Data were insufficient for constructing separate actuarial tables by family characteristics for individual appliances with reasonable reliability. The dilemma then was how to use what data that had been collected a) to see what characteristics of families might account for variation in the age of the discard, and b) to be able to make concrete statements about variation in the period of retention by families with those characteristics. Pooling standardized data for several appliances overcame the problem of small sample size and permitted use of the actuarial method to develop service-life estimates by family characteristics (8). The disadvantage of pooling data, of course, is that the estimate is not as precise as an estimate for each appliance would be.

Prior to pooling, multiple regression was performed to learn how family characteristics are related to discard behavior. The results were examined to determine which appliances were similarly related to the family characteristics and could therefore be pooled. Ages at discard of major appliances--ranges, refrigerators, washers, dryers, and dishwashers--were found to be similarly related (as indicated by sign and significance of $b$ coefficients) to age of head, household income, and whether the family had recently moved. The age of each owned and discarded appliance was standardized and given a proportionate share of the sample weight for the household. Data were then pooled into two 
groups--one for appliances acquired new and one for appliances acquired used; actuarial tables were constructed from the standardized, pooled appliance age data for all households and for subsets having specified characteristics. The resulting estimates of the household retention period (service-life expectancy) for each subgroup were expressed as a percentage of that for all households. Confidence intervals were computed to provide an indication as to whether the adjusted servicelife estimate for families with each specified characteristic differed from the population average.

Results from pooled standardized data revealed several trends in variation by family characteristics. For appliances acquired new, the greatest variation from the average retention period was among households that had moved in the 18 months prior to the survey; on average, these households shortened the service life of their appliances by 60 percent, compared with all households. Estimated service life of appliances owned by households that did not move in the 18 months prior to the survey was more than three times as long as for households that did move. Retention was shorter for households in which the head was under age 50 than for all households (about 20 percent less) and about 40 percent greater than the average among households whose head was over 50 years. The least variation occurred by income groups, although the service life of appliances owned by households with lower incomes tended to be longer.

The pattern of variation for appliances acquired used was similar to that of appliances acquired new although the amount of variation was less, perhaps because the retention period was shorter.

\section{$\underline{\text { References }}$}

(1) Jaeger, C.M., and Pennock, J.L. Household service life of appliances. Journal of Home Economics, 1957, 49, 787-788.

(2) Jaeger, C.M., and Pennock, J.L. An analysis of consistency of response in household surveys. Journal of the American Statistical Association, $1961,56,320-327$.

(3) Pennock, J.L., and Jaeger, C.M. Estimating the service life of household goods by actuarial methods. Journal of the American Statistical Association. 1957, 52, 175-185.

(4) Pennock, J.L. Planning for the replacement of durable goods. Talk at the Annual Agricultural Outlook Conference, U.S. Department of Agriculture, 1958. (Mimeographed copy available from Consumer and Food Economics Institute, U.S. Department of Agriculture, Federal Building, Hyattsville, Md. 20782.) 
(5) Pennock, J.L. Planning ahead for the buying of major equipment. Talk at the 40th Annual Agricultural Outlook Conference, U.S. Department of Agriculture, 1962. (Mimeographed copy available from Consumer and Food Economics Institute, U.S. Department of Agriculture, Federal Building, Hyattsville, Md. 20782.)

(6) Pennock, J.L., and Jaeger, C.M. Household service life of durable goods. Journal of Home Economics, 1964, 56, 22-26.

(7) Ruffin, M.D., and Tippett, K.S. Service-life expectancy of household appliances: new estimates from the USDA. Home Economics Research Journal, 1975, 3, 159-170.

(8) Tippett, K.S., Magrabi, F.M., and Gray, B.C. Service 1ife of appliances: variations by selected family characteristics. Home Economics Research Journal, 1978, 6 (March 1978, forthcoming).

(9) U.S. Department of Agriculture, Consumer and Food Economics Institute. Life tables for major household appliances--July 1972 survey. 1975. (Copy available from Consumer and Food Economics Institute, U.S. Department of Agriculture, Federal Building, Hyattsville, Md. 20782.) 
APPLICATION OF HISTORICAL REPAIR DATA

IN LIFE CYCLE COSTING ANALYSIS

\author{
S. Wayne Stiefel \\ William B. Beine \\ Center for Consumer Product Technology \\ National Bureau of Standards \\ Washington, D.C. 20234
}

Abstract: Historical repair data are useful for estimating life cycle costs as well as guiding development of life cycle performance laboratory tests. A general model is discussed which integrates available data for electric clothes dryers to estimate repair costs. Results are presented and their implications for various purposes are considered. The applicability of the model and extension of the technique to other appliances is also discussed.

Key words: Life cycle costing, repair cost analysis; frequency of failure; electric clothes dryer

\title{
1. Introduction
}

Life cycle costing (LCC) has a long history of use by the military and industrial sectors of our economy to compare ownership costs for alternative products. The LCC technique considers the total ownership costs and accounts for the timing of cash outlays and the time value of money in converting all costs to a present value [1]. A general expression of the LCC formula can be shown as follows. $L C C=P L C+\sum_{t=1}^{N} \frac{1}{(1+r)^{t}}\left[(O C)_{t}+(M T C)_{t}+(R C)_{t}\right]+\frac{1}{(1+r)^{N}}$ (DC)

where,

LCC = present value of costs incurred during $\mathrm{N}$ periods, PLC = consumer's initial price and logistics (i.e., transportation and installation) cost,

$r=$ discount rate (per period),

$\mathrm{OC}$ = operating (energy, water, etc.) cost for specified maintenance, repair, and use conditions,

$\mathrm{MTC}=$ maintenance cost,

$\mathrm{RC}=$ repair cost, and

$\mathrm{DC}=$ disposal cost (This item becomes negative if a 
consumer received money when disposing of an old product.)

The widespread use of LCC analysis for weapon systems and plant equipment by the military and industry may be attributed to their control over operation, repair and maintenance as well as their record keeping activities. A similar observation cannot be made for consumer products. The application of LCC to consumer products is new. Application to consumer products to date has concentrated on combining energy costs with purchase price ignoring other costs, such as repair [2]. The reason repair costs have not been included is in large part due to the lack of data and the difficulty in obtaining repair cost information, especially beyond the warranty period. This paper will present a repair cost model suitable for estimating appliance repair rates and their associated costs and will illustrate the model's use on a major consumer durable, the electric clothes dryer.

Repair rate and cost estimates have multiple purposes. In the context of ICC analysis it is possible to examine the importance of repair costs relative to total ownership costs, to examine the variability and sensitivity of cost estimates to machine and non-machine related parameters and to provide a basis for translation of failure rate data to estimated repair costs. Because LCC information is needed on appliances at time of purchase and yet these appliances will be in use for more than ten years, accelerated testing under controlled laboratory conditions is a possible approach to estimate failure rates. Two underlying problems associated with accelerated testing involve the uncertainty that results are representative of actual experience and the scaling factor between laboratory time and field use time. Therefore, estimates of failure rates on similar machines provide useful information for directing the development of test methodologies. Specifically historical repair data provide:

- estimates of expected failure rates and average time to first failure,

- indication of most frequent repaired components, and

- a means for translating laboratory results to the consumer's environment. 
Potential sources for appliance repair data include manufacturers, consumers and repair agencies. Manufacturers are reluctant to provide repair data either because their records are not adequate beyond the warranty or the possible advantage it may offer to a competitor.

Consumers of appliances were also investigated as repair data sources. The individual purchaser generally does not keep good records and use of recall for extended periods is not accurate. Aggregate data based upon an extensive survey of many thousands of consumers over a short recall period was not feasible. However, future analysis of the Department of Labor Statistics Consumer Expenditure Survey data tapes (soon to be available) may provide aggregate repair data. Large institutional purchasers, such as the Federal Government, local housing authorities, laundry companies and apartment complexes, generally do not have data at the level of detail required. However, many organizations expressed their willingness to collect data for future analyses.

Repair agencies proved to be the most fruitful source for data, particularly the repair organizations located in utility companies. The utility company's customers typically buy the machine from the utility, purchase a longterm service contract and continue to rely on the company for service after the service contract terminates. Utility companies, having a high proportion of units under service contract, maintain complete well kept records for purposes of providing service and analyzing their costs for providing the service.

The repair information being sought during data searches consisted of a continuous set of records from installation through disposal including for each machine:

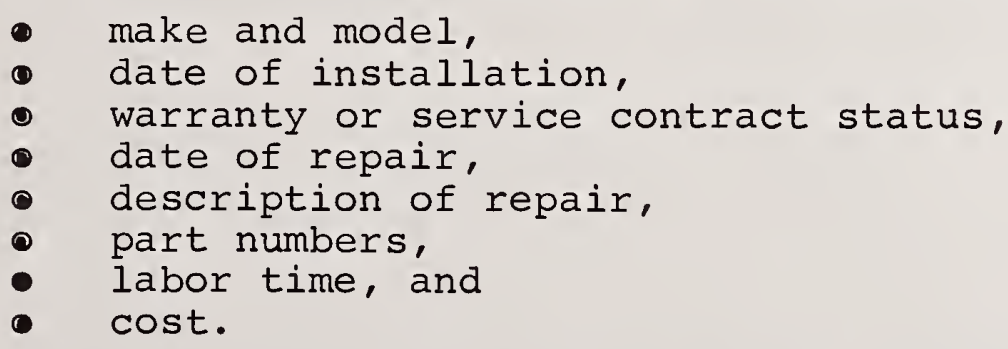

Based upon the information located during the search an expected repair cost model was developed which integrates the available data. Although records exist which provide the time trace of repairs, their collation from company files 
involved approximately one-half hour per machine. obviously, for a large sample size this longitudinal approach is very expensive. The repair cost model permits use of either cross sectional or longitudinal data sets. Cross sectional data provide information on machines of various ages repaired during a one or two year period. For the purpose of exercising the repair cost model a combination of cross sectional and longitudinal data were used. The longitudinal data were obtained from a master chronological file for consumers maintained for over 15 years. The chronological record contained information on date of purchase, date of repair, warranty and service contract data and possibly date of repurchase. The cross sectional data consisted of repair records containing the detailed information on manufacturer and model, machine age, cost of repair, warranty status, labor time and a description of repair procedures. The description of repair procedures included the:

1. action taken (e.g., installed, adjusted, replaced, repaired, cleaned, lubricated, etc.),

2. major subsystems affected (e.g., electrical, drive system, drum assembly, blower assembly, cabinet/console, etc.),

3. components affected (e.g., heater element, timer, motor, etc.) and

4. part costs if parts were replaced.

\section{Expected Repair Cost Model}

The following cost equation was derived to construct a distribution of expected annual repair costs over a prescribed number of years of operation. The equation specifies the data required and is in a form consistent with repair records of many repair firms.

$$
E_{j}(C)=\sum_{i} R_{i j} \cdot\left(\overline{S T}_{i j} \cdot S_{j}+\overline{P C}_{i j}\right) \quad j=1,2, \ldots, t,
$$

where,

$$
\begin{aligned}
\mathrm{E}_{j}(\mathrm{C})= & \begin{array}{l}
\text { expected repair cost for the } j \text { th year of } \\
\text { operation (year since purchase), }
\end{array} \\
\mathrm{R}_{i j}= & \begin{array}{l}
\text { number of repair procedures } i \text { divided by the } \\
\text { number of units in their jth year of operation, }
\end{array}
\end{aligned}
$$




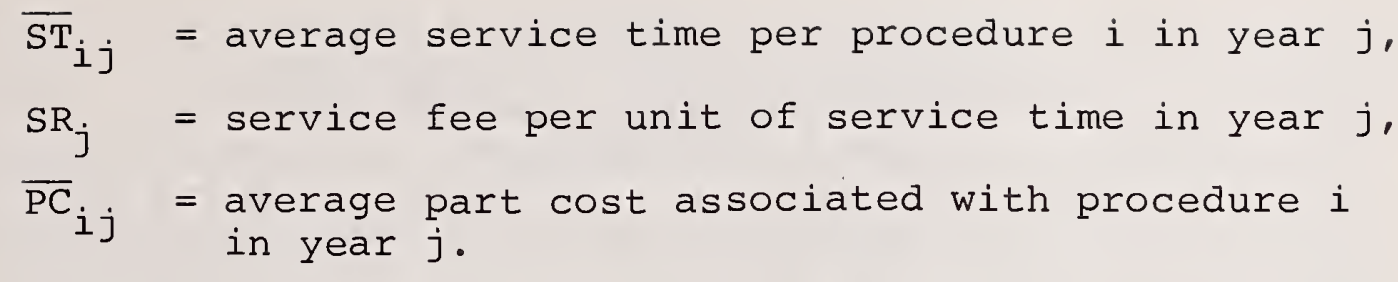

The model is flexible and allows for gauging the sensitivity of repair costs as a function of different values for the repair rates, labor and parts cost parameters.

\subsection{Repair Rates}

It must be emphasized that the intent of this paper is to demonstrate the application of LCC to electric clothes dryers and only to illustrate the process for characterization of repair costs for this appliance. Consequently, emphasis was placed on developing methodology. Requirements for a statistical sampling of repair data that could provide the repair cost characterization were relaxed to facilitate this approach. The results which follow are based upon relatively few repair agencies and brands and therefore are not meant to be representative for the electric clothes dryer as a class.

Repair rates provide measures of the incidence of repair relative to the number of units in operation. They are derived from repair records and, as such, may exhibit characteristics stemming from decisions that determine repairs. Unlike failures, defined by established substandard levels of performance, the existence of a repair record is the result of a decision by the owner or user of an appliance to seek the services of a repair firm. This decision is predicated on the user's perception of an abnormal symptom and the influence introduced by the presence of external variables, such as cost, inconvenience, within warranty period, among others. These influencing factors are observable but extremely difficult to quantify. The influence of warranty on repair rates for televisions and refrigerators is discussed in a report by the Massachusetts Institute of Technology [3]. The authors of that report claim repair rates during warranty are inflated beyond that normally attributable to strict machine failure. According to the authors, calls "of the education type" or nuisance calls make up about 30 percent of all warranty service calls. Further, other service center practices, according to that report, tend to raise the repair rate even higher than expected. 
A second factor influencing repair rates is the 5-year service contract. The influence of this factor is demonstrated in repair rates provided by company $B$. These rates, shown in figure 1, correspond to two time periods. The first period is for units operating in the 2nd through 5 th year prior to implementing a 5-year service contract. During this period the rates are relatively constant, averaging 0.26 repairs per unit per year. The second period involves dryers with 5-year service contracts. These rates begin at the level of previous period but dramatically and continually increase to 0.46 in the last and final year of the 5-year service contract. The average repair rate is 0.33 repairs per unit per year for a $27 \%$ increase in the average repair rate between the two sets of repair rates.

FlGURE 1

\section{REPAIR RATES FOR ONE BRAND OF ELECTRIC DRYERS SOLD AND SERVICED BY COMPANY B PRIOR TO IMPLEMENTING A 5-YEAR SERVICE CONTRACT \\ AND FOR YEARS IMMEDIATELY FOLLOWING FOR DRYERS SOLD WITH A G-YEAR SERVICE CONTRACT}

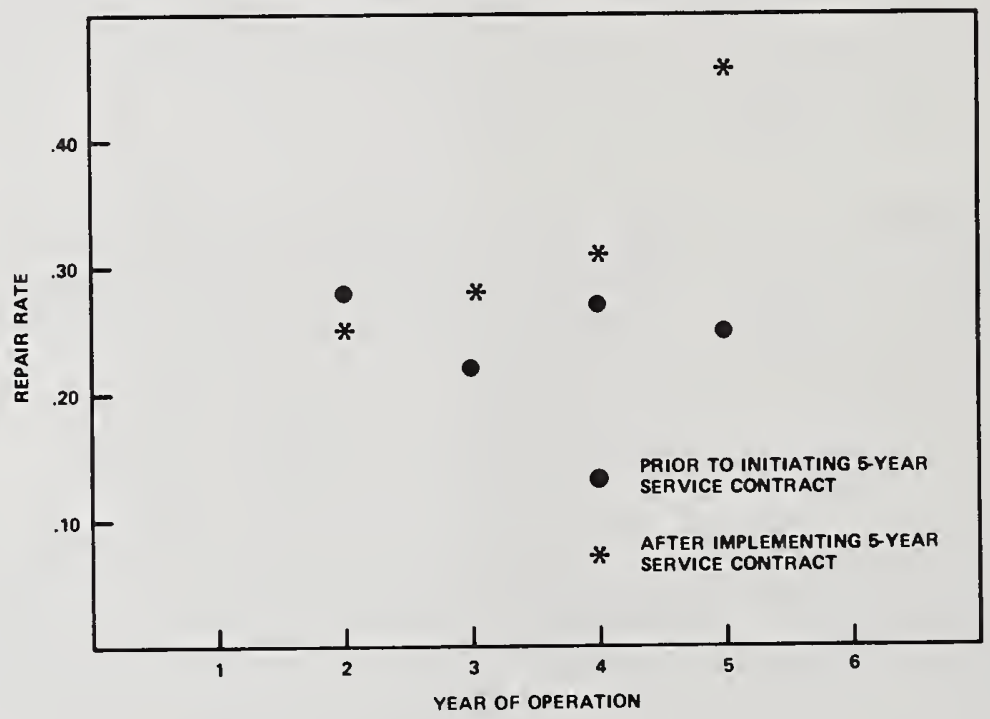

The repair rates computed from the repair frequency data obtained from company A also exhibit these characteristics. These rates are displayed graphically in figure 2. Consistent with the previous data, the first year rate is high and rates for the 2 nd through 5 th years of operation increase more rapidly than the overall average increase. This 2nd through 5 th years increase, in part, is possibly due to the 5-year service contract since all dryer sales made by company A after approximately 1963 included a 5-year service contract. The linear fit of the data was included to reduce this effect. 


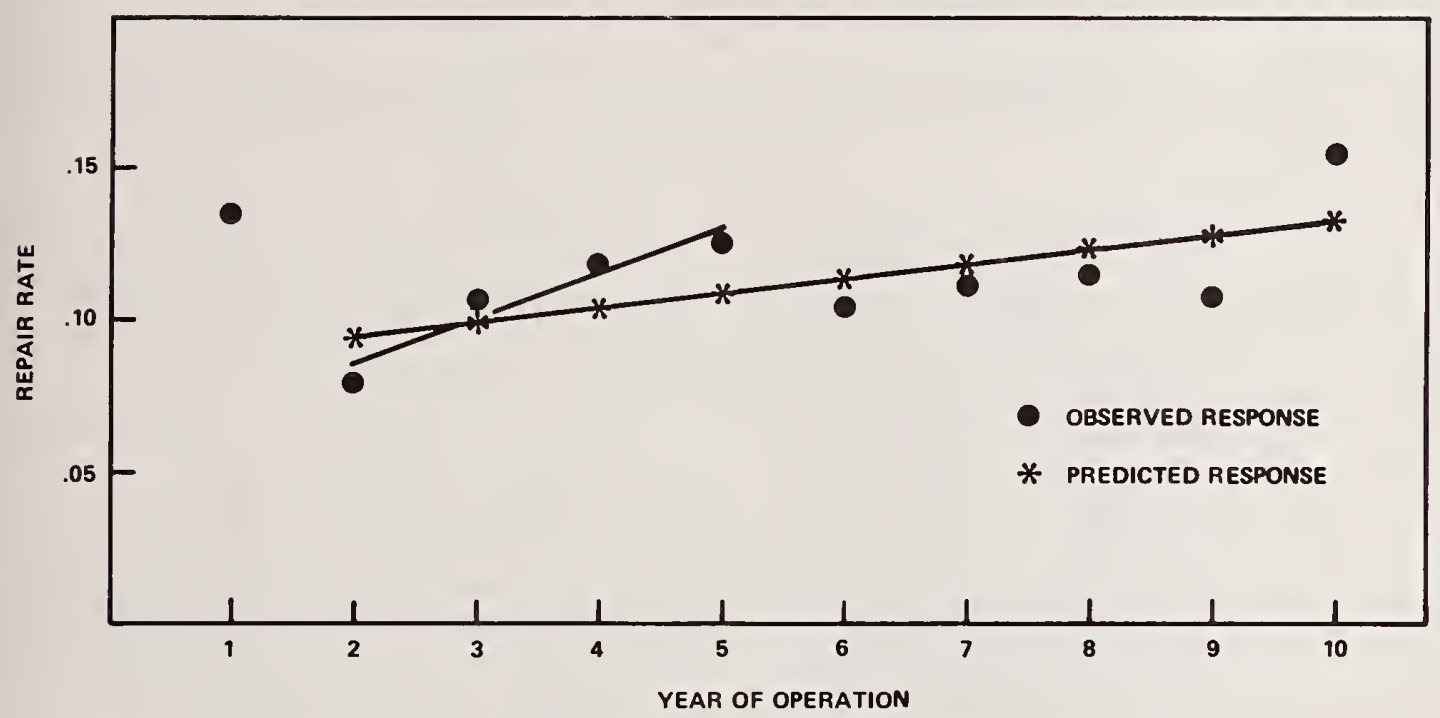

Repair rates vary between brands and repair firms. For example, the fifth year repair rates were 0.46 for company $B$ and 0.13 for company $A$.

Different levels of repair rates between 3 major brands of electric clothes dryers are also indicated in first year (warranty) sales and repair data provided by company $C$. These repair rates, shown in table 1 are for the 12 months of 1976 and first 7 months of 1977 . Repair rates vary slightly across years for each brand. However, the repair rates for Brand III differ considerably from Brands I and II.

Table 1. First year (warranty) repair rates for three brands of electric dryers serviced by company $C$

\begin{tabular}{|l|c|c|c|}
\hline \multirow{2}{*}{ Year } & \multicolumn{3}{c|}{ Repair Rates } \\
\cline { 2 - 4 } & $\begin{array}{c}\text { Brand } \\
\text { I }\end{array}$ & $\begin{array}{c}\text { Brand } \\
\text { II }\end{array}$ & $\begin{array}{c}\text { Brand } \\
\text { III }\end{array}$ \\
\hline 1976 & 0.22 & 0.20 & 0.12 \\
1977 & 0.22 & 0.18 & 0.12 \\
\hline
\end{tabular}


There is agreement in the year-to-year pattern of repair rates between data provided by the three companies. There is also evidence that repair rates are influenced by external factors such as warranty and five-year service contracts. Finally, repair rates differ between brands and different repair firms.

\subsection{Results of Sensitivity Analyses on Expected Repair Costs}

This section will address the effects of observed variations in the parameters of the repair cost model on the expected annual repair costs. The expected costs are more affected by changes in some parameters than others. The repair costs which follow exclude the first year of operation, which are absorbed by the manufacturer and passed back to the consumer through the initial purchase price. Thus the consumer's expected annual repair cost would be those of the second and successive years of operation. The repair rate has the greatest influence over expected costs, given the same percentage increase in each of the parameter values. Figure 3 illustrates the possible effect of the extremes in expected annual repair costs resulting from observed differences in repair rates between firms. The lower value (\$3.57) represents a ten year average (2nd through loth year of operation) for the repair rates observed in figure 2. The calculated average values were nearly constant ranging from $\$ 3.47$ in year 2 to a high of $\$ 3.65$ in year 5 . The higher value in figure 3 (\$11.21) results from averaging the repair rates indicated in figure 1 for the 2 nd through 5 th year of operation and holding the remaining cost parameters constant.

FIGURE 3

EXTREMES IN EXPECTED ANNUAL REPAIR COSTS RESULTING FROM OBSERVED DIFFERENCES IN REPAIR RATES BETWEEN REPAIR FIRMS

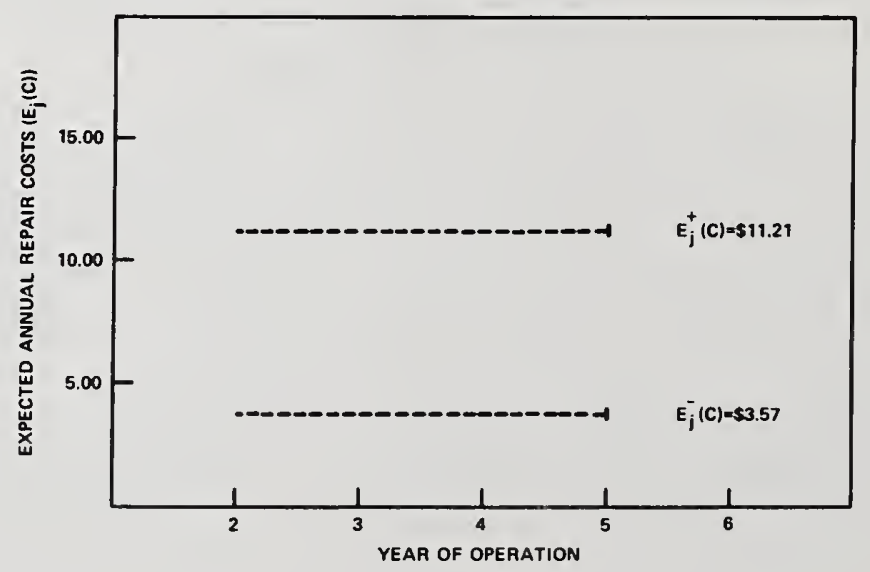


In addition to observed differences in repair rates, table 2 indicates the extremes in parts costs and service charges for labor time observed during a survey of nine repair firms [4]. Using these values as an index relative to the base case shown in figure 3 , the expected annual repair costs attributable to variations in service fees and parts cost were computed for years 1 through 10. These average annual repair costs are shown graphically in figure 4. The value of $\$ 3.71$ corresponds to the $\$ 3.57$ value shown in figure 2, but includes $\$ 4.92$ for the first year of operation.

Table 2. Parts cost and service charge variability

\begin{tabular}{|l|c|c|}
\cline { 2 - 3 } \multicolumn{1}{c|}{} & $\begin{array}{c}\text { Hourly } \\
\text { Service Fee }\end{array}$ & $\begin{array}{c}\text { Average Part. } \\
\text { Costs Based on } \\
\text { A Selected Set } \\
\text { of Parts }\end{array}$ \\
\hline Low & $\$ 15.00$ & $\$ 8.73$ \\
High & $\$ 47.50$ & $\$ 16.20$ \\
\hline
\end{tabular}

FIGURE 4

EXTREMES IN EXPECTED ANNUAL REPAIR COSTS AS A RESULT OF

OBSERVED DIFFERENCES IN PART COSTS AND SERVICE FEES

(AEPAIR RATES ARE NOT VARIED)

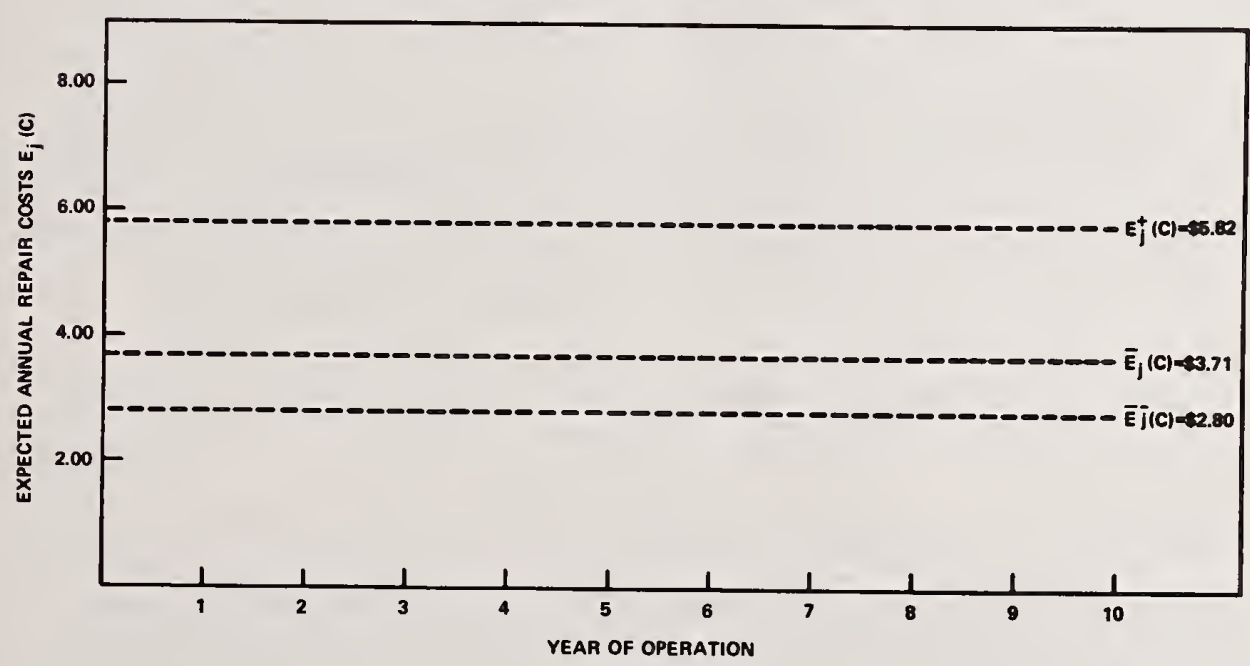

The extremes of $\$ 2.80$ and $\$ 5.82$ reflect their respective low and high service fee and parts cost shown in 
table 2. The repair rate was held constant for all three values in figure 4.

\section{Application of Historical Repair Data to Test Method Development}

Historical repair data have application beyond LCC analysis. They provide useful information for guiding the development of laboratory tests. Estimates can be derived for expected failure rates and average time to first failure. They also can provide indications of the most frequently repaired components, a means for translating the results of laboratory testing to the field environment and guidance in determining acceptable levels of accuracy.

\subsection{Failure Rate and Average Time to First Failure}

Repair rates are measures of the incidence of repairs relative to the number of units operating in year $j$. These rates are derived from repair records which in turn exist as a result of decision processes invoked by consumers to repair. External factors exist that influence these processes (e.g., existing warranty and extended service contracts). In instances where the influence of these factors can be quantified and ultimately subtracted out of the repair rate estimate or where their influence is simply not substantial, repair rates provide reasonable estimates of failure rates.

Table 3 provides estimates [5] of failure rates for the first ten years of operation. Also shown are values which indicate the probability that the first failure occurs in year j. An average time to first failure of 7.3 years has been derived for this sample by extrapolating the failure rate for 20 years and terminating the survivors at the 21 st year. 
Table 3. Failure rate and probability of first failure estimates based on data obtained from Company A.

\begin{tabular}{|c|c|c|}
\hline $\begin{array}{c}\text { Year of } \\
\text { Operation }(j)\end{array}$ & $\begin{array}{c}\text { Estimated } \\
\text { Failure Rate* }\end{array}$ & $\begin{array}{c}\text { Estimated Probability } \\
\text { of First Failure }\end{array}$ \\
\hline 1 & 0.133 & 0.133 \\
2 & 0.096 & 0.083 \\
3 & 0.100 & 0.078 \\
4 & 0.105 & 0.074 \\
5 & 0.110 & 0.069 \\
6 & 0.114 & 0.064 \\
7 & 0.119 & 0.059 \\
8 & 0.124 & 0.054 \\
9 & 0.129 & 0.050 \\
10 & 0.133 & 0.045 \\
&
\end{tabular}

This value can be placed in more useful terms by incorporating results of other studies. A field study of clothes dryer usage found that dryers are used at a rate of 7.1 loads per week [6]. This value was applied to the average time to first failure as follows:

$$
7.3 \text { years } \times 7.1 \frac{\text { loads }}{\text { week }} \times \frac{52 \text { weeks }}{\text { year }}=2695 \text { loads. }
$$

This value is an estimate of the average number of loads to first failure. The validity of this estimate is related to four assumptions:

(1) The average number of loads per year estimate is valid over all years of operation.

(2) The expected number of repairs is a function only of the number of loads.

(3) The repair rate is a good estimator of the failure rate.

(4) Repairs occur independent of previous history.

The average time to first failure can be expressed another way, that is, in terms of hours of use. The operating time per dryer load is required for this transformation. An estimate of operating time has been derived from two studies which provide dryer performance estimates [7] and energy consumption per load estimates [8]. The estimate derived is 
28.5 minutes per load. The average use time to first failure can then be estimated as follows:

2695 loads $\times 28.5 \frac{\text { minutes }}{\text { loads }} \times \frac{\text { hour }}{60 \text { minutes }}=1280$ hours.

Thus, for each 1280 hours of operation, one failure would be expected.

\subsection{Most Frequently Repaired Components}

The repair procedure data provide information at the component level. This information is essential to compare the laboratory setting as a surrogate for field conditions and use environment. A percentage distribution of repair procedures by affected system and component is shown in figure 5 .

FIGLRE 5

PERCENTAGE DISTRIBUTION OF REPAIR PROCEDURES

BY AFFECTED SYSTEM AND COMPONENT

(1677 OBSERVATIONS)

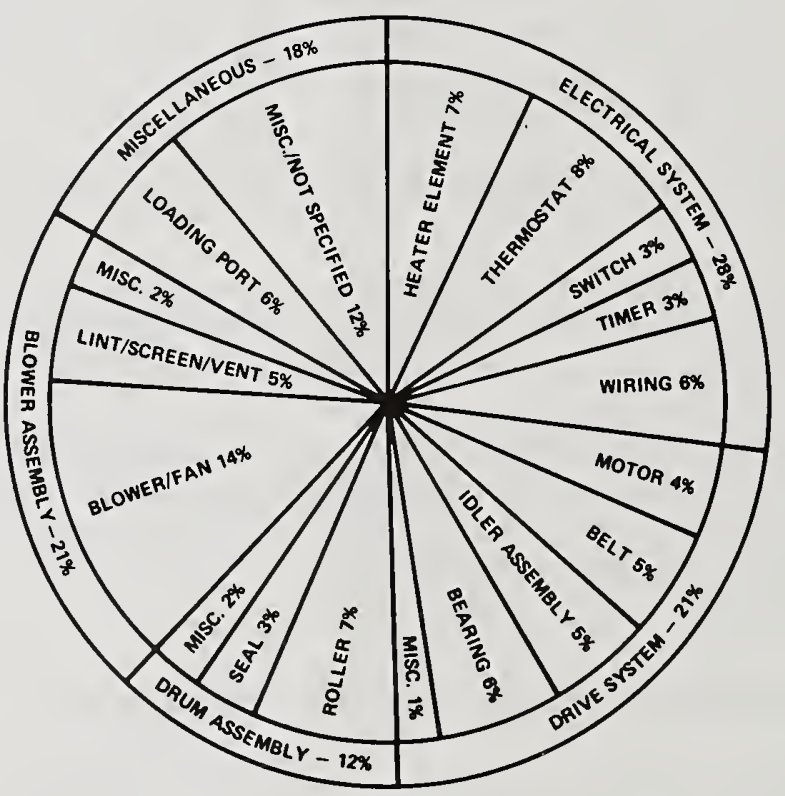

In addition for each component the type of repair performed can be provided. Figure 6 is an aggregate distribution of types of repairs performed on the entire electric clothes dryer system. 


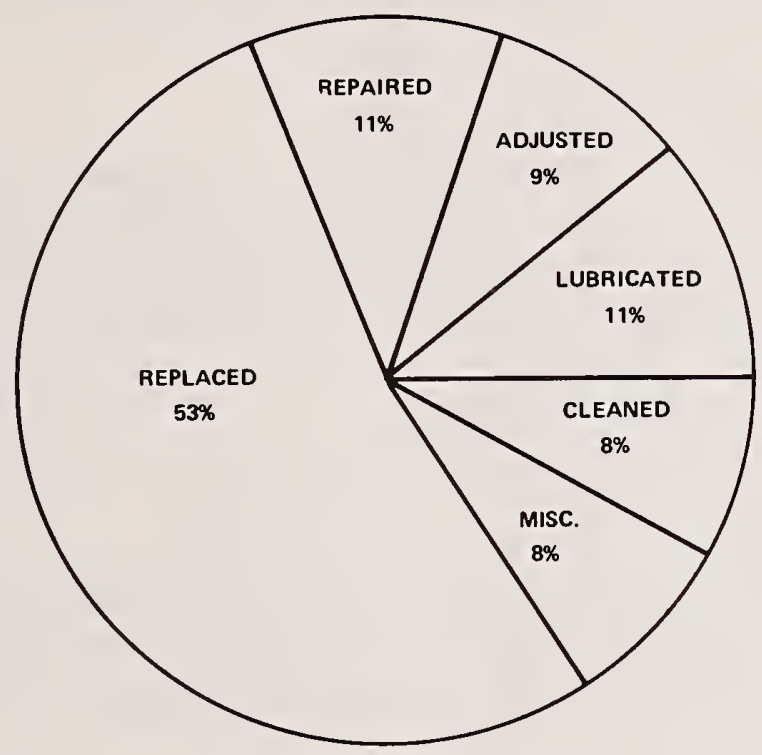

4.3 Translating the Results of Laboratory Testing to the Consumer's Environment

Laboratory test data to be of value in consumer decisions must be put into appropriate units. This process can be thought of as the reverse of that previously discussed in section 4.1. It also has implications for LCC analyses. For example, the frequency of a specific component failure can be determined in laboratory testing. How this affects the repair cost is determined by merging these test data with field parameters, such as, usage patterns, service fee per unit of time, part cost, and average time required to perform the appropriate repair task. A histogram indicating the distribution of service times, averaging around one hour, to repair the aggregate of repair procedures is shown in figure 7 . A similar histogram can be generated for each repair procedure (e.g., replacing a belt). Integrating these data with laboratory results can provide estimates of expected repair cost. 


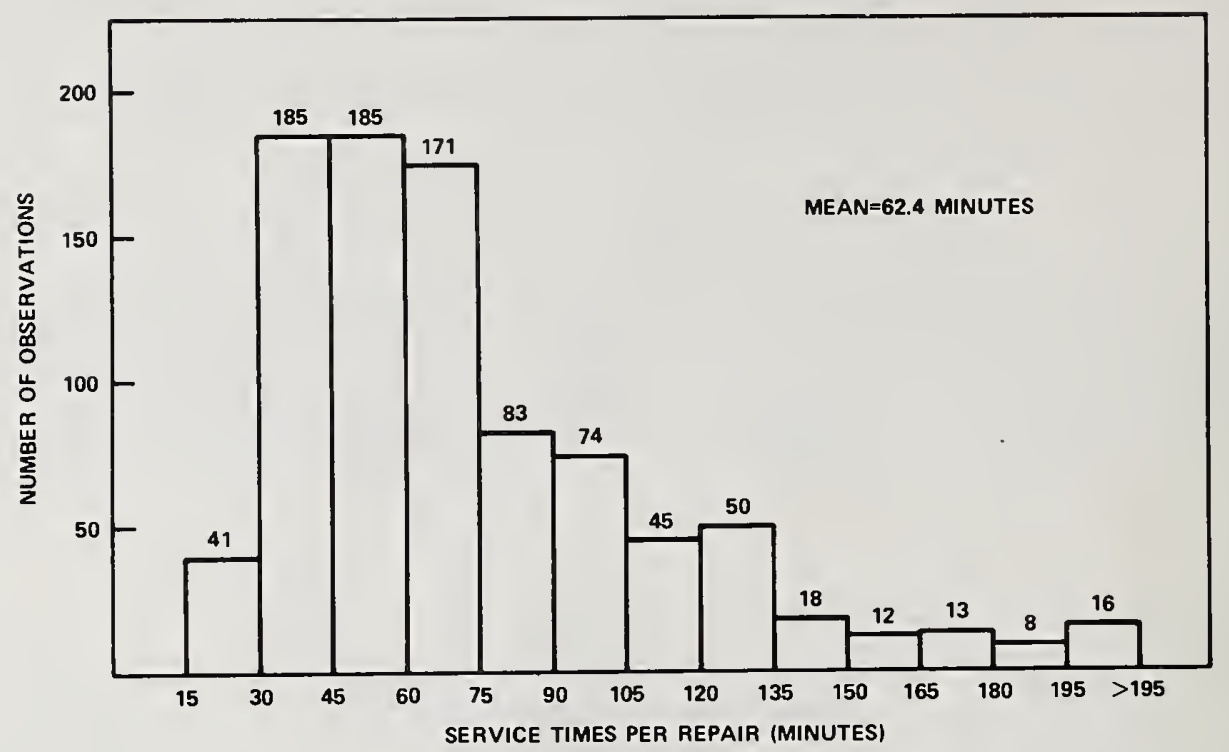

5. LCC Analysis for Electric Clothes Dryers

In the introduction to this paper the LCC formula was presented. The LCC formula consists of initial purchase price plus the discounted values for operating, maintenance, repair and disposal costs. For electric clothes dryers maintenance and disposal costs are negligible compared to the other ownership costs. The average purchase price was $\$ 227$ in 1976 [9] and the operating cost reduces to energy consumption cost. Based upon 7.1 uses per week and a value of $2.43 \mathrm{kWh}$ per use [10], the average annual energy consumption is $897 \mathrm{kWh}$. Using electricity costs of $4 \mathrm{c}$ per $\mathrm{kWh}$ the average annual energy cost is $\$ 36$. Therefore, the ten year ownership cost picture involves an initial outlay of $\$ 227$ and annual expenditure of $\$ 36$ for energy and $\$ 3.57$ for repairs in years 2 through 10 [11]. Figure 8 indicates the relative share of ownership costs attributable to purchase, repair and energy costs at a 5 percent discount rate. Repair costs only contribute 4 percent and are dominated by energy costs and purchase price. Certainly these relative costs have implications for the type of information which should be emphasized to consumers, as well as the level of accuracy necessary in characterizing repair versus energy costs in laboratory testing. Even doubling the repair rate, as shown in the figure 8 pie chart, only 
increases the repair cost share to 9 percent. Repair costs are also insensitive to variations in discount rate. At a zero discount rate the repair cost share increases by one percent while at a 10 percent discount rate the repair cost contribution decreases by one percent.

FIGURE 3

\section{DISTRIBUTION OF ESTIMATED TEN YEAR \\ OWNERSHIP COSTS FOR ELECTRIC CLOTHES DRYERS \\ (USING A 5\% DISCOUNT RATE AND ENERGY COST OF $4 \% / \mathrm{KWH}$ )}
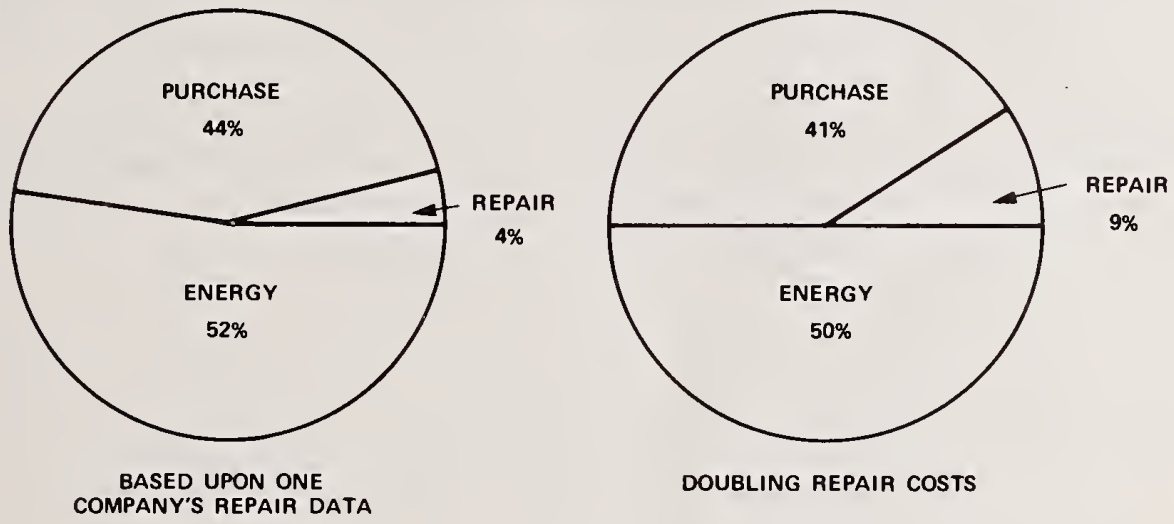

6. Conclusion

Historical repair rates and cost estimates have multiple purposes. Using LCC analysis it is possible to ascertain the importance of repair costs relative to total ownership costs, to examine the sensitivity of cost estimates to variations in machine and non-machine related parameters and to provide a basis for translation of failure rate data to estimated repair costs. Analysis of repair frequency data indicated general agreement in the year-toyear pattern of repair rate between three different companies. There are also indications that repair rates are influenced by external factors such as warranty and service contracts and that repair rates differ between brands and repair firms.

The repair cost model is applicable to major household appliances and permits not only computation of a 
distribution of expected annual repair costs, but also the flexibility to observe the effects of variations in the parameters values of repair rate, service fees and parts cost on expected repair costs. Since the repair data sources located for electric clothes dryers can provide information on other major household appliances, the techniques developed could be extended to these appliances.

Historical repair data have application for guiding development of laboratory based testing. Estimates can be derived for expected failure rates by component and average time to first failure. Using usage pattern data together with failure rate estimates it is possible to translate from the field use (calendar) time to laboratory (operating) time. Finally, the use of the LCC approach permits a comparison of the relative share of ownership costs attributable to purchase, repair and energy consumption. These relative costs have implications for addressing the required level of accuracy of test methods intended to generate repair or energy cost estimates. 
[1] Grant, E. L. and W. G. Ireson, Principles of Engineering Economy, 5th ed., Ronald Press, New York, 1970 .

[2] Stiefel, S. W., S. J. Kim and H. Hung, Life Cycle Costing: An Assessment of Practicability for Consumer Products, NBSIR 77-1212, December 1976, p. 15.

[3] Center for Policy Alternatives, The Productivity of Servicing Consumer Durable Products, Massachusetts Institute of Technology with the Charles Stark Draper Laboratory, Inc., Report No. CPA-74-4, 1974, p. 93.

[4] The study was limited to nine firms because of time constraints involved with securing office of Management and Budget approval to exceed nine firms.

[5] An intrinsic assumption is that the sample is truly representative of the respective population. The sample used in this study was adequate for the purpose of this study but, since it represents a single repair firm, may not be adequate for predicting time to first failure. The procedures used, however, are valid.

[6] Proctor and Gamble, field study results submitted to the Federal Energy Administration "Appliance Proposed Energy Efficiency Improvement Targets," June 10, 1976.

[7] Consumers' Research Magazine, "Electric clothes dryers," July 1975, p. 7 .

[8] Oklahoma Gas and Electric Company, "Field Study-Electric Clothes Dryer Energy Consumption," 1971.

[9] Merchandising, "1977 Statistical and Marketing Report," March 1977, p. 60.

[10] Oklahoma Gas and Electric Company, 1oc. cit.

[11] The base case value of $\$ 3.57$, as shown in figure 3, was chosen for the purposes of illustration. However, the above caution (see note 5) also applies here. 


\section{P. L. Fontaine}

Stevenson \& Kellogg, Ltd.

Ottawa, Ontario, CANADA

Abstract: The economic and environmental impacts of increasing the durability of major domestic appliances and automobile tires in Canada were assessed. Increased durability was also compared to other major alternatives such as recycling and reuse. Energy, solid waste, resources consumption, air and water pollution, employment and industry sales were considered. Also, approaches which the federal government might follow to affect product durability were evaluated. Basic data were developed by examination of published data, through personal interviews with members of a wide range of related organizations, manufacturers, distributors, reconditioners, commercial users, etc., and from a national consumer survey conducted to establish how and why people dispose of major appliances. The study concluded that increased durability is practical and does decrease materials and energy usage for passenger car tires. However, the same comments cannot be made for major appliances for a number of reasons. These reasons include the difficulty of insuring that increased durability will in fact be used by consumers and the lack of hard technical data on the materials and energy costs of increasing appliance durability.

Key words: Environmental impact; appliance durability; tire durability.

In this study the implications of increasing the life of the following products were evaluated:

- Electric ranges and microwave ovens;

- Refrigerators and freezers;

- Automatic clothes washers and dryers;

- Home air conditioners;

- Automobile tires. 
In particular, we studied the effects of increased product life on:

- Energy consumption;

- Consumption of resources;

- The environment;

- The economy.

The project was split into four sections:

1. Gathering Public Data

In this section, data were obtained from published sources, and by discussion with public bodies -- departments of the governments of Canada and the U.S.A.

2. Field Research

We interviewed a wide range of people involved in the manufacture, use, and disposal of these products. These sources included:

- Relevant associations, including major tire and appliance associations in Canada and the U.S.A.

- Works departments, including those of most of the major metropolitan centers in Canada.

- Major manufacturers and distributors of tires and appliances.

- Service organizations, reconditioners, and major users.

- Industry experts and others.

3. Consumer Survey

A national consumer survey was conducted to assess:

- the proportion of appliances which replaced a previous model;

- the disposition of the previous appliance. 
The environmental impacts and other relationships were analyzed and approaches were discussed with the representatives of the various government departments involved.

From the analysis, it was concluded that increased durability is practical and does decrease materials and energy usage for passenger car tires. However, the same statement cannot be made for major domestic appliances because:

- The impact of consumer behaviour is much more important. We cannot be sure that the increased durability will be used.

- There is a lack of hard technical data on the materials and energy costs of increasing the durability of appliances.

\section{Major Domestic Appliances}

About half of all new appliances are purchased to replace old appliances. The majority of the replaced appliances are retained in use. When they are finally disposed of, about $70 \%$ of appliances are send to landfill, the remainder are recycled. Appliances contribute approximately $1 \%$ to total residential and commercial landfill by weight.

Appliance manufacturing uses around $1 \%$ of Canadian production of steel, polyethylene and polyvinyls. It consumes about $0.14 \%$ of Canadian energy production. Appliance manufacturing uses less than one-fifth of the steel used by the fabricated structural steel industry. Appliances use less than one-tenth of the steel of the Canadian motor vehicle industry.

The main source by far of energy consumption and environmental pollution during the lifetime of washing machines (which we looked at in detail) was derived from the energy production necessary for the heating of the water used. The average automatic washing machine uses four hundred fifty tons of hot water in its lifetime. The energy used to heat this water is approximately fifty times the energy used to make the washing machine. 
In the last fifteen years there has been little change in the recorded durability of appliances. However, the available data are only for the "first owner" lifetime, such that the ultimate durability of appliances through second and third-hand ownership is not readily apparent. Servicemen report, though, that the number of appliances rebuilt for sale second-hand has recently been declining, partly due to the fact that appliances are becoming less durable. However, this observation was not substantiated in our study in any statistical way.

The cost of appliances compared to total consumer income decreased nearly $50 \%$ between 1966 and 1974. The cost of repairs relative to the price of new appliances has increased sharply as a result. Consequently, the economics of rebuilding appliances have recently become very poor, and the market has thus become almost non-existent.

The most frequent failures in washing machines occur in pumps, switches, agitators and transmissions. A major cause of failure is seized bearings in pumps and transmissions. Bearings are also a problem in motors.

The useful life in terms of cycles performed is nearly three times longer for commercial washing machines than domestic machines. However, the mechanics of both types are nearly identical. The different usage obtained is partly the result of better maintenance in the commercial enviromment, and partly a greater propensity to repair the commercial machines rather than purchase new ones.

Consumer behaviour has a major influence upon appliance life. In particular, for washing machines, excessive or imbalanced loads cause increased wear. Other factors which alter the life of a washing machine are the detergent used, water chemicals, and the temperature selected.

We conclude in this study that:

Appliances do not consume a significant proportion of Canada's resources during their manufacture. However, the consumption can be economically and effectively reduced by recycling through scrap metal shredders. 
- Durability has a low priority with consumers. This, we believe, is largely due to the fact that most appliances already last about ten years. The perceived present value to the consumer of additional durability whose benefits will not be received for ten years is low.

- Consumers know very little about durability. There are no comparative tests to guide them. (It is very difficult to compress a ten year life into a reasonable length of time for a test.) Hence, they are guided by the apparent visual quality and the brand's reputation.

\section{Automobile Tires}

Tire manufacturing uses $65 \%$ of all the rubber consumed in Canada. It also uses about $0.4 \%$ of Canadian energy production. This is nearly three times the energy consumed by appliance manufacturing. However, nearly half of that energy can be saved through tire reclamation.

The durability of tires has increased considerably in recent years. This is principally due to the trend toward radial ply tires. Of the three main types of automobile tires -- bias ply, belted bias, and radial ply -- the radials give the highest mileage.

Radials provide a significant reduction in materials used per 1,000 miles of driving. This saving is due to their increased durability, despite the higher consumption of materials and energy during manufacture. Because radials are more expensive, the cost to the consumer per 1,000 miles is comparable or higher than the other types of tire. However, this cost is offset by the reduced fuel consumption resulting from their low rolling resistance.

The tread life achieved by a set of tires is closely related to the way that they are driven. "Hard" driving with sharp acceleration and braking reduce tread life drastically. Conversely, smooth driving increases tread life, obtaining up to three times the tread life of hard driving.

Tire maintenance also affects tire durability. Incorrect inflation, especially under-inflation, shortens tread life considerably. It also reduces the value of the carcass for re-capping purposes, as the 
walls may be seriously damaged. Other maintenance, often neglected, includes correct suspension set-ups and tire rotation.

The majority of the materials in a tire are in the carcass. Recapping enables these materials to be re-used, hence increasing their useful life and effectively reducing the materials and energy used per 1,000 miles of driving. Unfortunately, to date the availability of sound carcasses has been limited because there is little incentive for users to return old tires, sound or otherwise.

Nearly $50 \%$ of the energy in a tire can be recovered by thermal cracking. This process can produce a gas suitable for burning, a fuel oil fraction, and char which can be re-used in tires.

We conclude that:

- Tires are a better subject for government action than appliances because they consume more energy, their manufacture is simpler to regulate and influence, and their durability can be much more explicitly measured.

- There is little evidence that the tire companies can improve the durability of their best tires without adversely affecting other desirable features such as safety and "ride".

- The use of the top quality radial ply tires should be encouraged as they cause less energy to be consumed and use less material per 1,000 miles of driving.

Contract Authority

This study was carried out under joint contract to the Department of Fisheries and Environment (Waste Management Branch) and the Department of Energy, Mines and Resources of the Government of Canada. 



\section{SESSION V}

\section{PANEL DISCUSSION:}

\section{CAN AND SHOULD PRODUCT \\ LIFE BE EXTENDED?}

CHAIRMAN: E. PASSAGLIA

NATIONAL BUREAU OF STANDARDS 



\author{
William E. Davis \\ Office of Technology Assessment \\ Congress of the United States \\ Washington, DC 20510
}

\title{
Introduction
}

I am by training and inclination a behavioral scientist; thus the perspective I bring to this panel is from the human point of view. That is to say, the point of view of the scientist of human behavior -- since I assume that all of us here today are to some degree human.

The behavioral sciences, which more or less encompass anthropology, psychology, and sociology, seek to provide an objective description and analysis of behavior -- both individual and social. I have assumed my appearance today is to see if any of these disciplines can shed light on the issues of the Symposium. I think they can and I hope to share some of my ideas with you.

\section{Declaration of Ignorance}

Since it is customary for foreigners entering a new territory to protest their ignorance, I shall begin by emphasizing that I know nothing about your areas of technical proficiency. Indeed, in my own professional jargon, "stress" is what occurs when you get too many white rats in a cage or too many people in a bis city; a "clutch" is something you get into when it's fourth down and you are only three yards from a first; and "abuse" is measured by the number of times you beat your wife or children and tends to be independent of maintenance.

Having thus declared my ignorance, I feel free to plunge ahead and express my opinion about anything and everything I have heard during the Symposium. I also view my ignorance as license to ignore the Panel Chairman's request that we address issues of importance.

On the Nature of our Knowledge About Human Behavior

I want to stress one thing about the state of our knowledge of human behavior. To state the situation kindly, our understanding is at best meagre. We really know very little about how and why individuals and groups behave; to be sure, there is an abundance of hypotheses, a plethora of speculation, and even a few pockets of hard data. The state of our science, however, is far from being able to predict behavior even when we have a good understanding of the forces operating in a given situation. 
Thus I will offer you no sure answers today. Instead I would like to offer some suggestions about a few of the factors which play a role in product usage, which may influence durability, which influence how we approach these topics, and which I believe should be remembered when we approach the technical questions at hand.

\section{Some Dangers of False Categorization}

The first factor that I would raise has to do with the placing of individuals in categories. In the normal discourse of life, we must of necessity sort out those with whom we come into contact; we do this using various common characteristics. So it is we treat ladies differently than ruffians and children differently from grown-ups.

A careful analysis of behavior, however, must examine these categories to verify their importance. Let me cite a few examples.

We have heard several references to a little old lady in tennis shoes who only drives her car to the supermarket and to church. The example conjures up a certain class of product users. I suggest that there needs to be an empirical check on whether there are such people, and if so just exactly how they do handle their cars.

Similarly the general category of "consumer" has been used. I suggest that this is a most unusual way to lump people and the sooner the class labeled "consumers" is broken down into more meaningful categories, the better off we all will be.

There are retail consumers, industrial consumers, affluent consumers, poverty-stricken consumers -- and each manifests significantly different kinds of behavior. If we must use the label "consumer, "then the least we can do is qualify the usage with some additional descriptive attributes.

You yourselves have admitted that you drive your cars for years. You are therefore a very peculiar category of consumers. You should refer to yourselves as "professional consumers", or "weird consumers", as the case may be. There are differences in consumer behavior as a function of whether or not the individuals are ladies or ruffians, young or old, rich or poor, professionals or weirdo's. Not to include these important qualifiers obscures essential information.

When it comes to categorizing people or groups we must be sure we are using reasonable and relevant criteria for that categorization.

Related to this is what I see as a need for greater communication between the real categories of consumers which exist in society and those who supply those groups. I have no ready means to increase this 
contact, but I do believe that some of the problems which I am convinced arise from false categorization might evaporate if we purged ourselves of our false groupings.

On the Importance of Perception

The third factor which I would like to stress relates to how we view the world. One of the most intriguing qualities of human beings is our ability to take raw information and process it -- the results of that processing constitutes our perceptions.

There is a fundamental importance to the distinction between objective reality and to an individual's or a society's perception of that reality. Again a few examples.

I would suggest that in our culture, both consciously and unconsciously, we have equated "new" with "good" and "not new" with "not-so-good." I have heard from you that if we are going to save materials and energy and yet retain a decent 1 ife, we must depend more and more on re-cycled and remanufactured goods. We are also going to have to get used to keeping things around much 1onger. But I suggest to you that there are a lot of people in this country who are going to be uncomfortable doing this because of the way they perceive "not-so-new" products. Many of us are suspicious of used-car dealers (especially former ones) and we are reluctant to buy from them.

In other words, regardless of the objective quality of products, so long as they are perceived as "second-hand" they will not be as welcome as "new" products.

In a similar vein, so long as new models of anything are perceived as endowing their owner with prestige, they are going to be more valued than older models.

Again I have no quick or certain solutions to go about changing perceptions. But, believe me, until our perceptions are changed, it will be a long haul before products with long-lives will be generally accepted.

\section{Values and Facts}

My final point is to raise the issue posed by the title of today's discussion: "Can and Should Product Life be Extended?" The "can" part really is your area -- that is to say, "Can it be done?" is a question to be answered by technical analysis.

The "should" part is everybody's business. 
I am sure that you recognize this as the traditional distinction between values and facts. Whether or not a product's life can be extended is a matter depending on our knowledge about the properties of that product and the factors bearing on its degradation. These are matters of fact.

Whether or not a product should be built with those properties is a matter of values. Here we ask, "Is it a good idea to spend the money, time, and resources to make the beast?"

It is my personal conviction that all scientists and engineers should spend far more time addressing the question of values than we presently do -- and I include behavioral scientists, too.

We all carry far too many unstated values and we all too often act on our value assumptions without considering their consequences.

I have been impressed by the way this Symposium has struggled with some of the issues involved on the "Should We?" side of this equation. I commend you for this and hope that you will continue to do so in the future. 
Some Technical Aspects of Extending Product Life

\author{
W. A. Glaeser \\ Battelle Columbus Laboratories \\ Columbus, Ohio 43201
}

Do we have the technology at hand to extend product life? I see two questions which should be answered first. Will it be necessary to predict product life within a given confidence limit? Will it be sufficient to just improve durability with no guarantee on how much the life is extended?

Products involving mechanical action have multiple parts comprising a system often vulnerable to the weakest part. Some components most likely to fail include:

Component

Seals

Spline couplings

Piston-Cylinder

Brakes

Rolling Contact Bearings

Impellers

Gears
Failure Mode

Wear, distortion, spring breakage

Wear, fretting corrosion

Scuffing, fouling, corrosion

Wear, thermal degradation, change in friction properties

Wear, spalling, retainer breakage, corrosion

Erosion, corrosion, fracture

Wear, spalling, scuffing, corrosion, tooth fracture

The components listed above usually cannot be designed to avoid some kind of moving surface contact. Thus, they are subject to some degree of surface degradation. The extent of surface damage (wear, erosion, spalling) depends on the whole operating environment (temperature, load, fluids, gases, velocity). Surface damage can suddenly become excessive when the right combination of operating conditions exist. The probability of expected -- or worse yet -- unexplained component failure increases as its sensitivity to changes in operating conditions increases. The sensitivity of the system can be reduced by proper design 
and use of appropriate materials that exist today. Thus, the operating conditions, over which the manufacturer of a product often has no control, can determine life of the product more than deliberate design. However, the manufacturer can reduce early failures by proper use of materials and design. This will probably involve bench tests and proof tests on the product before the required reduction in system sensitivity is achieved. Testing is necessary because most of the information on solid contact performance is based on empirical means.

For instance, a critical seal in a sewing machine (we don't want oil stains on the fabric) might require more attention in design than one in a hand drill. If the seal were a 1 ip type, special attention might be given to the rubber material, to the way in which the lip is molded, the location of the load spring, and the surface roughness of the shaft against which the lip rides. Perhaps an integral dust seal might be required to prevent wear of the seal lip by debris.

All of this improves the durability of the product but in no way does it allow us to predict its life. Even with bench testing, expected scatter in results for surface contact mechanisms makes life prediction very chancy. That is, we do not have analytical tools as yet by which we can predict wear rate for real operating conditions even if we can define them quite precisely. So that in answer to the first question, we cannot sit down and design a washing machine to last for $x$ years with a 99 percent probability. I believe we can design a washing machine that will not show an unreasonable number of early failures in the field. 


\author{
N. R. Pugh \\ Sears, Roebuck and Company \\ Chicago, Illinois 60684
}

The first question for this panel, "Can product life be extended?", seems easy to answer -- "Yes, and fairly economically." Furthermore, Marshall Peterson gave us some insight into that question this morning.

It took a while, however, to realize that a significant change took place with the addition of the second operative word, "Should product life be extended?" As a result, Elio Passaglia, that most objective, analytical and handsome of scientists, finds himself presiding over what has to be a metaphysical discussion.

The question posed is what Schumacher calls a "divergent" problem. That is, it cannot be solved by logical reasoning, but requires balancing of opposites which cannot be handled by pure logic. Instead, "human values," i.e. moral/ethical considerations, etc. must be the bases of decision.

Perhaps this group would prefer to say that what is needed is a better medium of exchange for expressing human values, and long range effects, often called "societal values," without making clear the subjective base for such values.

Two great examples were given in the first two papers of this conference. Mike Denney showed the importance of the matrix of technological factors and human behavior (consumer usage of products) on one axis; and shortrange/ long-range policy impacts on the other.

The concept of remanufacturing as a strategy, which the MIT paper emphasized, seems to me an admirable example of a strategy evolved through a sound problem-solving process. First -- gathering, second -- analys is of data to produce meaningful information, third -- applying judgement to select (or recommend) courses of action.

This judgement need not necessarily reflect currently favored techniques for judging strategies. For example, Dr. Lerman showed us so well that use of the "net present value" equation would militate against starting any major program that cannot be expected to provide quick returns.

The point is that remanufacturing as a strategy does not meet that criteria. It does, however, meet the criteria of helping to cope with long-range societal needs predictable by extension of trends which are 
painfully evident today such as the need to shift from energy-intensive to labor-intensive activities, wherever this can be done without excessive trade-off disadvantages.

This panel cannot do much about the broad overview of the question "Should product life be extended?" in one afternoon. We can, however, do some exploring of the micro-aspects of the question. That is, what can be done and should be done, on an incremental basis, one step at a time.

For my part, I would like to dwell a bit on the concept of a National Information Center for product reliability.

In my talk, the concept was mentioned too briefly, and some people assumed such a center would jump immediately into brand, and even model, product life data. Actually, the paper specifically warns against trying to do too much, too soon.

Instead, what is visualized is an evolutionary extension of some pioneering work that has been described at this seminar -- gathering information on:

1. Consumer usage (such as the impressive GM work described by Mr. Larsen).

2. Reasons for product discard (several papers had something to say about this).

3. Maintenance, repair, and serviceability data (along the lines of the work described by Wayne Stiefel). 
APPENDIX A 



\section{Elio Passaglia \\ National Bureau of Standards \\ Washington, D.C. 20234}

Abstract

When considering durability, it is useful to make a distinction between two different aspects of it. These aspects may be called economic durability and technical durability. Economic durability means the length of time a durable good lasts in service. Technical durability may be defined as the number of services embodied in the durable good- 1 . Examples of technical durability are the number of shaves in a razor blade, or the number of miles of travel in an automobile tire. Economic durability is thus the quotient of technical durability and the rate of use of the services embodied in the durable good. Technical durability is not always easy to define, and one of the main technical challenges is the determination of its magnitude. When the physical basis for loss to service is known, technical durability can in principle be determined quite easily. An example is the number of cycles a spring will operate before failure by fatigue. In other cases, when the physical basis is not known, technical durability is more difficult to determine. In such cases, simulated service tests or exposure tests, which are a special case of simulated service tests, are used to determine technical durability. In both cases the reliability of the durable good (the ability to perform in service) must be considered. One problem of design is to increase durability and reliability within the constraints of economics.

\section{1/ R. Avinger, Jr. "The Economics of Durability", Thesis, Duke} University, 1968. 
M. B. Peterson

Office of Technology Assessment

U. S. Congress

Washington, D. C. 20510

Abstract

OTA has been conducting a study on materials conservation in which it is considering ways in which materials could be saved if and when it becomes necessary to do so. At the beginning of this study it was felt that extending product life would result in substantial savings of material. Figuratively speaking, if all products lasted forever, no more materials would be needed. More realistically, even one year of extended life would on the surface appear to save appreciable materials. For this reason, a considerable amount of time was spent investigating the potential for product life extension. Basic approaches were followed:

(1) A workshop was held to discuss product durability. To provide a focus, wear control was chosen as the means of achieving improved product durability.

(2) A contractual study was undertaken to investigate materials savings using refrigerators, automobiles, and containers as case examples.

(3) A study was conducted of the product end uses of a variety of metals. From this, an analysis was made of the potential metal savings possible.

The general conclusion from all of these studies was that increasing product durability would not be an efficient means of saving materials. Products are retired from service for many reasons other than poor durability. The material savings which would result would not be fully realized until all existing products had been retired (construction machinery, electrical equipment, etc., already have long lives). A more effective strategy would appear to be the reuse of discarded parts and components. 
The Concepts of Product Life and Consumer Product Safety

\author{
Joann H. Langston \\ Consumer Product Safety Commission \\ Washington, D.C. 20207
}

Abstract

This presentation highlights some of the needs for and uses of product life information in the development of consumer product safety regulations. These needs include calculation of exposure rates, determination of time until full compliance with a regulation and evaluation of the effects of a standard on product performance, product demand, and product safety. In the event of a product recall, this information is needed to determine the number of affected products in the environment and the appropriate refund deduction based on use of the product. This presentation also presents the problems of choosing appropriate difinitions for product life and of gathering product life data at the appropriate level of detail. To date, most of the research of this area has focused on industrial products and consumer durables which have measurable usage rates. The universe of products over which CPSC has jurisdiction is subject to many variations in use. 

APPENDIX B 



\section{7th Meeting}

\section{Product Durability and Life}

List of Registrants

Lt. Col. Beason

United States Marine Corps

Code: LMM Navy Dept.

Washington, DC 20380

Donald A. Becker

National Bureau of Standards

B-50, Building 221

Washington, DC 20234

J. F. Belton

Whirlpool Corporation

Monte Road

Benton Harbor, MI 49022

L. E. Bensch

Oklahoma State University

Stillwater, OK 74074

Allan W. Beres

GSA Federal Supply Service

Rm. 1110, Crystal Mal1 B1dg. 4 Washington, DC 20406

Richard E. Berger

Caterpillar Tractor Company

100 N.E. Adams Street

Peoria, IL 61629

H. C. Burnett

National Bureau of Standards

B-264, Materials Building

Washington, DC 20234

D. B. Butrymowicz

National Bureau of Standards A-151, Materials Building Washington, DC 20234
Julius Cohen

National Bureau of Standards

A-113, Polymers Building

Washington, DC 20234

W. D. Conn

University of California

School of Architecture \& Urban Planning

Los Angeles, CA 90024

John Coutinho

U.S. Army Materiel Systems

Analysis Activity

602 Westgate Road

Aberdeen, MD 21001

W. Davis

Office of Technology Assessment

U.S. Congress

Washington, DC 20510

M. Denney

Massachusetts Institute of Technology

Cambridge, MA 02139

W. J. Derner

FMC Corporation, Bearing Division

7601 Rockville Road, Box 85

Indianapolis, IN 46206

Thomas Deutsch

Chief, Appliance Division

Consumers Union of U.S., Inc.

256 Washington Street

Mount Vernon, NY 10550 
Madan G. Dhawan

Naval Ship Engineering Center Code 6145F, Room 378, NC\#4

Washington, DC 20362

Albert A. Domingorena

Oak Ridge National Laboratory

Oak Ridge, TN 37830

Andrew Dorney

American Standard Corporation

P. 0. Box 2003

New Brunswick, NJ 00903

George G. Earle

Boeing Vertol Company

P. 0. Box 16858

Philadelphia, PA 19142

Sonny G. Edwards

General Motors Corporation

1921 Garey Sue Lane

Milford, MI 48042

Peter A. Enge 1

IBM System Products Division Endicott, NY 13760

Stephen N. Finger

Pratt \& Whitney Aircraft

P. 0. Box 2691

West Palm Beach, FL 33402

Paul M. Fleming

National Bureau of Standards

B-264, Materials Building

Washington, DC 20234

Phil ip L. Fontaine

Stevenson 0. Kellogg, Ltd.

Toronto, Canada

A. J. Fowel1

National Bureau of Standards

A-109, Polymers Building

Washington, DC 20234
W. Glaeser

Battelle Columbus Laboratories 505 King Avenue

Columbus, $\mathrm{OH} 43201$

Nathan Glassman

David Taylor Naval Ship R \& D Center

Annapolis, MD 21401

Walter W. Gunkel

General Motors Corporation

Technical Center

Warren, MI 48090

John H. Haley

Black \& Decker Manufacturing Co.

701 East Joppa Road

Towson, MD 21204

John Haluska

Consumers Union of U.S., Inc.

256 Washington Street

Mount Vernon, NY 10550

H. D. Harback

FSS-General Services Admin.

Washington, DC 22406

Henry R. Hegner

GARD, Inc.

7449 N. Natchez Avenue

Niles, IL 60648

J. D. Hoffman

National Bureau of Standards

B-364, Materials Building

Washington, DC 20234

R. R. Holden

Hughes Aircraft Company

P. 0. Box 90515

Los Angeles, CA 90009

Bruce L. Huntley

TEAM Corporation

9949 Hayward Way

S. El Monte, CA 91733 
R. B. Johnson

National Bureau of Standards

B-348, Materials Building

Washington, DC 20234

Frank Kalivoda

Copeland Corporation

Campbell Road

Sidney, $\mathrm{OH} 45365$

Ellen F. Kandell

Consumer Product Safety Commission 5401 Westbard Avenue

Bethesda, MD 20207

Elmer E. Klaus

The Pennsylvania State University 133 Chemical Engineering Building University Park, PA 16802

J. Langston

Consumer Product Safety Commission 5401 Westbard Avenue

Washington, DC 20207

H. W. Larsen

Genera 1 Motors Corporation

Warren, MI 48090

Paul Lerman

Fairleigh Dickenson University

Rutherford, NJ 07070

Paul Lewis

Mechanical Technology, Inc.

968 Albany-Shaker Road

Latham, NY 12110

Thomas E. Lewis

Armstrong Cork Company

1666 K Street, Suite 205

Washington, DC 20006

Kenneth Ludema

University of Michigan

Mechanical Engineering Dept.

Ann Arbor, MI 48109
James McGregor

Office of Naval Attache

Embassy of Australia

1601 Massachusetts Avenue, NW

Washington, DC 20036

M. R. Meyerson

National Bureau of Standards

B-364, Metrology Building

Washington, DC 20234

Raymond F. Misialek

U.S. Navy

NAVSEC Philadelphia Division

Philadelphia, PA 19112

Joseph Morton

Gillette Medical Evaluation Labs

1413 Research Boulevard

Rockville, MD 20853

Edward Mosley

Black \& Decker Manufacturing Co.

701 E. Joppa Road

Towson, MD 21204

V. F. Mustafayev

National Academy of Sciences

2101 Constitution Avenue

Washington, DC 20418

Charles M. Overby

Office of Technology Assessment

U.S. Congress

Washington, DC 20510

Elio Passaglia

National Bureau of Standards

B-354, Materials Building

Washington, DC 20234

B. F. Perry

Black \& Decker Manufacturing Co.

626 Hanover Pike

Hampstead, MD 21074

Marshal Peterson

Office of Technology Assessment

U.S. Congress

Washington, DC 20510 
LCDR W. K. Petrovic

Office of Naval Research

800 N. Quincy Street

Arlington, VA 22217

William C. Pirowski

Naval Sea Systems Command

Navy Department

Washington, DC 20362

John Preston

Consumer Product Safety Commission 5401 Westbard Avenue

Bethes da, MD 20207

Norman Pugh

Sears Roebuch and Company

Dept. 817, BSC 23-32, Sears Tower Chicago, IL 60684

F. J. Quai1

Canadian Standards Association

178 Rexdale Boulevard

Rexdale, Ontario, Canada

Mark Raabe

House Committee on Interstate \&

Foreign Commerce

2125 Rayburn House Office B1dg.

Washington, DC 20515

Martin Rayl

RCA Corporation

RCA Laboratories

Princeton, NJ 08540

S. K. Rhee

Bendix Research Laboratories

Southfield, MI 48076

Saul Ricklin

Dixon Industries Corporation

Bristo1, RI 02809

W. H. Rockwe11

American National Standards Inst. 1430 Broadway

New York, NY 10018
A. W. Ruff

National Bureau of Standards B-264, Materials Building

Washington, DC 20234

Marilyn Doss Ruffin

Agricultural Research Service, USDA CFE-ARS-USDA, Federal Building Hyattsville, MD 20782

Edwin Sage

General Motors Corporation

General Motors Road

Milford, MI 48042

Albert Schmudde

Caterpillar Tractor Company

Industrial Div. - Engineering

Peoria, IL 61629

John J. Scialdone

NASA/Goddard Space Flight Center

Code 726

Greenbe1t, MD 20771

T. Robert Shives

National Bureau of Standards

A-111, Materials Building

Washington, DC 20234

William H. Skewis

Telcom Systems, Inc.

2300 S. Ninth Street

Arlington, VA 22204

Arlen J. Slobodow

Consumer Product Safety Commission

5401 Westbard Avenue

Bethesda, MD 20207

Fred Smith

Environmental Protection Agency

401 M Street, SW

Washington, DC 20460

S. W. Stiefel

National Bureau of Standards

A-359, Metrology Building

Washington, DC 20234 
J. E. Stern

NASA/Goddard Space Flight Center

Code 721

Greenbelt, MD 20771

D. A. Swankin

Swankin \& Turner

1625 Eye Street, NW

Washington, DC 20006

W. S. VanDelinder

Lockheed California Co.

P.0.Box 551, Dept.70-71, B1dg.90-2

Burbank, CA 91520

Stephen L. Vick

Black \& Decker Manufacturing Co.

701 E. Joppa Road

Towson, MD 21204

David Wallace

Black \& Decker Manufacturing Co.

701 E. Joppa Road

Towson, MD 21204

Theodore Wang

National Bureau of Standards

Room A-359, B 1dg. 220

Washington, DC 20234

James R. Ward

Value Engineering Laboratory

2550 Huntington Avenue

Alexandria, VA 22303

Stanley Warshaw

National Bureau of Standards

A-355, Polymers Building

Washington, DC 20234

W. A. Willard

National Bureau of Standards

B-128, Materials Building

Washington, DC 20234

K. W. Yee

National Bureau of Standards

A-113, Polymers Building

Washington, DC 20234 
Both printed and microfiche copies of the following MFPG publications (1-11) whose catalog numbers start with "AD" or "COM" may be obtained from the NTIS.

\section{National Technical Information Center 5285 Port Royal Road \\ Springfield, VA 22151}

1. Glossary of Terms . . . . . . . . . . . AD 721354

2. Proceedings of Meetings 1-9 (set of 5) . . . . . AD 721359

Meeting Nos. 1-5 Papers and discussion on failure analysis and control.

Meeting No. 6 "Detection, Diagnosis and Prognosis", December 6, 1968.

Meeting No. 7 "Failure Mechanisms as Identified with Helicopter Transmissions", March 27, 1969.

Meeting No. 8 "Critical Failure Problem Areas in the Aircraft Gas Turbine Engine", June 25-26, 1969.

Meeting No. 9 "Potential for Reduction of Mechanical Failure Through Design Methodology", November 5-6, 1969.

3. Proceedings of Meeting No.10 ......... . AD 721912 "Vibration Analysis Systems" January $21-22,1970$

4. Proceedings of Meeting No. 11 . . . . . . . . AD 724475 "Failure Mechanisms: Fatigue" Apri1 7-8, 1970

5. Proceedings of Meeting No. 12 ......... AD 721913 "Identification and Prevention of Mechanical Failures in Internal Combustion Engines" JuTy $8-9,1970$ 
6. Proceedings of Meeting No. 13 . . . . . . . . AD 724637

"Standards as a Design Tool in Surface

Specification for Mechanical Components

and Structures"

October 19-20, 1970

7. Proceedings of Meeting No. 14......... AD 721355

"Advances in Decision-Making Processes

in Detection, Diagnosis and Prognosis"

January 25-26, 1971

8. Proceedings of Meeting No.15 .......... AD 725200

"Failure Mechanisms: Corrosion"

Apri1 14-15, 1971

9. Proceedings of Meeting No.16.......... AD 738855

"Mechanical Failure Prevention Through

Lubricating 0il Analysis"

November 2-4, 1971

10. Proceedings of Meeting No. 17 .......... AD 750411

"Effects of Environment Upon Mechanical

Failures, Mechanisms and Detection"

Apri] 25-27, 1972

11. Proceedings of Meeting No. 18 . . . . . . . AD 772082

"Detection, Diagnosis and Prognosis"

November 8-10, 1972

12. Proceedings of Meeting No. 19 (NBS SP 394)

"The Role of Cavitation in Mechanical Failures"

COM-74-50523

October 21 - November 2, 1973

Printed copies of the following MFPG publications (catalog numbers starting with SD) may be obtained from the Government Printing Office.

Superintendent of Documents

U.S. Government Printing Office Washington, DC 20402

Microfiche copies of these publications (catalog numbers starting with NBS-SP) may be obtained from NTIS.

13. Proceedings of Meeting No. 20 (NBS SP 423)

"Mechanical Failure - Definition of the Problem" SN 003-003-01451-6

May 8-10, 1974

Cost: Printed copy $\$ 6.10$ 
14. Proceedings of Meeting No. 21 (NBS SP 433)

"Success By Design: Progress Through

Failure Analysis"

November 7-8, 1974

Cost: Printed copy $\$ 3.50$. . . . . . SN003-003-01639-0

Microfiche copy $\$ 2.25$. . . . . . NBS-SP-433

15. Proceedings of Meeting No. 22 (NBS SP 436)

"Detection, Diagnosis and Prognosis"

Apri1 23-25, 1975

Cost: Printed copy $\$ 4.25$. . . . . . . SN003-003-01556-3

Microfiche copy $\$ 2.25$. . . . . NBS-SP-436

16. Proceedings of Meeting No. 23 (NBS SP 452)

"The Role of Coatings in the Prevention

of Mechanical Failures"

October 29-31, 1975

Cost: Printed copy $\$ 2.65$....... SN003-003-01664-1

17. Proceedings of Meeting No. 24 (NBS SP 468)

"Prevention of Failures in Coal

Conversion Systems"

Apri1 21-23, 1976

Cost: Printed copy $\$ 3.00$. . . . . . SN003-003-01760-4

18. Proceedings of Meeting No. 25 (NBS SP 487)

"Engineering Design"

November $3-5,1976$

Cost: Printed copy $\$ 5.25$. . . . . . SN003-003-01829-5

19. Proceedings of Meeting No. 26 (NBS SP 494)

"Detection, Diagnosis and Prognosis"

May 17-19, 1977

Cost: Printed copy $\$ 4.50$. . . . . . SN003-003-01844-9 


\begin{tabular}{|c|c|c|c|}
\hline $\begin{array}{l}\text { U.S. DEPT. OF COMM. } \\
\text { BIBLIOGRAPHIC DATA } \\
\text { SHEET }\end{array}$ & $\begin{array}{l}\text { 1. PUBLICATION OR REPORT NO. } \\
\text { NBS SP } 514\end{array}$ & $\begin{array}{l}\text { 2. Gov't Accession } \\
\text { No. }\end{array}$ & 3. Recipient's Accession No. \\
\hline \multirow{2}{*}{\multicolumn{3}{|c|}{$\begin{array}{l}\text { 4. TITLE AND SUBTITLE } \\
\text { Product Durability and Life - Proceedings of the 27th } \\
\text { meeting of the Mechanical Failures Prevention Group, } \\
\text { held at the Nationa } 1 \text { Bureau of Standards, Gaithersburg, } \\
\text { Maryland, November 1-3, } 1977\end{array}$}} & $\begin{array}{r}\text { 5. Publication Date } \\
\text { May } 1978\end{array}$ \\
\hline & & & 6. Performing Organization Code \\
\hline \multicolumn{3}{|c|}{$\begin{array}{l}\text { 7. AKXXXXXXXX EDITORS } \\
\text { T. Robert Shives and William A. Willard }\end{array}$} & 8. Performing Organ. Report No. \\
\hline \multicolumn{3}{|c|}{$\begin{array}{l}\text { 9. PERFORMING ORGANIZATION NAME AND ADDRESS } \\
\qquad \begin{array}{l}\text { NATIONAL BUREAU OF STANDARDS } \\
\text { DEPARTMENT OF COMMERCE } \\
\text { WASHINGTON, D.C. } 20234\end{array}\end{array}$} & 10. Project/Task/Work Unit No. \\
\hline \multicolumn{3}{|c|}{$\begin{array}{l}\text { 12. Sponsoring Organization Name and Complete Address (Street, City, State, ZIP) } \\
\text { Inst. for Matls. Res., \& Ctr. for Cons.Product Tech., NBS, Wash, DC } \\
20234 \text {; ONR, Arlington, VA 22217; NADC, Warminster, PA 18974 } \\
\text { NASA, Greenbelt, MD 20771; DoE, Fossil Energy, Washington, D } \\
20545\end{array}$} & $\begin{array}{l}\text { 13. Type of Report \& Period } \\
\text { Covered } \\
\text { 14. Sponsoring Agency Code }\end{array}$ \\
\hline
\end{tabular}

15. SUPPLEMENTARY NOTES

Library of Congress Catalog Card Number: 78-606044

16. ABSTRACT (A 200-word or less factual summary of most significant information. If document includes a significant bibliography or literature survey, mention it here.)

These proceedings consist of a group of nineteen submitted papers from the 27th meeting of the Mechanical Failures Prevention Group which was held at the National Bureau of Standards in Gaithersburg, Maryland, on November 1-3, 1977. The central theme of the proceedings pertains to the durability of consumer products. Special emphasis is on durability technology, product testing, product performance, the economics of extending product 1 ife, and labeling products for durability.

17. KEY WORDS (six to twelve entries; alphabetical order; capitalize only the first letter of the first key word unless a proper name; separated by semicolons)

Design quality; durability; durability technology; materials conservation; product $1 \mathrm{ife}$; product performance; product testing; wear analysis

18. AVAILABILITY XX] Unlimited

For Official Distribution. Do Not Release to NTIS

XX Order From Sup. of Doc., U.S Government Printing Office Washington, D.C. 20402, SD Stock No. 003-003-

$\square$ Order From National Technical Information Service (NTIS) Springfield, Virginia 22151
19. SECURITY CLASS (THIS REPURT)

UNCL ASSIF IED

20. SECURITY CLASS (THIS PAGE)

UNCLASSIFIED
21. NO. OF PAGES 188

22. Price $\$ 3.75$ 


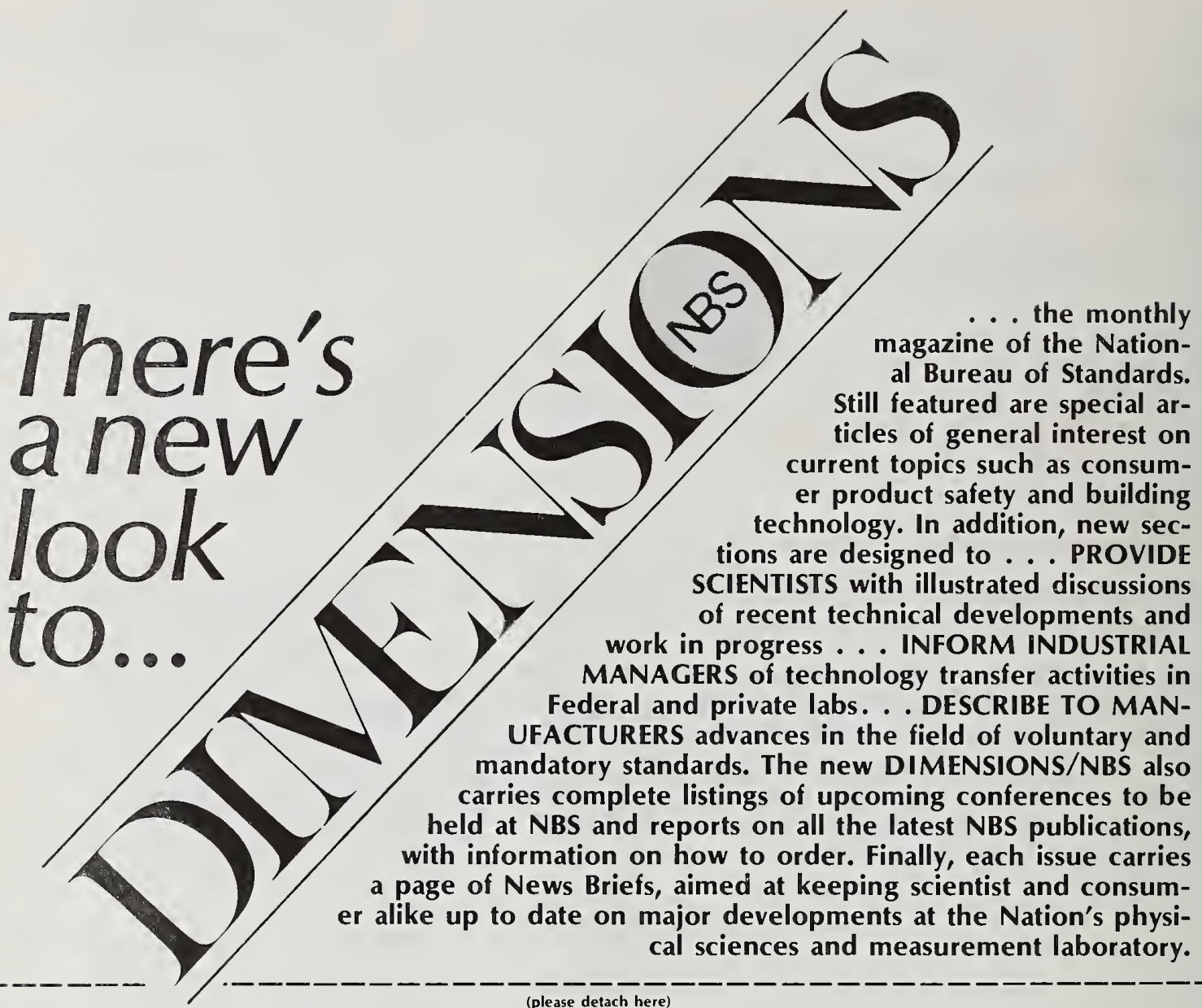

\section{SUBSCRIPTION ORDER FORM}

Enter my Subscription To DIMENSIONS/NBS at \$12.50. Add $\$ 3.15$ for foreign mailing. No additional postage is required for mailing within the United States or its possessions. Domestic remittances should be made either by postal money order, express money order, or check. Foreign remittances should be made either by international money order, draft on an American bank, or by UNESCO coupons.

Send Subscription to:

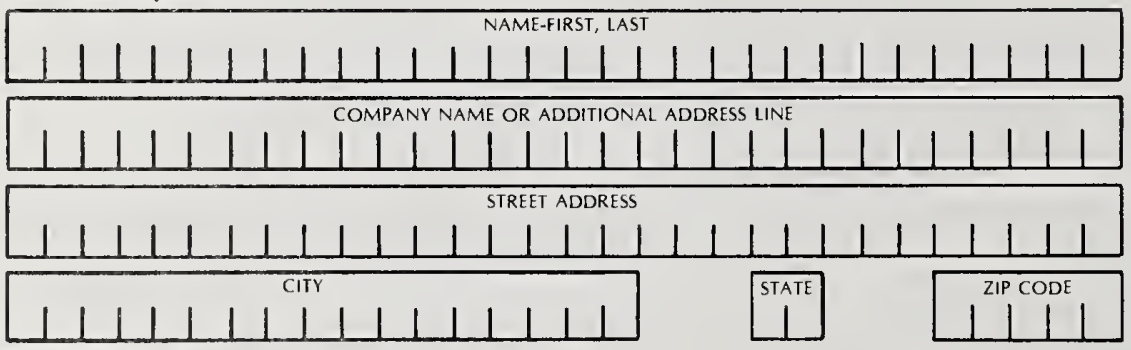

Remittance Enclosed (Make checks payable to Superintendent of Documents)

Charge to my Deposit Account No.

MAIL ORDER FORM TO:

Superintendent of Documents Government Printing Office Washington, D.C. 20402 

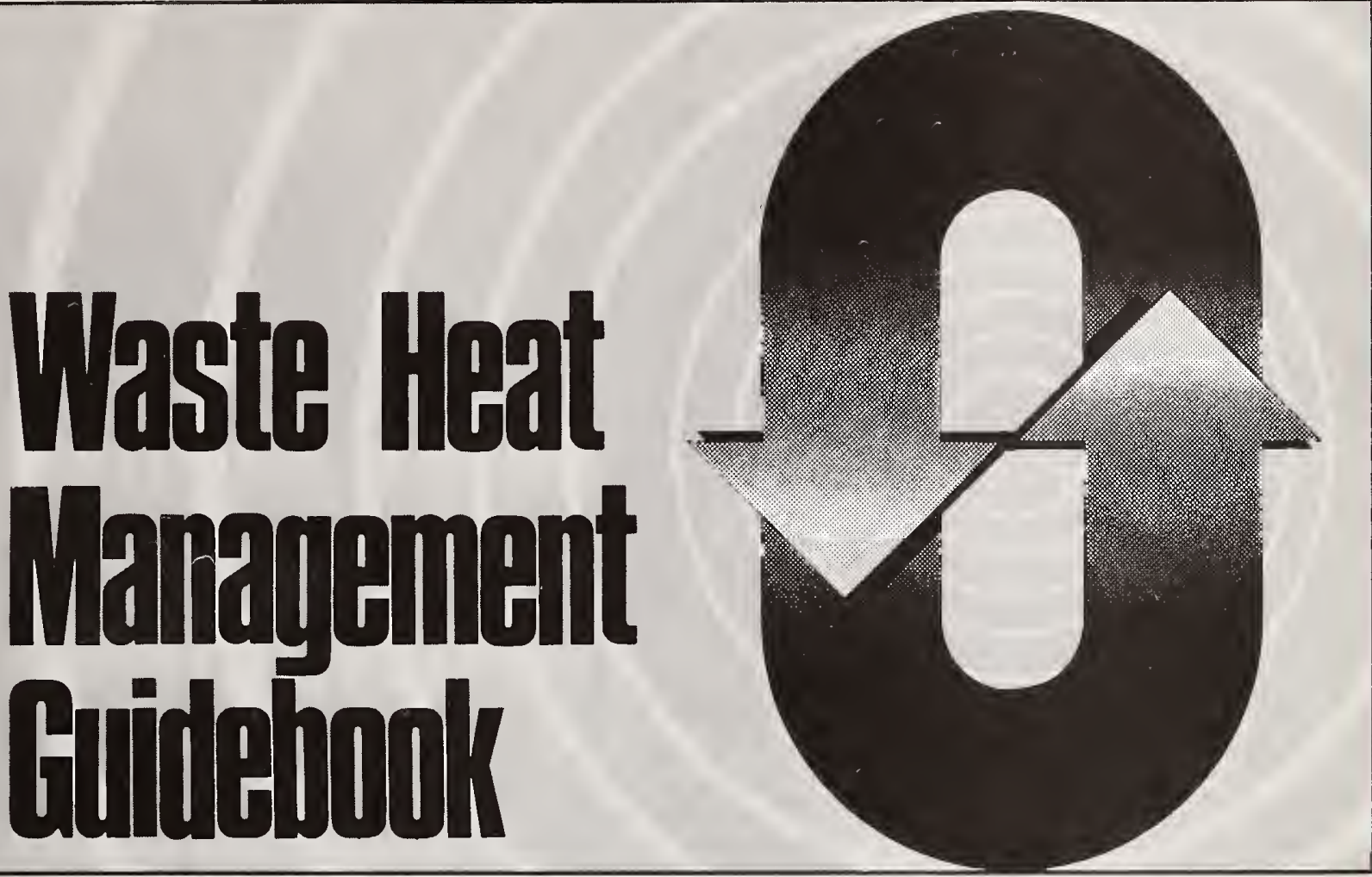

A typical plant can save about 20 percent of its fuel-just by installing waste heat recovery equipment. But with so much equipment on the market, how do you decide what's right for you?

Find the answers to your problems in the Waste Heat Management Guidebook, a new handbook from the Commerce Department's National Bureau of Standards and the Federal Energy Administration.

The Waste Heat Management Guidebook is designed to help you, the cost-conscious engineer or manager, learn how to capture and recycle heat that is normally lost to the environment during industrial and commercial processes.

The heart of the guidebook is 14 case studies of companies that have recently installed waste heat recovery systems and profited. One of these applications may be right for you, but even if it doesn't fit exactly, you'll find helpful approaches to solving many waste heat recovery problems.
In addition to case studies, the guidebook contains information on:

- sources and uses of waste heat

- determining waste heat requirements

- economics of waste heat recovery

- commercial options in waste heat recovery equipment

- instrumentation

- engineering data for waste heat recovery

- assistance for designing and installing waste heat systems

To order your copy of the Waste Heat Management Guidebook, send $\$ 2.75$ per copy (check or money order) to Superintendent of Documents, U.S. Government Printing Office, Washington, D.C. 20402. A discount of 25 percent is given on orders of 100 copies or more mailed to one address.

The Waste Heat Management Guidebook is part of the EPIC industrial energy management program aimed at helping industry and commerce adjust to the increased cost and shortage of energy. 


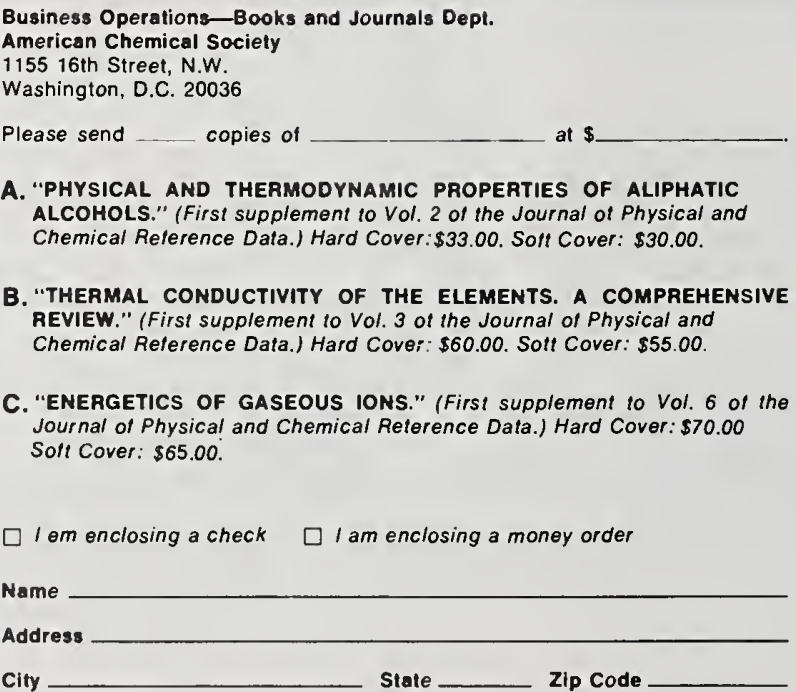
LCOHOLS." (First supplement to Vol. 2 of the Journal of Physical and "THERMAL CONDUCTIVITY OF THE ELEMENTS. A COMPREHENSIVE REVIEW." (First supplement to Vol. 3 of the Journal of Physical and

"ENERGETICS OF GASEOUS IONS." (First supplement to Vol. 6 of the Journal of Physical and Chemical Reterence Data.) Hard Cover: $\$ 70.00$ Solt Cover: $\$ 65.00$

$\square$ I em enclosing a check $\square$ I am enclosing a money order

Name

Address Zip Code

Three comprehensive reference volumes, each, as the Journal itself, published by the American Institute of Physics and the American Chemical Society for the National Bureau of Standards... your triple assurance of their accuracy, immediacy, and usefulness.

Supplement No. 1 to Vol. 2

"PHYSICAL AND THERMODYNAMIC PROPERTIES OF ALIPHATIC ALCOHOLS"

B. J. Zwolinski, Thermodynamics Research Center, Department of Chemistry, Texas A \& $M$ University Represents the most exhaustive review and critical analysis of selected physical and thermodynamic properties of aliphatic alcohols that has been published in the world literature of chemistry.

"THERMAL CONDUCTIVITY OF THE ELEMENTS: A COMPREHENSIVE REVIEW"'
Pophysical Properties Research Center, Purdue University, West Lafayette, Indiana This comprehensive review of the world's thermal conductivity data presents recommended or estimated values for all 105 elements.

Supplement No. 1 to Vol. 6

ENERGETICS OF GASEOUS IONS

by H. M. Rosenstock, K. Draxl, B. Steiner, and

J. T. Herron, National Bureau of Standards

Provides a comprehensive body of critically evaluated information on ionization potentials, appearance potentials, electron affinities and heats of formation of gaseous positive and negative ions. It is a complete revision and extension of the earlier reference work, "Ionization Potentials, Appearance Potentials and Heats for Formation of Gaseous Positive lons," NSRDS-NBS 26. 


\section{PERIODICALS}

JOURNAL OF RESEARCH-The Journal of Research of the National Bureau of Standards reports NBS research development in those disciplines of the physical and ngineering sciences in which the Bureau is active. These nclude physics, chemistry, engineering, mathematics, and omputer sciences. Papers cover a broad range of subjects, ith major emphasis on measurement methodology, and basic technology underlying standardization. Also inluded from time to time are survey articles on topics closely elated to the Bureau's technical and scientific programs. As special service to subscribers each issue contains complete citations to all recent NBS publications in NBS and nonNBS media. Issued six times a year. Annual subscription: domestic $\$ 17.00$; foreign $\$ 21.25$. Single copy, $\$ 3.00$ domestic; $\$ 3.75$ foreign.

Vote: The Journal was formerly published in two sections: ection A "Physics and Chemistry" and Section B "Mathematical Sciences."

\section{DIMENSIONS/NBS}

This monthly magazine is published to inform scientists, engineers, businessmen, industry, teachers, students, and consumers of the latest advances in science and technology, with primary emphasis on the work at NBS. The magazine ighlights and reviews such issues as energy research, fire protection, building technology, metric conversion, pollution labatement, health and safety, and consumer product performance. In addition, it reports the results of Bureau prorams in measurement standards and techniques, properties matter and materials, engineering standards and services, strumentation, and automatic data processing.

Annual subscription: Domesticic, $\$ 12.50$; Foreign $\$ 15.65$.

\section{NONPERIODICALS}

Monographs-Major contributions to the technical literature on various subjects related to the Bureau's scientific nd technical activities.

Handbooks-Recommended codes of engineering and indusrial practice (including safety codes) developed in cooperain with interested industries, professional organizations, nd regulatory bodies.

ppecial Publications-Include proceedings of conferences ponsored by NBS, NBS annual reports, and other special ublications appropriate to this grouping such as wall charts, ocket cards, and bibliographies.

Applied Mathematics Series-Mathematical tables, manals, and studies of special interest to physicists, engineers, chemists, biologists, mathematicians, computer programmers, and others engaged in scientific and technical work.

Vational Standard Reference Data Series-Provides quantitative data on the physical and chemical properties of materials, compiled from the world's literature and critically evaluated. Developed under a world-wide program coprdinated by NBS. Program under authority of National Standard Data Act (Public Law 90-396).
NOTE: At present the principal publication outlet for these data is the Journal of Physical and Chemical Reference Data (JPC'RD) published quarterly for NBS by the American Chemical Society (ACS) and the American Institute of Physics (AIP). Subscriptions, reprints, and supplements available from ACS, 1155 Sixteenth St. N.W., Wash., D.C. 20056.

Building Science Series-Disseminates technical information developed at the Bureau on building materials, components, systems, and whole structures. The series presents research results, test methods, and performance criteria related to the structural and environmental functions and the durability and safety characteristics of building elements and systems. Technical Notes-Studies or reports which are complete in themselves but restrictive in their treatment of a subject. Analogous to monographs but not so comprehensive in scope or definitive in treatment of the subject area. Often serve as a vehicle for final reports of work performed at NBS under the sponsorship of other government agencies. Voluntary Product Standards--Developed under procedures published by the Department of Commerce in Part 10, Title 15, of the Code of Federal Regulations. The purpose of the standards is to establish nationally recognized requirements for products, and to provide all concerned interests with a basis for common understanding of the characteristics of the products. NBS administers this program as a supplement to the activities of the private sector standardizing organizations.

Consumer Information Series-Practical information, based on NBS research and experience, covering areas of interest to the consumer. Easily understandable language and illustrations provide useful background knowledge for shopping in today's technological marketplace.

Order above NBS publications from: Superintendent of Documents, Government Printing Office, Washington, D.C. 20402.

Order following NBS publicaiions-NBSIR's and FIPS from the National Technical Information Services, Springfield, Va. 22161.

Federal Information Processing Standards Publications (FIPS PUB)-Publications in this series collectively constitute the Federal Information Processing Standards Register. Register serves as the official source of information in the Federal Government regarding standards issued by NBS pursuant to the Federal Property and Administrative Services Act of 1949 as amended, Public Law 89-306 (79 Stat. 1127), and as implemented by Executive Order 11717 (38 FR 12315, dated May 11, 1973) and Part 6 of Title 15 CFR (Code of Federal Regulations).

NBS Interagency Reports (NBSIR)_A special series of interim or final reports on work performed by NBS for outside sponsors (both government and non-government). In general, initial distribution is handled by the sponsor; public distribution is by the National Technical Information Services (Springfield, Va. 22161) in paper copy or microfiche form.

\section{BIBLIOGRAPHIC SUBSCRIPTION SERVICES}

he following current-awareness and literature-survey bibligraphies are issued periodically by the Bureau:

Cryogenic Data Center Current Awareness Service. A literatare survey issued biweekly. Annual subscription: Domestic, $\$ 25.00$; Foreign, $\$ 30.00$.

Liquified Natural Gas. A literature survey issued quarterly. Annual subscription: $\$ 20.00$.
Superconducting Devices and Materials. A literature survey issued quarterly. Annual subscription: $\$ 30.00$. Send subscription orders and remittances for the preceding bibliographic services to National Bureau of Standards, Cryogenic Data Center (275.02) Boulder, Colorado 80302. 
U.S. DEPARTMENT OF COMMERCE

Mational Bureau of Standards

Washington, D.C. 20234

POSTAGE AND FEES PAID U.S. DEPARTMENT DF CDMMERCE COM-2I5

SPECIAL FOURTH-CLASS RATE BOOK 